\title{
Energy saving potential of occupancy sensors in intermittent-use space types.
}

\author{
By
}

Georgia Clare Lapage Alexander

A Thesis submitted to the Victoria University of Wellington in fulfilment of the requirement for the Master of Architectural Science (Research).

Victoria University of Wellington

Te Herenga Waka

2020 
AUTHOR

Georgia Alexander

SUPERVISOR

Dr Nigel Isaacs

Senior Lecturer 
I would like to thank and express my appreciation for my supervisor Nigel Isaacs for his guidance and open door throughout this process. I would like to acknowledge Victoria University of Wellington, particularly the department of Architectural Science for their support and knowledge over the last five years. Thanks to Jack Steele for working alongside me each day offering timely coffee breaks and daily quizzes.

A big thankyou to friends and family who have supported and encouraged me along this journey, especially, my husband Gareth Alexander, my parents Richard and Nicky, Grant and Nanette, and Gracenet Church. 


\section{ABSTRACT}

For decades, studies have been suggesting the idea of occupancy sensors in intermittent use spaces for energy savings. This work investigates the potential energy savings of occupancy sensors in hallways, stairwells, seminar rooms and lavatories of an education building. Lighting is one of the largest consumers of energy in the building industry and these space types are often fully illuminated for long periods of vacancy. Lighting is for the user, not the building. Discussions centre around light use habits, energy saving behaviours and sensor technology such as time delay and daylight sensors. The experiment uses wireless light sensors and PIR sensors to measure light energy use and occupant use of 20 intermittent use spaces. A user survey was planned to run alongside the experiment to investigate user perceptions of changes in lighting but was discontinued due to unresolved software issues. Results of the experiment encouraged the use of occupancy sensors in intermittent use spaces. Lavatories attained highest energy saving potential $54 \%$, seminar rooms highest annual cost savings per fitting $\$ 15.47$ and highest annual energy savings $482 \mathrm{kWh}$ and hallways calculated the quickest payback of 8.6 years. Hallways, stairwells, seminar rooms and lavatories all offer potential for energy savings, supporting the theoretical ideas and success of occupancy sensors in intermittent use spaces. 



\section{CONTENTS}

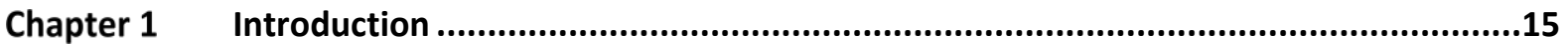

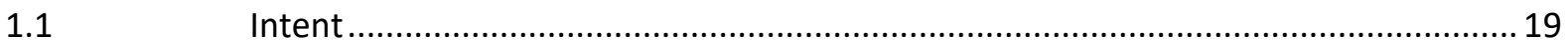

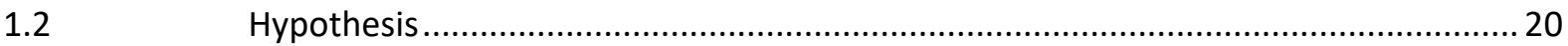

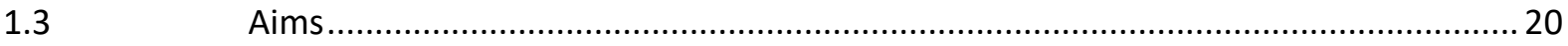

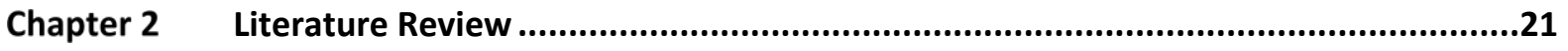

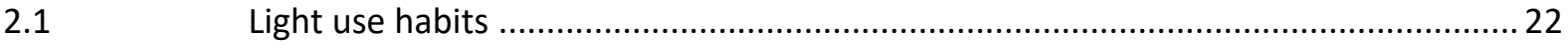

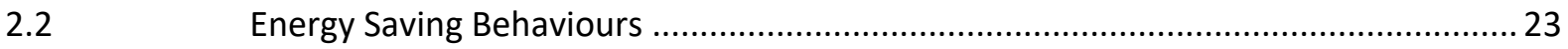

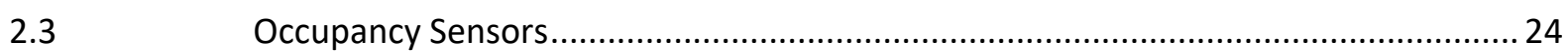

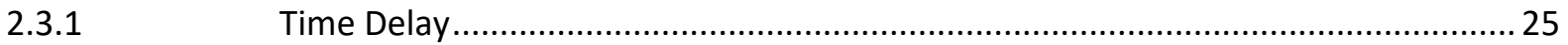

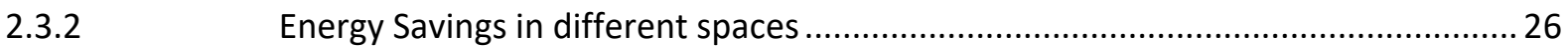

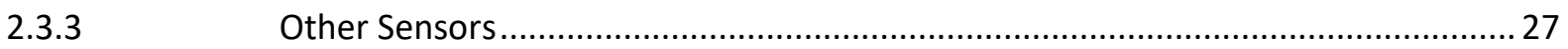

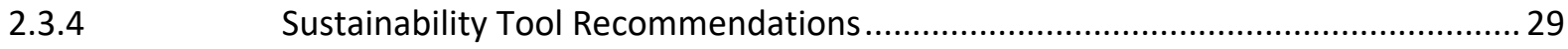

2.4 National Standards and Government Authority recommendations............................ 30

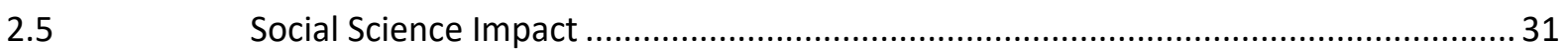

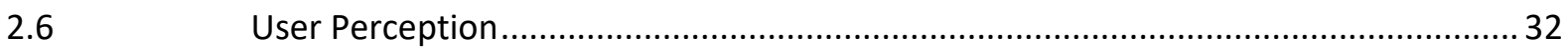

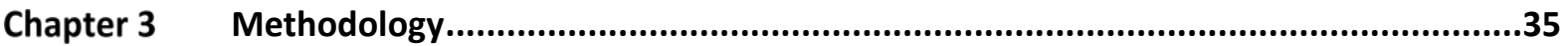

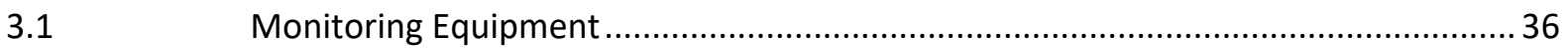

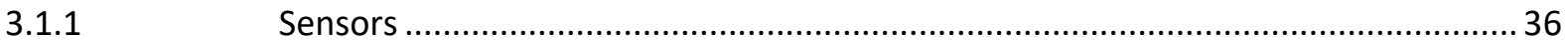

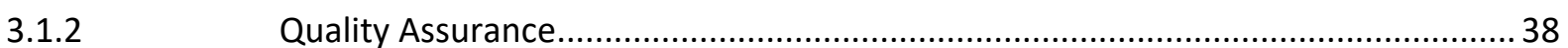

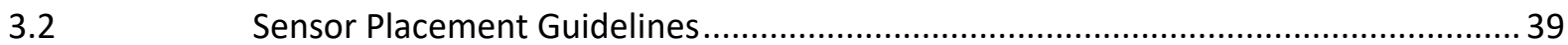

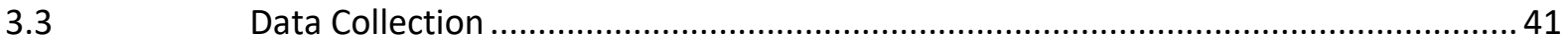

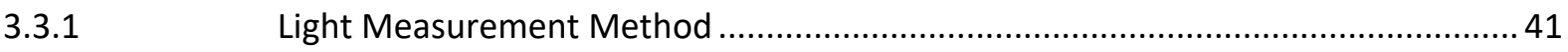

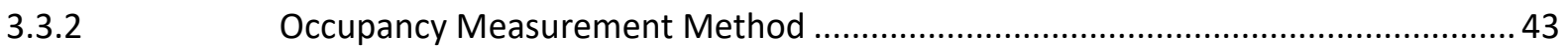

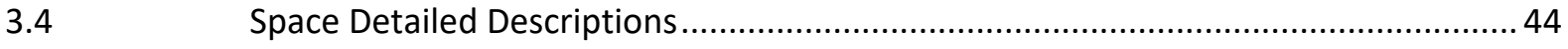

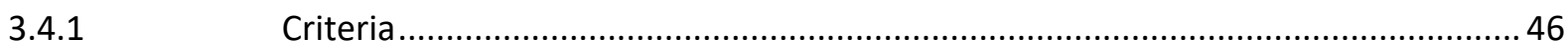

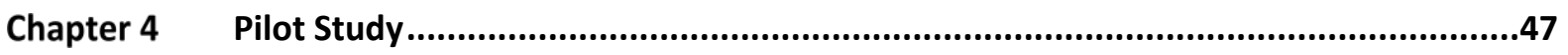

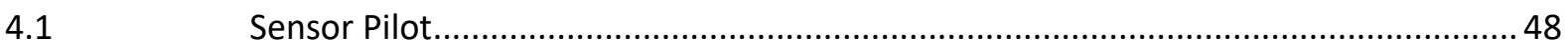

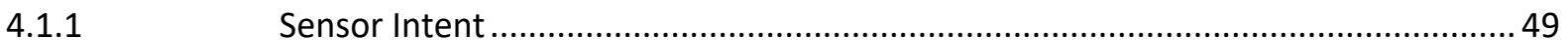

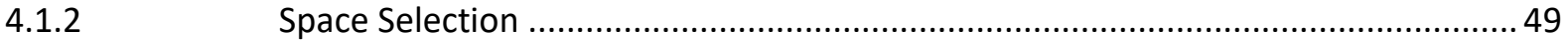

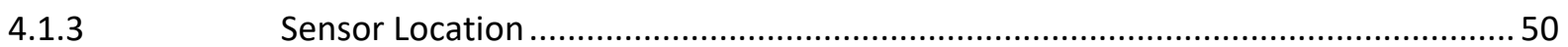

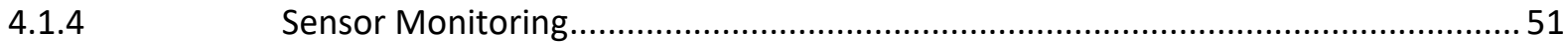

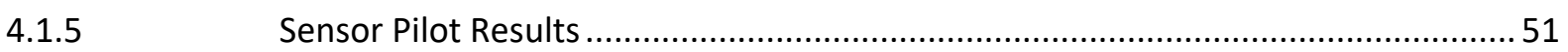

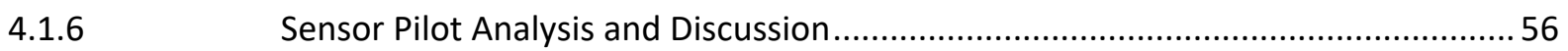

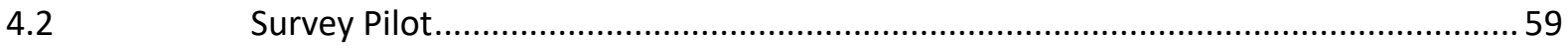




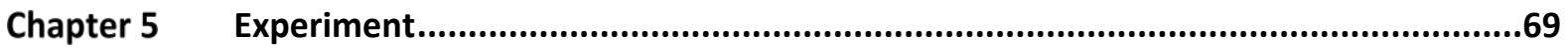

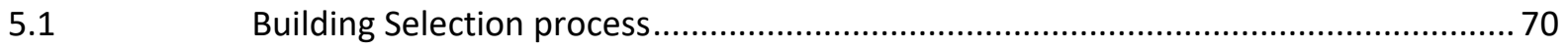

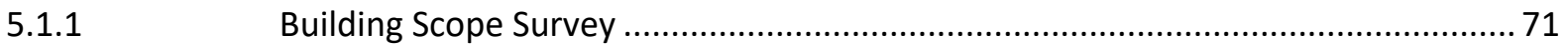

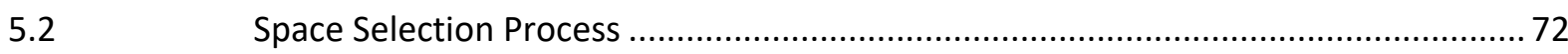

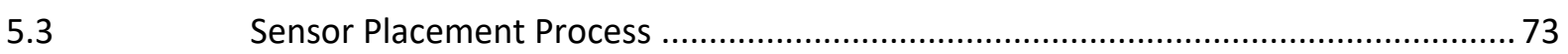

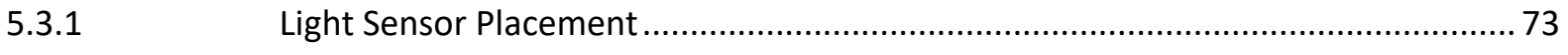

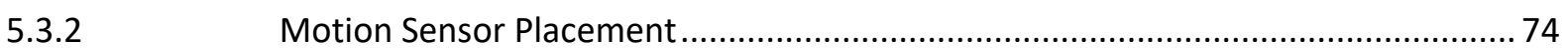

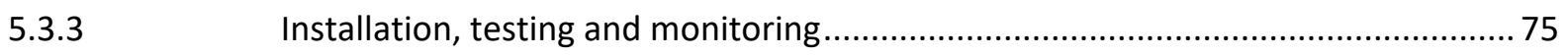

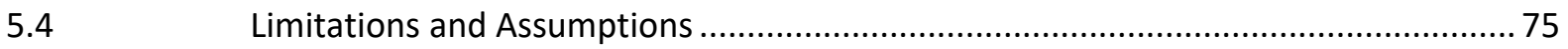

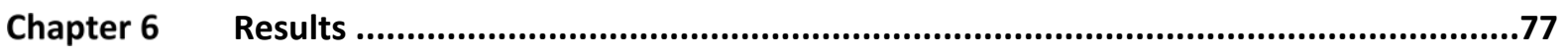

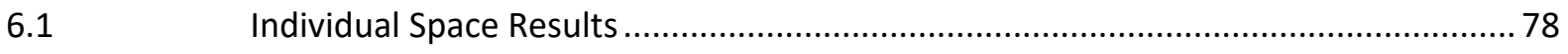

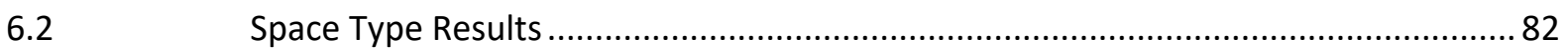

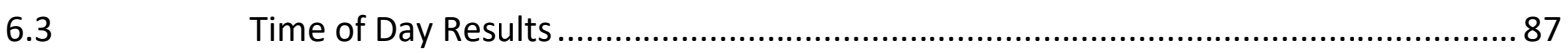

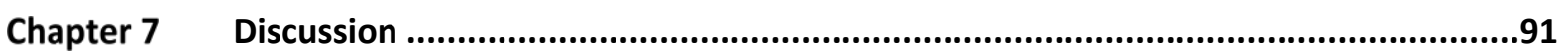

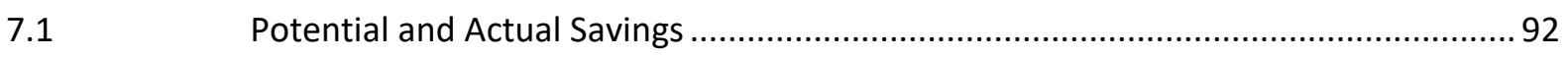

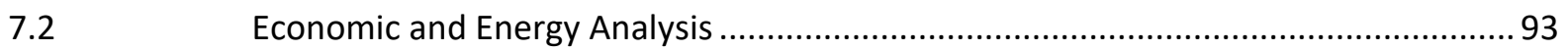

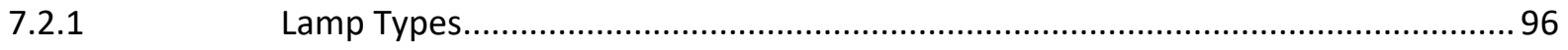

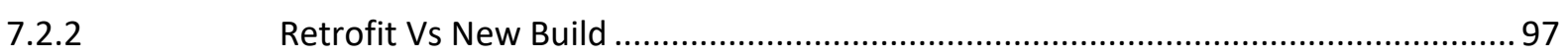

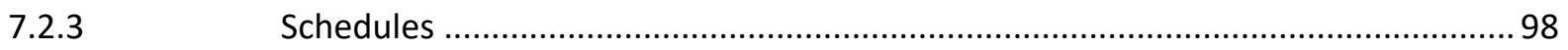

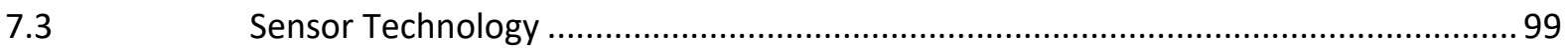

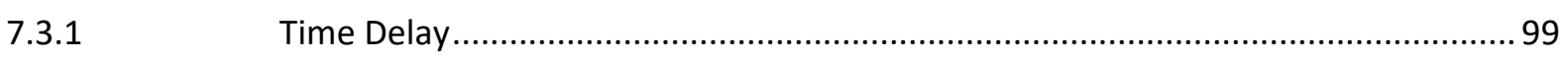

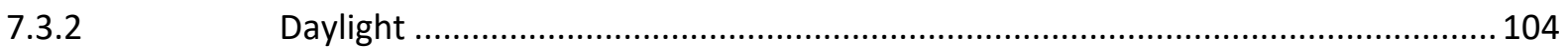

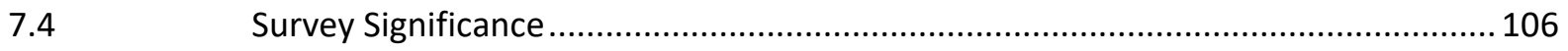

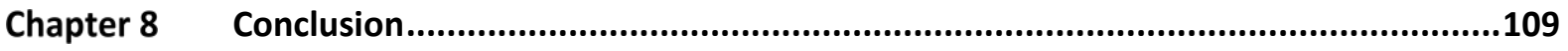

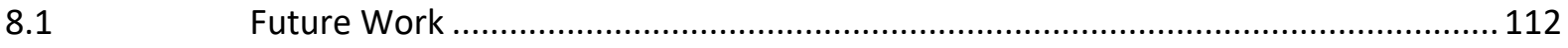

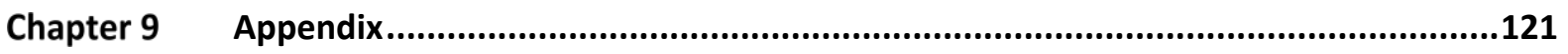

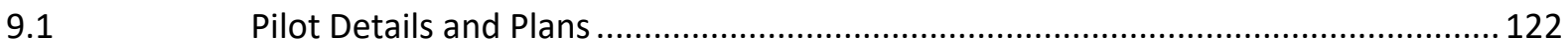

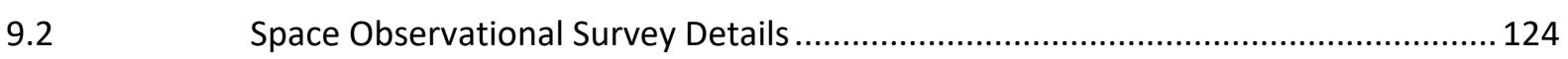

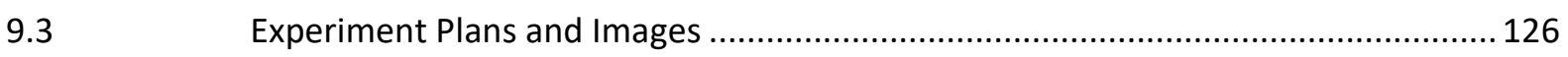

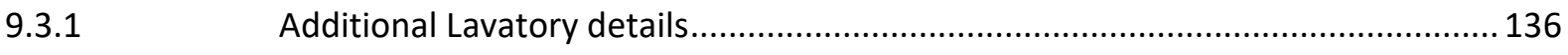

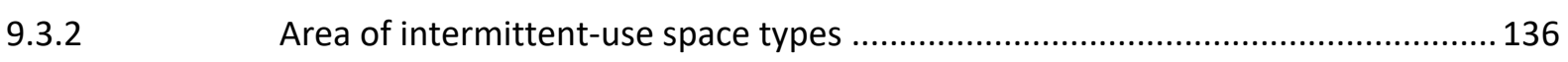

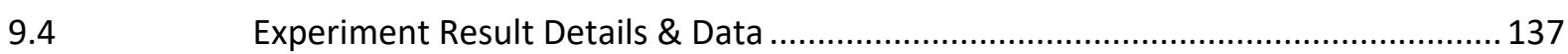




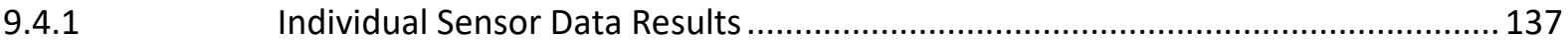

9.4.2 Individual Space Annual Cost Savings and Payback .............................................. 138

9.4.3 Analysis Sunrise and Sunset Details .............................................................. 138

9.4.4 Light Fitting Details for Calculations.............................................................. 139

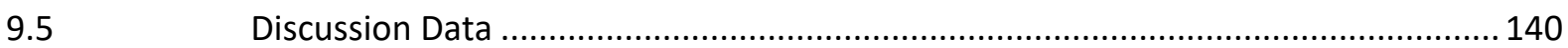

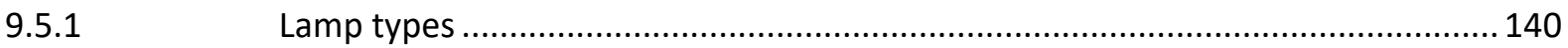

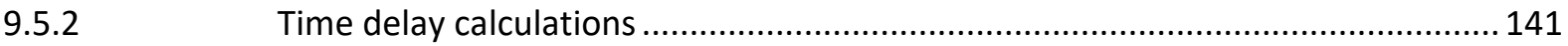

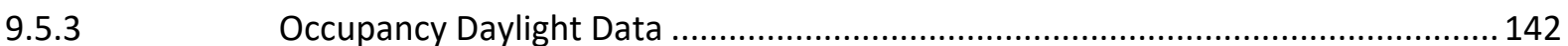




\section{LIST OF GRAPHS}

Graph 1 Light sensor data compared to manual light observation data. .38

Graph 2 Daylight Vs Artificial Light.

Graph 3 Sample Occupancy Data.

Graph 4 Pilot Study Hallway Results.

Graph 5 Pilot Study Seminar Results.

Graph 6 Pilot Study Stairwell Results.

Graph 7 Pilot Study Annual Cost savings per fitting. .....................................................................5

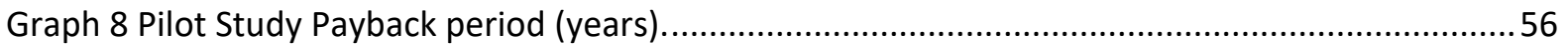

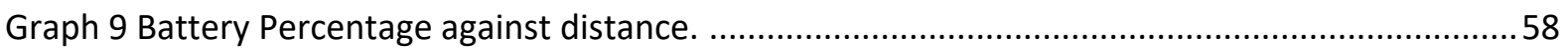

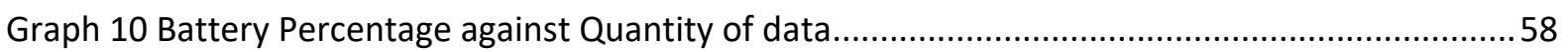

Graph 11 Battery Percentage against obstructions .............................................................................5

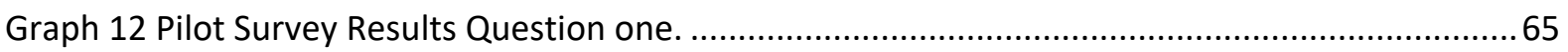

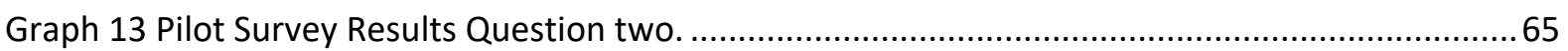

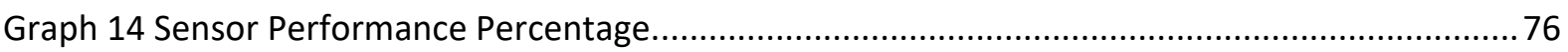

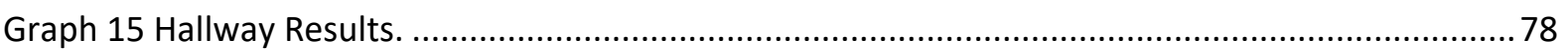

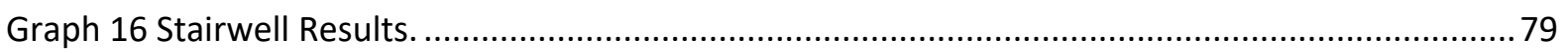

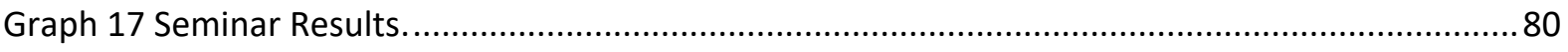

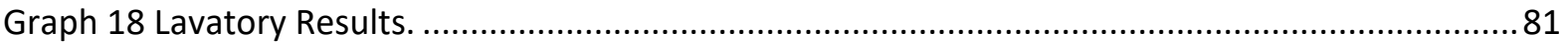

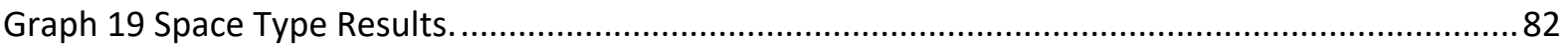

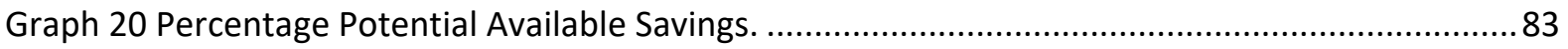

Graph 21 Energy (kWh) performance of the Space Types................................................................. 84

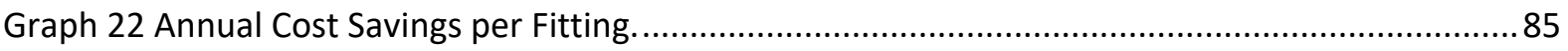

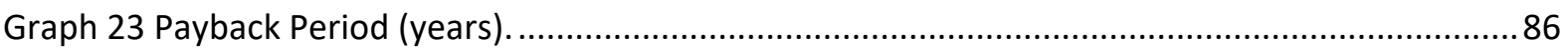

Graph 24 Weekday potential compared to Weekend potential. .......................................................87

Graph 25 Daytime potential compared to Night-time potential...................................................... 88

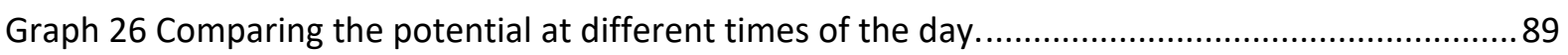

Graph 27 Comparison of Light Types Annual Cost Savings..............................................................96

Graph 28 Duration of recorded occupancy periods. One to 10 minutes shown (part one)...............100

Graph 29 Duration of recorded occupancy periods. 11 to 60 minutes shown (part two) .................100

Graph 30 Instances of Occupancy in the space types. Data excerpt from 2/08/2019....................... 101

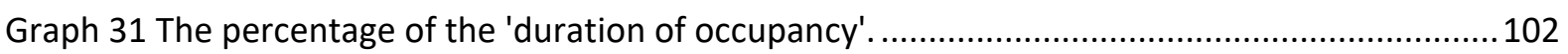

Graph 32 Percentage of time seminar rooms were occupied during daylight hours........................105 
Table 1 Data Categories.

Table 2 University Space Type Descriptions.

Table 3 Space Type Inclusion and Exclusion Criteria.

Table 4 Pilot Sensor Details.

Table 5 Space Information and Choice Rational. .50

Table 6 Battery Life Analysis (Pilot data) .58

Table 7 Pilot Survey Details .60

Table 8 Survey Answers. .64

Table 9 Survey Questions and Results. .65

Table 10 Survey responses compared to motion count. ....................................................................66

Table 11 Experiment Details. .70

Table 12 Building Survey Space Type count. .71

Table 13 Floor area percentage of intermittent-use space types. .71

Table 14 Observation Space Type Distribution .72

Table 15 Recommendations and Worth. .94

Table 16 Performance of Space Types. .94

Table 17 Time Delay Calculation. 103

Table 18 Combined result output example. 108

Table 19 Pilot Space Details 122

Table 20 Pilot Study Plans and Sensor Locations. 123

Table 21 Additional lavatory details 136

Table 22 Measured building areas for scope building survey. 136

Table 23 Experiment Individual Sensor Data Results 137

Table 24 Experiment individual space annual cost savings per fitting data .138

Table 25 Experiment Sunrise and Sunset Details 138

Table 26 Light Fitting Database for experiment analysis 139

Table 27 Light type comparison data.

Table 28 Percentage of Occupancy Instances up to 30 minutes. 141

Table 29 Room booking daylight occupancy data. 


\section{All figures are the authors own unless stated otherwise.}

Figure 1 Integration of daylight and electric light in a side-lit room using automated switching........28

Figure 2 Available research on "energy efficiency" by subject area....................................................31

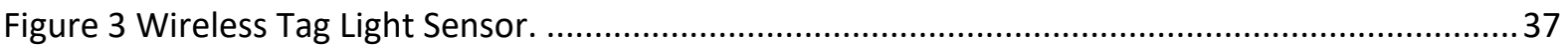

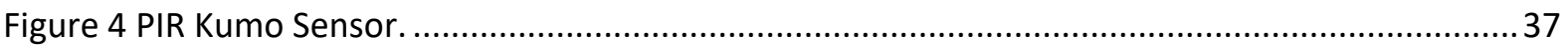

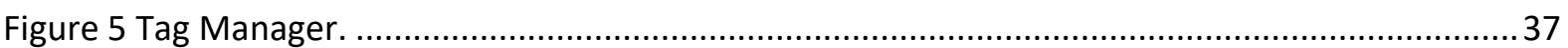

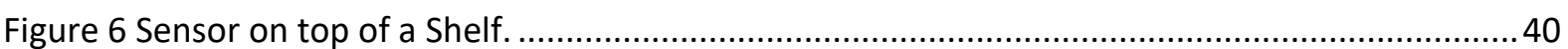

Figure 7 Light sensor directly on light fitting. Wigan 5th Floor Hallway...........................................42

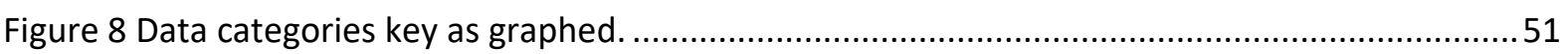

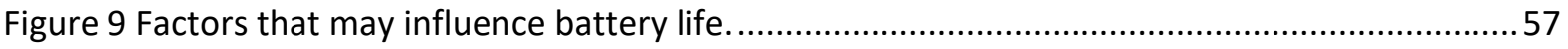

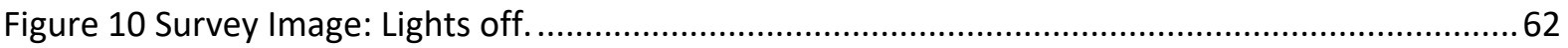

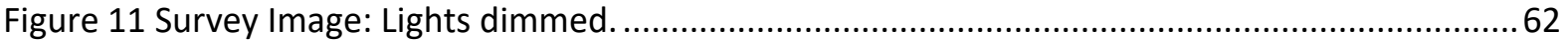

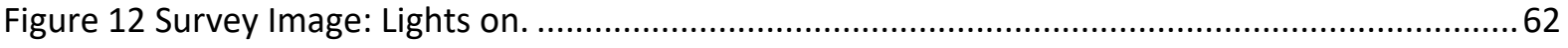

Figure 13 Survey Question example from Pilot Survey. ……..............................................................63

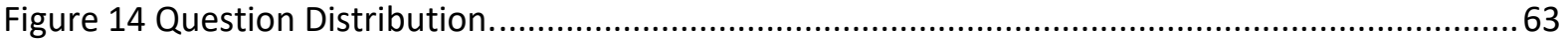

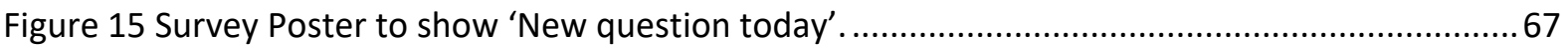

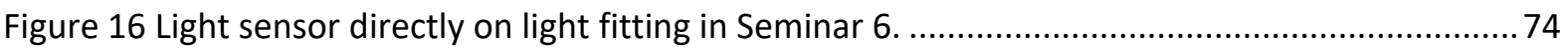

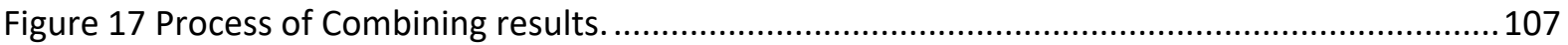




\begin{tabular}{c|c} 
EECA & Energy Efficiency and Conservation Authority \\
OS & Occupancy Sensor \\
DS & Daylight Sensor \\
BREEAM & Building Research Establishment Environmental Assessment Method \\
BMS & Building Management System \\
BPS & Building Performance Simulation \\
NZS & New Zealand Standard
\end{tabular}




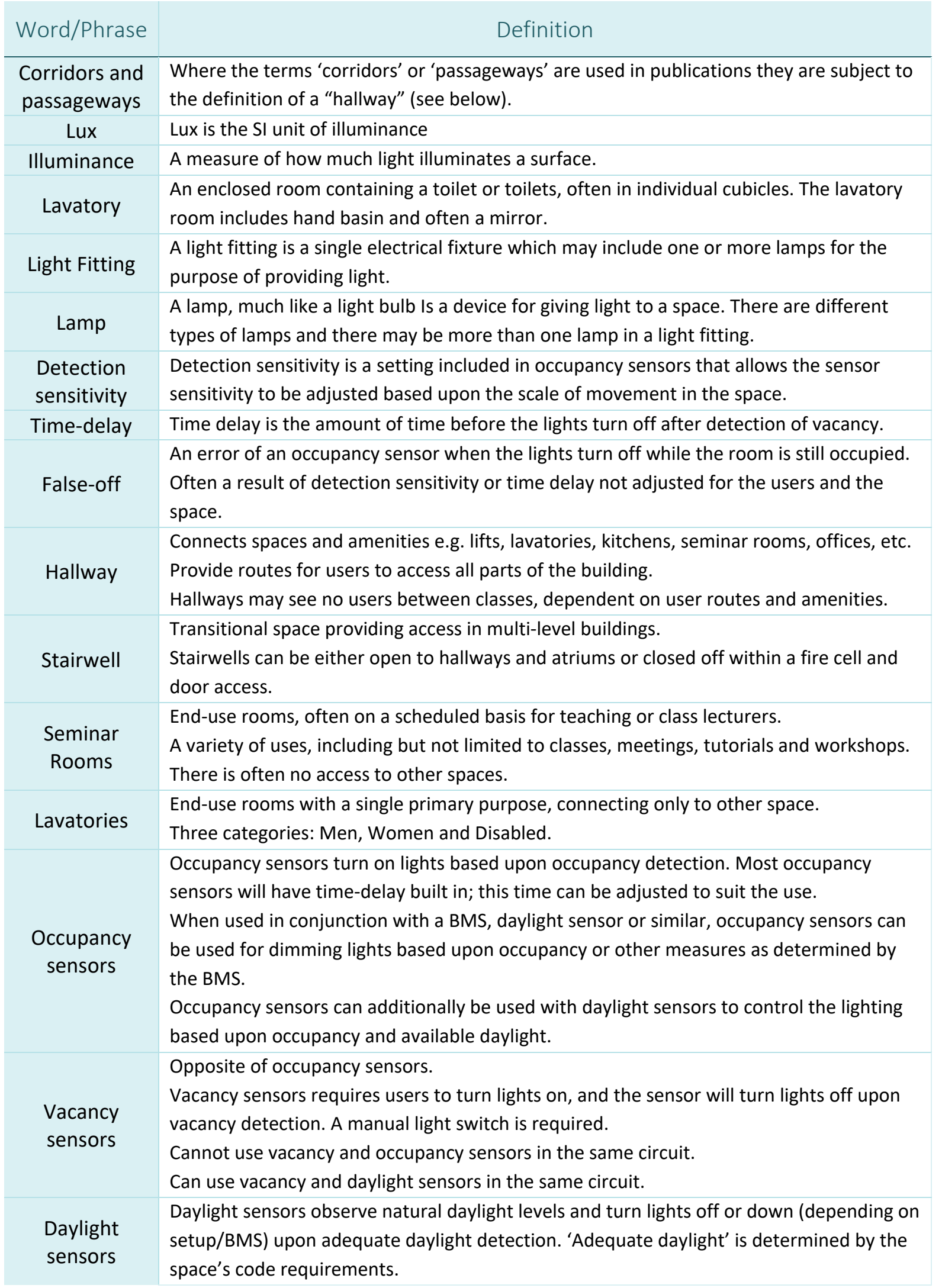



Masters of Architectural Science

Georgia Alexander

Chapter 1 INTRODUCTION 
High energy consumption is an issue that many buildings face as the resource continues to diminish quicker than renewable resources can produce. Advances in technology have found many solutions to improve the efficiency of technology and reduce energy consumption. As many aspects of building technologies are revised and improved our own actions and behaviours should improve also.

Gardner and Stern (2002) paint a picture of an ideal future where benefits would accumulate in their own nature if people felt an intrinsic motivation to undertake and maintain energy-saving behaviour with little or no incentive. This would in the long term be a great achievement for sustainable energy use. If occupants of a building had developed an energy conservation culture their behaviours would continue and spread to other areas of their lives (Masoso and Grobler, 2010). Energy saving influences are more accessible and outspoken than ever in our current day as implied by the large number of companies and government led organisations around the world working towards energy reduction and energy efficient design. Evidence shows on a global scale that energy demand continues to rise (Dunlop, 2019). Rising energy demand, may be the push that industries need to improve the build environment, but also to stop pointing the finger and consider our own behaviours can be more energy efficient.

Building performance simulation (BPS) is a useful method to model real-world problems of our built environment and find solutions. Accurate modelling and prediction of occupant behaviour could not only improve the accuracy of building simulation but also enhance the performance of building control systems (Wang et al., 2019). BPS could compare energy saving behavioural methods to find the best way we can live more energy efficiently with our own actions. However, a restriction of BPS is modelling the complexity of human behaviour. Often this is restrained through over simplification of occupant behaviours (Wang et al., 2019, Li et al., 2019). Oversimplification does not account for many aspects of humans including user behaviour and changes in behaviour over time.

The International Energy Agency (IEA) Annex 66 has spent four years (2013-2017) researching the 'definition and simulation of occupant behaviour in buildings. Their concluding remarks reiterate the difficulties of simulating unpredictable human nature and recognise that data collection is fundamental for the modelling of occupant behaviour. Annex 66 made progress to better represent occupant behaviour in simulations, however, there are still many behavioural aspects that cannot yet be modelled. 
"Interdisciplinary research across building science, building technologies, social science, behavioural science, data science and computer science is needed to deeply understand, represent, model and simulate human behaviour in buildings and quantify their impacts on building energy use, occupant comfort and health"(Yan et al., 2017).

While human behaviour continues to baffle BPS researchers there is under-utilised technology at our fingertips. Occupancy sensors are a common technology in new builds and retrofits which help minimise unnecessary light use. These sensors are often under-utilised as the industry reduces their use to open-plan spaces. Occupancy sensors for lighting control in open-plan offices in particular are well researched and well understood (Galasiu et al., 2007, Williams et al., 2012, De Bakker et al., 2018). Energy savings resulting from the use of occupancy sensors in offices have been reported to range from 20\% - 60\% (De Bakker et al., 2018), with older (before LED) research suggesting larger ranges. The wide range of savings is not easily refined due to variances between studies such as existing lighting control, space type, occupant behaviour and lighting system design.

Studies indicate that occupancy sensors reliably deliver savings in infrequently or unpredictably occupied spaces such as washrooms, stairwells, corridors and storage areas (Guo et al., 2010). These spaces often use the lights for significant periods when they could be turned off. Researchers have for years been suggesting that lights should be turned off in areas of irregular inhabitancy, in passageways, stairs, library stacks and restrooms (Kinsley, 1979). Researchers can collectively agree that occupancy sensors promote energy savings, although the lack of research on this issue was identified in 2008, (Roisin et al.). Lighting in secondary spaces, such as those mentioned may operate 24 hours a day, seven days a week and are consequently potentially one of the largest areas of lighting energy use (Graeber and Papamichael, 2011). Papamichael (2017) suggests that "stairwells, corridors and hallway spaces offer significant opportunities for energy savings as they are usually illuminated fully continuously, while they are vacant for long periods of time, especially during the night". The question of the value of occupancy sensors in intermittent-use spaces continues, but the lighting industry has not yet answered it with qualitative research.

Occupancy sensors are currently primarily used for lighting in open plan spaces, but there are many situations where infrequently used rooms are being lighted, heated or cooled unnecessarily (Xu et al., 2011). Although this research does not investigate heating and cooling issues, the results may be of interest to other energy consuming building services in intermittent use spaces. 
This research will explore the use of occupancy sensors to investigate the potential energy savings and benefits of automated light control in intermittent-use spaces. Space types to be assessed are hallways, lavatories, stairwells and seminar rooms (for definitions see Definitions, page XIII). Occupancy sensors are intended to compensate for humans' failure to manually control lighting to reduce unnecessary energy consumption (Hebert et al., 2014). At a basic level, occupancy sensors will detect when there are no users, turn off the lights and avoid the situation when users forget to turn off the lights upon leaving (Wang et al., 2017).

Time-delay and sensitivity of occupancy sensors can often be issues when the sensors are not correctly adjusted for the occupants. If not tuned, lights can sometimes turn off on users when after short periods, or due to minimal movement. The effects of time delay are reviewed in section 2.3.1. There are many different questions to be considered in establishing the need for or value of occupancy sensors. Open-plan areas with lots of users increases occupant variability and decreases the likelihood of all users leaving the space at once. Smaller spaces with intermittent or infrequent users decreases occupant variability and increases the likelihood of all an empty space. Observation suggests that open-plan office spaces typically have higher occupant use than seminar rooms, hallways, lavatories or stairwells.

Intermittent-use spaces have intended and specific use(s), which influence users to act similarly in like spaces e.g. all stairwells. Hallways and stairwells are transitional spaces allowing users to move from one location to another. It is speculated that transitional spaces are primarily not used for loitering, but this may be observed where there is seating, or while waiting for class/peers. Seminar rooms and lavatories are end-use spaces for designated purposes. Seminar rooms are often temporary workspaces used by large groups of people at periodic intervals for allocated tutorials, classes or seminars. Similarly, lavatories users have a primary purpose, but the space may be used for a wider range of activities e.g. applying makeup. Neither seminar rooms nor lavatories are likely to be used after their purpose is complete, so they are not often found with people loitering.

In commercial and public spaces, light switching is not perceived as a responsibility of the users as Ji et al. (2017) noted "users lack of a sense of responsibility for public facilities causes difficulties such as energy waste". Responsibility subconsciously influences users to be more considerate about their actions and behaviours, for instance, it is more likely for someone to turn off the lavatory light at home than at work. A residential setting or individual office identifies the light switch as the user's responsibility. 
Kollmuss and Agyeman (2002) list various factors that shape pro-environmental behaviour [an energy conservation culture] including, demographic, economic, social, cultural, motivation, proenvironmental knowledge, awareness, values, attitudes, responsibilities and priorities. Responsibility can be considered a reasonable deterrent for users lack of pro-environmental behaviour in workplaces, or in public places. Often, energy use is not a consideration in workplaces as there is little relevance to most employees and the sharing of facilities and appliances may create barriers to better energy saving behaviour change. Users are more likely to show pro-environmental/energysaving behaviours at home where they are directly responsible for the energy use and energy bills, rather than at their workplaces (Bedwell et al., 2014).

Occupant behaviour is a crucial factor in determining lighting energy use in buildings, and consequently, how to reduce that energy use (Masoso and Grobler, 2010). Occupancy sensors are an ideal solution to uncontrolled occupants as they monitor occupant behaviour and control lights accordingly. Energy saving behaviour should always be encouraged, however, the current literature and research can provide guidance, but has not yet found 'the most beneficial methods' of encouragement. Automated technology while not perfect, doesn't need occupant encouragement, is well researched and understood, is feasible and readily available, yet not implemented in intermittent-use spaces.

There are many positive theories, but no qualitative results to date which support the use of occupancy sensors in intermittent-use spaces or justify how effective they may be. Taking VUW buildings as an example, the current light systems rely on control from light switches or building management schedules. The goal of this research is to identify the potential benefits of occupancy sensors at VUW to save energy and as a result remove the reliance of humans to turn lights off.

\subsection{INTENT}

This research will explore the potential energy savings from occupancy sensors in intermittent use spaces. These spaces, which include hallways, stairwells, seminar rooms and lavatories are often fully illuminated and provided with user-controlled switches BUT can be vacant for long periods. This research will help identify energy savings opportunities in spaces that are often overlooked due to small space or intermittent use. The work will use light sensor data and motion sensor data to calculate wasted light energy use when spaces are empty. The results may also help identify opportunities in other buildings, benefitting the industry with added knowledge and use of these sensors. 


\subsection{HYPOTHESIS}

Research on office buildings proposed that spaces such as corridors may present significant energy savings (Akrasakis and Tsikalakis, 2018), implying that intermittently used spaces such as corridors offer potential energy savings through occupancy-based sensors. This perception and the work of others (Hebert et al., 2014, Guo et al., 2010, Papamichael, 2017), support the selection of intermittently used spaces for this research.

It is hypothesised that even after the cost of installing occupancy sensors in a selection of intermittently used spaces, the low occupancy in these spaces will provide significant lighting energy savings. This hypothesis is based both on the infrequent use of these all space types and their role as transitional space with low to zero responsibility taken (or able to be taken) by the occupants. User responsibility is considered an aspect of behaviour, specifically relevant when considering the energy savings behaviours.

\subsection{AIMS}

The aim of this research is to provide measurable and scalable data from monitoring real buildings to provide insight into the potential energy savings of occupancy sensors in intermittent-use spaces. They can be broken down into three main areas:

1. Identify which space types provide the greatest energy savings potential and the optimal smallest payback period.

2. Provide discussions around the influence of energy-saving behaviours and lighting use.

3. Calculate the potential for additional savings through use of daylight sensors. 
Masters of Architectural Science

Georgia Alexander

Chapter 2 LITERATURE REVIEW 
The following chapter provides a literature review regarding the use of occupancy sensors to reduce lighting energy use. These include the use of building management systems (BMS), schedules and detection sensors. Specifically, these publications cover light use habits, energy saving behaviours, daylight sensors, vacancy sensors, national standards, the influence of the social sciences and user perception of lighting. There is a general idea in the lighting industry that occupancy sensors could be beneficial in intermittent use spaces, so this section reviews some of the perceptions around occupancy sensors in different space types. Additionally, literature on the effects of time delay settings and recommendations from local and international sustainability tools is investigated.

The first part of the chapter forms a general perspective around light use habits and energy saving behaviours before delving deeper into occupancy sensor technology, their use within the social science world, recommendations and user perspectives.

\subsection{LIGHT USE HABITS}

This section reviews artificial light use habits and BMS schedules. The habits of 'light switching behaviour' is often un-related to energy use as it is more commonly influenced by daily routines. Light switching behaviours can be a result of bad habits - turning lights on upon arrival and off at home time, poorly designed building, or poorly designed building management system (BMS) schedules.

One of the most commonly targeted behaviours to encourage through energy saving behaviour interventions has been the control of lighting. Encouragement to turn lights off has been around as long as artificial lights, but why is it that lights are so often left on when no one is there? It is likely that turning lights off is better executed at home, perhaps where users take ownership for the usage of lights and responsibility for the power bills. One of the hurdles of 'energy saving behaviours' in commercial buildings is encouraging users to care about energy use, and therefore, to reduce it. It is easy to ignore energy consumption in the workplace when we are not required to pay for the energy use. As technology becomes increasingly more efficient, the encouragement of reducing energy use in the workplace becomes more difficult. Why should the lights be turned off if they're energy efficient LED? What benefit do occupancy sensors provide if the lights are already efficient? Occupants tend to turn lighting on habitually as they first enter an office and keep the lighting on until they leave (Yun et al., 2012, Moore et al., 2003). "Three quarters of users' use of manual controls occur less than five minutes after their arrival in their office or before their departure, likely a direct consequence of the traditional placement of controls close to the door". 
Lindelöf and Morel (2006) found through their research that lights were left on although daylight levels provided enough illumination. Additionally, dimmable features were seldom used.

Time of day habits, such as those noted by Yun et al. (2012) are also discussed in work by Reinhart and Voss (2003), who also noted the growing interest of integrated lighting control systems 17 years ago. More recent research found that occupant controlled lighting in offices is not statistically related to daylight illuminance, but rather has a close relationship with the occupancy patterns (Yun et al., 2012). Users require lighting only when they are in the space, but lighting is controlled by habits regardless of space use or daylight availability.

Delgoshaei et al. (2017) stated a responsible [energy conscious] occupant aims to benefit from the daylight when possible or to turn off the light switches when no one is in the space. However, it is not possible to rely on everyone to behave as a responsible energy conscious user.

One of the most important variables of lighting energy consumption is occupant behaviour, with a common light switching behaviour profile to turn on all the lights in the morning upon arriving at work and turn them off at the end of the day. This behaviour takes no consideration of daily schedules or when users are out of office for long periods, in meetings, or other tasks. The main routes of commonly used technologies to reduce lighting consumption are schedules, building management systems (BMS) and detection sensors. BMS can control lighting via time, user schedules or sensors. Schedules are cost effective to implement as it only requires knowledge of general staff patterns. However, a BMS controlled case study by Delgoshaei et al. (2017) found when occupants had no access to light switches the lighting schedule operated for about two hours after the standard workday. The BMS had inaccurate schedules which overestimated the use of lights at the end of the day. As it was controlled by the BMS, even if the users had intended to switch off, they had no control and could not turn the off lights. It is difficult to generalise from a single case study whether this would be a consistent phenomenon, but this is one example of how a BMS system could disrupt energy savings intent of the users.

\subsection{Energy SaVIng BeHAVIOURS}

"Despite the continuing technological advances and the development of energy-efficient devices, energy is used because of people's needs, not because of the needs of technology, infrastructure or buildings" (Endrejat et al., 2017). It is the users who require the lighting or air conditioning for their comfort needs. The following section reviews publications discussing how occupants can be encouraged to become more energy conscious and established as 'energy saving behaviours'. 
Literature investigating 'energy saving behaviours' does not find any one ideal solution or method to encourage these behaviours, nor do they agree how effective energy saving behaviours can be. One thing they do agree upon is that there are benefits to encouraging energy saving behaviours from building users. Work by Agha-Hossein et al. (2015) and Tetlow et al. (2014) suggest that behaviour of building occupants can have a significant impact on energy performance.

Masoso and Grobler (2010) go as far as to suggest that occupant behavioural change has comparable if not higher energy-saving potential and more benefits compared with technological innovation, based upon the fact that behavioural change is largely cost free and requires no technology. A lighting study by Darby et al. (2016) found 20\% energy savings in lighting due to user awareness and behaviour change.

The method of encouraging energy savings behaviours considers the science of buildings and the psychology of behaviour. A systematic literature review investigating behavioural interventions to save energy found nine methods across 29 studies (Staddon et al., 2016). Psychological discussions (Agha-Hossein et al., 2015, Darby et al., 2016, Endrejat et al., 2017, Staddon et al., 2016) and categorised interventions (Staddon et al., 2016) highlight that they are most effective when used in combination with at least two interventions, the most effective being real-time feedback to users. Although real-time feedback was one of the most commonly used and most successful interventions, due to lack of consistency between studies it is difficult to determine which interventions and/or combinations are best.

Occupant behaviour is not simple, as energy-related behaviour considers their comfort, preference, presence, movement and interactions with building components and systems (Wang et al., 2019). Occupant behaviour is not well known. Researchers around the world have been studying it for decades if not centuries (O'Sullivan and Vaughan, 1987), it is however, complex and influenced by many variables from person to person. Trying to understand the complexity of human behaviour to aid our building design is an on-going effort. Occupant behaviours are one of the key reasons for the performance gap between the design and operation stage of buildings (Bordass et al., 2001, Taylor et al., 2018). The behaviour of occupants and other building users is an area that building performance simulations often fail to simulate accurately (Yan et al., 2017).

\subsection{OCCUPANCY SENSORS}

Occupancy sensor controls are considered an effective solution to reduce unnecessary light use without relying on occupants to use the manual light switches. Occupancy sensors are most commonly used and have proved their effectiveness to reduce office energy consumptions (De Bakker et al., 2018, Rubinstein and Enscoe, 2010, Galasiu et al., 2007). 
Sensors use real-time processing to allow immediate reaction in order to be used only when occupancy is detected (Xu et al., 2011). Occupancy-based controls aim at minimising electric lighting energy levels during vacancy periods, either by turning lights off or dimming them to a low level, depending on application; they automatically adjust their output in real time based on environmental changes in order to maximise energy efficiency (Papamichael, 2017).

Occupancy sensors are adaptable based on scheduling and tuning, more advanced devices include daylight systems, they are appropriate for retrofit installations and BMS (Graeber and Papamichael, 2011). There are a number of varying types of motion sensors (see section 2.3.3) depending on the space type and space use. Legrand (2014) provides a detailed guide considering the different sensor types based upon application, recommending PIR sensors for passageways due longer range and good detection performance of people moving.

\subsubsection{TIME DELAY}

A weakness of occupancy sensors is the time delay period, this is the amount of time before the lights turn off after detection of vacancy. Time delay intends to minimise false OFF's if users have been stationery for period. In 2017 a Virginia, USA, energy code limited the time delay to 30 minutes, with more recent codes shortening this to 20 minutes for energy savings (Dilouie, 2017). New Zealand Standard (NZS) 1680 suggests that a time-lag should be built into the system to prevent premature switch-offs but does not specify a length of time (StandardsNZ, 2008). The NZ Energy Efficiency and Conservation Authority recommends a 10-minute time delay in warehouses aisles, store rooms and bathrooms, some of which are intermittently used spaces (EECA, 2020).

Some studies have investigated the effect of various time delay settings on occupancy sensor energy savings and encourage commissioning for each space application to account for different occupant behaviours (Chung, 2001, Richman et al., 1996, Manzoor et al., 2012). The shortest documented case study achieved a time-delay of seven minutes after careful and professional commissioning and sensitivity adjustments (Guo et al., 2009).

Occupancy sensor benefits include convenience and added security, but in the absence of a user controlled by overriding switch, restrict the user from control of the lighting, particularly where there is adequate natural light entering the space. Guo et al. (2010) reports typical time delay settings of 20-30 minute which result in more wasted energy than if occupancy patterns were more accurately measured. A study by Richman et al. (2013) suggests that savings can be doubled if the time delay setting is reduced (from 20 minutes to five minutes), this suggestion should be considered on a case by case basis as it may potentially increase the number of false-OFFs, upsetting occupants in workspaces. 
A reduced time period as suggested may not be such an issue in secondary spaces, especially transitional spaces, Legrand (2014) specifically recommended five minutes for passageways. VonNeida B. (2000) recommended shorter time delays for increased energy savings particularly in rooms that are infrequently/briefly occupied.

\subsubsection{ENERGY SAVINGS IN DIFFERENT SPACES}

The reviews in this section consider the literature of occupancy sensors and their use or effectiveness in different locations. It considers current positive use of occupancy sensors and the continued idea of their effectiveness in intermittent-use spaces.

A field study by Galasiu et al. (2007) found occupancy sensors resulted in an average of $25 \%$ energy savings in private offices with sporadic use, $40 \%$ in open-plan offices and $30 \%$ in scheduled use spaces such as classrooms. This work recorded lower average savings in spaces where users have more responsibility - such as private offices. Suggesting that "the larger energy savings related to occupancy sensors installed in shared spaces was attributed to the fact that in such spaces the occupants generally do not feel as responsible for manually switching off the lights when leaving a space as they would when leaving a private office". Other research suggests occupancy sensors may offer significant energy savings in intermittent-use spaces such as lavatories, stairwells, corridors and storage areas (Kinsley, 1979, Guo et al., 2010, Papamichael, 2017). These research papers suggest and support occupancy sensors in intermittent-use space, but their logic is theoretical and lacking any results to back them up.

A 2011 experiment of occupancy controlled dimmable lighting in vacant corridors (between use) showed significant reduction in lighting energy use. Their results show average savings of $73 \%$ with payback period ranging from four-and-a-half to eight years. Occupants reported about their understanding of the energy saving benefits of occupancy sensors, that they enjoyed the satisfaction that comes from being in an eco-friendlier space. Managing lighting in secondary spaces (common among all building types) such as corridors, stairwells etc. demonstrates an effective strategy for energy savings and peak demand reduction. (Graeber and Papamichael, 2011). 


\subsubsection{OTHER SENSORS}

Sensors can address the uncertainty of lighting schedules by monitoring the spaces in real-time and controlling lights accordingly. This energy-effective design and operation can achieve significant savings without reducing performance and visual satisfaction when users are in the space.

There are two additional types of sensors relevant to this research, vacancy sensors and daylight sensors. Definitions for each type of sensor are provided in the Definitions section in the preface.

\section{VACANCY SENSORS}

The Vacancy sensor is theoretically the most energy efficient option as it does not automatically turn the lights on, encouraging users to consider the light in the space and the use of natural daylight. The benefits of vacancy sensors can be reduced by occupant behaviours who may habitually turn lights on at the start of the workday. Vacancy sensors are not ideal in transitional or circulation spaces with more than one entry as multiple light switches would be required and likely excessive. Occupants are not expected to know the location of light switches in these types of spaces such as hallways or stairwells.

Literature on vacancy sensors is minimal, as it appears that the lighting industry prefers occupancy sensors and/or daylight sensors. Perhaps occupancy sensors are preferred due to easy assurance and compliance with lighting code requirements. Leaving the occupants to turn the lights on in the first instance may not be an acceptable solution.

Vacancy sensors can be beneficial in fitting circumstances, but their benefits are hindered by poor light-switching habits and/or lack of control for lighting code compliance. The combination of vacancy sensors and daylight sensors could be successful as lights are manually switched on but will automatically turn off if there is adequate daylight or the space is vacant.

\section{DAYLIGHT SENSORS}

Daylight sensors can use daylight to minimise artificial light use while maintaining desired workspace lux levels. However, they can require significant reconfiguration of existing lighting circuits depending on the shape and depth of the room, as deeper spaces receive less daylight. Figure 1 from NZS1680 (2006) illustrated how a system is set up so that lights near windows can separately be turned off when adequate daylight is detected. Sectional view (b) indicates the likely lux distribution across the depth of the room. 


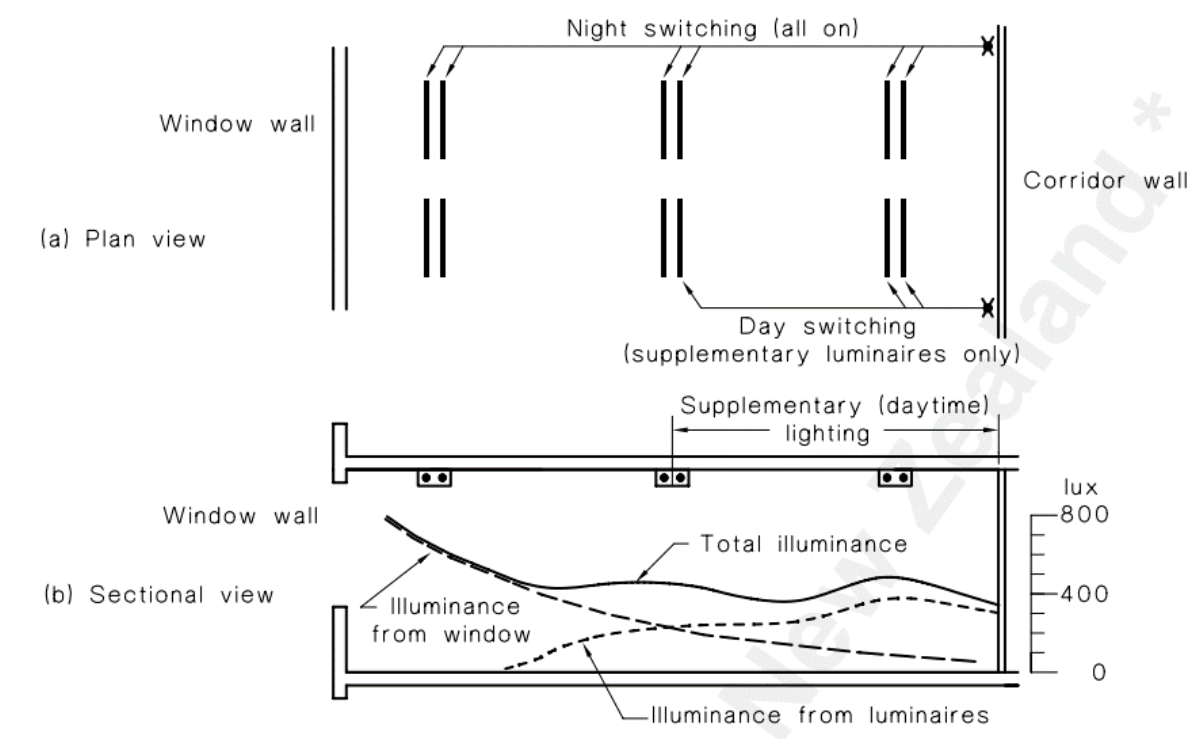

A new building with optimal access to daylight and a narrow floorplan would be the ideal building type to maximise energy savings with daylight sensors. They are not as effective in a building with a deep floorplan where daylight won't reach, South oriented building (Southern hemisphere) or a building significantly shaded by neighbouring buildings and/or landscapes.

Re-configuration of existing circuitry to integrate automated lighting systems can be tricky or costly, particularly re-circuiting for daylight sensor systems. The benefits can reduce energy consumption when daylight illumination is enough. The potential of energy savings through sensors varies depending on the space type, size and lights. Yun et al. (2012) claim that daylighting energy saving strategies have not been successful due to lack of understanding occupant perception and behaviour of natural and artificial lighting systems. More recent technology shows signs of improvement with lighting suppliers such as Legrand (2014) recommending them for areas with good access to natural light alongside recommendations for occupancy sensors.

Occupancy and daylight sensors are both widely used energy efficient technologies available on the market and can provide significant savings when used in their respective ideal locations. E.g. near the windows for daylight sensors (Dubois, 2011). Occupancy sensors have a greater opportunity for use as daylight is not always easily accessible, and therefore, they may likely be the preferred choice in the lighting industry. Unlike daylight sensors, they do not require extensive circuiting, can maintain lux levels, improve security and are applicable in more space and building types, regardless of orientation or window size. Vacancy sensors require occupants to know where the light switches are, which is not always feasible in a public building, open plan space, or circulation/transitional spaces. 
Occupancy sensors continue to become more popular and widely used across the building industry in an effort to easily reduce energy. This research uses occupancy sensors as they are the best suited type of sensor for use in intermittent-use spaces.

\subsubsection{SustaINABILITY TOOL RECOMMENDATIONS}

The New Zealand Green Building Council Sustainability Rating Tool GreenStar (2017) encourages the use of occupancy sensors as they are "particularly useful where occupancy is either infrequent or very consistent." A lighting control requirement forms part of the Greenstar energy category and requires office and education projects, presence detectors are to be "installed in all infrequently used areas to control lighting" (GreenStar v3.2 Section ENE-5 Lighting Control). These spaces include but are not limited to enclosed corridors, lavatories, storerooms, plant rooms and dedicated fire escapes.

Internationally the use of occupancy sensors is encouraged across various building types including educational and office. Abu Dhabi's sustainability tool, Estidama (2010) requires "occupancy sensors in ALL rooms intended for individual occupancy, conferencing or meeting rooms, open plan office spaces and hallways or corridors." The British Energy Performance Standard for Lighting (EN-15193, 2007) recommends automatic lighting controls (sensors) for education buildings for at least $60 \%$ of the lighting load. Other building types are all recommended manual control. It suggested the performance of occupancy (and vacancy) sensor detection area should "closely correspond to the area illuminated by the light fittings that are controlled by that detector." In contrast, the international WELL tool requires all lighting to be controlled with occupancy sensors for dimming or switch-off when spaces are unoccupied (WELL, 2019). In the UK, BREEAM recommends where appropriate either daylight sensors or occupancy sensors with the addition of manual over-ride switch (BREEAM, 2019).

These three sustainability tools either recommend or even require the use of lighting controls, either occupancy, vacancy or daylight, or some combination. NZ's own GreenStar tool encourages their use in infrequently used spaces. Sustainability tools can often be very generic, but for lighting they are specific as to the use of lighting controls. Lighting controls are recognised internationally as a technology that can provide energy savings. 


\subsection{NATIONAL STANDARDS AND GOVERNMENT AUTHORITY RECOMMENDATIONS.}

The design of lighting schedules should allow occupants to participate in conserving energy as much as possible. NZS1680 (2006) states that switching systems imposed on occupants may generate user resistance. The system adopted should therefore provide the occupants with some degree of choice for the control of the lighting. An alternative form of light switching without human intervention is the use of sensors to control lighting in response to occupancy, vacancy or availability of daylight.

The national lighting standard recognises the "need to minimise electrical energy consumption and encourage lighting designers to seek solutions which will maximise energy savings". There are no standard requirements for the type of light fitting or switching for any space type (NZS1680, 2006).

New Zealand's energy efficiency standard encourages effective use of lighting control systems, but details of application is outside the scope of the standard (NZS4243.2, 2007). The standard is referenced in the New Zealand Building Code Clause H1 as an acceptable solution. NZS4243.2 provides general information with automated systems which are encouraged to combat the oftenconsiderable amount of energy wasted after working hours when the lights are left to no useful purpose. It suggests the use of systems which automatically cancel lighting but are manually reset, such as vacancy sensors, as these can offer greater savings than those which switch on again automatically. Occupants can always be relied upon to turn on lighting if needed. This suggestion is most beneficial in spaces with single (or minimal) entrance(s) and a light switch near the entry.

Energy savings from occupancy sensors depend on the total hours that lights are normally on and the percentage of hours that they can be turned off (Niehus, 2004). The NZ Government formed the Energy Efficiency and Conservation Authority (EECA) dedicated to helping the country be intentional about clean and clever energy use. EECA provides information about energy use, energy impacts, courses and contacts to aid energy minimisation (EECA, 2019). "Lighting is one of the most intensive uses of energy in the education sector, typically making up around 30\% electricity use" (EECA, 2010). Occupancy sensors are one of the top recommendations EECA suggests for saving energy in all buildings. 


\subsection{SOCIAL SCIENCE IMPACT}

Dunlop (2019) emphasises the 'gap' between social sciences and technical sciences (quantitative, methodological). Their work found that there is very little research ( $2.6 \%$ of literature found in the study) that examines energy efficiency from a conceptual perspective taking into consideration both technical and sociological aspects. Figure 2 taken from Dunlop (2019), is based on a count of the words 'energy efficiency' in either article title, abstract or keywords in articles from 1909 to 2018 listed in the Scopus research publications database.

Social sciences is represented by one of the smallest percentages (2.6\%), in contrast, building science and building performance simulation can be considered a part of the top three subjects forming 59.6\%; Engineering (29.3\%), Computer science (16.8\%) and Energy (13.5\%)(Dunlop, 2019).

Figure 2 Available research on "energy efficiency" by subject area.

Graph credit: (Dunlop, 2019).

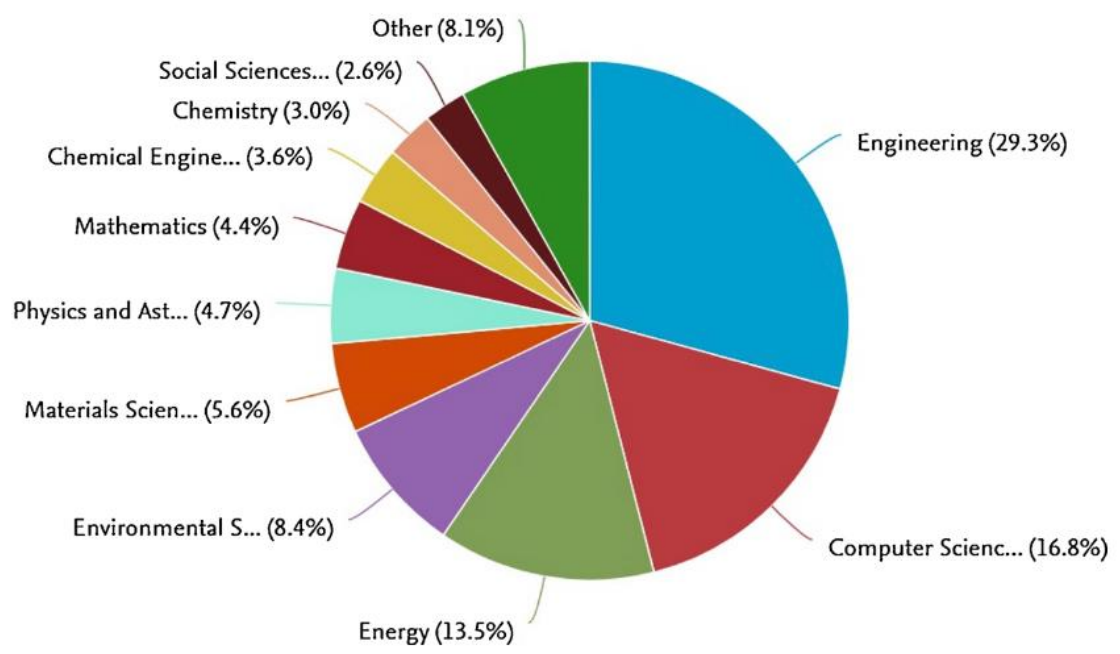

Limited knowledge of the psychology of energy saving behaviours and modelling occupants is restricting the Building Performance Simulation (BPS) industry. Collectively, the BPS industry lends itself toward multidisciplinary and inter-disciplinary work to attempt to understand more about users and their effect on a building and its systems (Bleil de Souza and Tucker, 2019). There are two limitations, the understanding of occupant behaviour and effectively modelling that behaviour. Without this the BPS industry will continue to produce models and designs that do not accurately reflect the users and their long-term behavioural impacts. It may be impossible to accurately model user behaviour, but it is possible to model useful behaviour scenarios such as best practice, typical practice and worst practice as long as the limitations of imperfect representation are known and disclosed. The review of literature about energy efficiency as detailed by Dunlop (2019) implies minimal research combining social sciences AND energy efficiency. 
Annex 66 iterated a similar need for a multidisciplinary approach to improve the understanding of occupants in BPS (Yan et al., 2017). It seems that the necessity of social sciences and a multidisciplinary approach has been recognised and thus needs to be implemented.

\subsection{USER PERCEPTION}

This section reviews the literature on surveys and user perception within the context of lighting and user comfort. Lighting not only affects the physical world and the requirement of task lighting, but is critical for humans functioning, affecting us physiologically and psychologically (Pathak et al., 2015).

Hebert and Chaney (2012) use a 40-item (five-point Likert scale) questionnaire to evaluate the effect of existing lighting design on end-users' perceptions to gather general opinions regarding sustainability. Their work uses citizen participation theory to influence facility design and promotes the success of user input which directly aided the design. Similar work by Pemsel (2010) "found the involvement of end-users throughout the design process offered not only benefits, but also detriments." For instance, they state that there can be difficulties making end-users see a greater and long-term benefits and overcoming social and cultural barriers. Therefore, it is important to consider the significance of lighting changes for both energy savings and the effect on users.

A recent article on colour perception considers the influencing factors of emotional states and user perception (Uluçay, 2019) . Colour, much like lighting affects the way users visually perceive their environment. The research suggests that colour (and lighting) perception can be influenced by experience, education, cultural and social factors. Similarly Valibeigi et al. (2018) discuss the cultural psychology of environment quality perception. Understanding that places contain more than one use and accommodate many behaviours allows better environmental design for the diversity of people.

Baird and Thompson (2012) surveyed users of 'sustainable' buildings to assess perceptions of lighting. A seven-point Likert scale was used. The purpose of asking the building users highlights their belief that people can provide one of the best measures of building performance. Baird quotes his earlier work stating "for many aspects of a building, the true experts are the people who know most about using it - the users" (Baird, 1995).

Matterson (2013) used visual environment and comfort surveys to compare user perceptions with simulated results. The work considers user behaviour to manipulate natural light with blinds. More than half of respondents, $54 \%$ indicate they do not use blinds. 
The two scenarios offered are comparable to the use of light switches; firstly, natural light is adequate, and they do not need to operate the blinds, or secondly the user does not operate the blinds regardless the level of natural light available.

Lighting can affect visual comfort in a space (Davoodi et al., 2020). If occupancy sensors were integrated in circulation areas from the beginning of the building design, users may not feel so uncomfortable if they understand that this is how the spaces operate. In an interview about the possibility of the use of occupancy sensors at VUW, Wilkes (2019) mentioned the positive psychological thought process created by occupancy sensors providing a positive message of sustainability as users see lights turning on due to sensors.

The literature reviewed confirms that lighting can influence user perception and comfort of a space. Where there is a change to what is considered normal, it can be difficult to make the users see the long-term benefits. Changing lighting can have some negative user reactions based upon personal experiences, cultural or social factors as Uluçay (2019) mentioned. However, Wilkes (2019) supports an approach which encourages the users to make the positive change rather than an occupancy sensor turning off lights in unused spaces and saving energy.

Although the occupancy sensor will not turn the lights off while users are in the space, the technology must be trusted so that users may comfortably enter and be reassured that the sensor will turn the lights on. 

Masters of Architectural Science

Georgia Alexander

Chapter 3 Methodology 
The literature review found no published results quantifying the effectiveness of occupancy sensors in intermittent-use spaces, although the use of such sensors was supported. The purpose of this research is to quantify the energy saving potential from using occupancy sensors to control lighting in selected intermittent use spaces.

Part of the experiment includes a user survey to assess people's perception of lighting in these spaces, and how they may feel if lights were on a sensor-based control. The purpose of a user-survey is to find out which scenario is more likely, will users be too affected by a change in the lighting control, or is it a matter of encouraging the positive benefits of the proposed change. Buildings do not require lighting, but the users do therefore, it is important to consider the users and their perspectives of a change in lighting to assess the potential of occupancy sensors within hallways.

This chapter discusses the details of the experiment, equipment used, quality assurance, sensor placement guidelines, data collection, data analysis, space descriptions and criteria. The following Chapter 4 Pilot Study details the two pilot studies, one focused on the sensors and the other on the survey.

\subsection{MONITORING EQUIPMENT}

The primary equipment used for the experiment was passive infrared (PIR) motion and light sensors. The selected sensors communicate on a wireless network allowing continuous monitoring and access of data. Additional equipment includes a Luxtrom LX-1102 model light meter, sensors, an iPad tablet and Qualtrics survey application. PIR sensors are used as a substitute for occupancy sensors in the experiment. Occupancy sensors as referred to in this research are integrated into lighting circuits which is not feasible for the experiment. PIR sensors use the same sensing technology, but rather than using the occupant movement to control the lighting, the movement data is gathered in a database for analysis. The analysis process is described in section 3.3 Data Collection.

\subsubsection{SENSORS}

Two sensor types are required to monitor artificial light and occupancy. The type of sensors used are 'Wireless Tags' for measuring light (Figure 3) and 'PIR Kumo Sensors' for occupancy (Figure 4), both made by Wireless Sensor Tags (Wireless Sensor Tags, 2019). Each space requires a minimum one of each type of sensor, allowing light use and occupancy data to be recording the same space at the same time. All sensors wirelessly connect to a tag manager (Figure 5) and the tag manager uploads the data from each sensor to an online database(Wireless Sensor Tags, 2019). 


\section{WIRELESS TAG}

The wireless sensor tag measures the artificial lux levels in the space. Sensors are placed regarding space observations and assessments to avoid daylight interference, away from windows and often directly facing/on artificial lights.

The light sensors are set to record the lux levels every five minutes as this was the smallest available measurement interval. Powered by CR2032 batteries.

\section{PIR SENSOR}

The PIR sensor continuously detects and records when occupants are detected. The PIR sensor uses passive infrared to measure the light radiating from objects within the sensors field of view. This achieves high sensitivity, 12-meter range and very low false alarm rate. Only one PIR sensor is required per room (except hallways longer or rooms wider than $12 \mathrm{~m}$ ).

Powered by CR2450 batteries.

\section{TAg MANAGER}

The tag manager connects wirelessly to the Light and PIR sensors and uploads the data to an online database. The tag manager is directly connected to the internet via ethernet cable for uploading information. They are powered by a wall plug. The range of the tag manager varies depending on the quantity of sensors connected. With 20 connected sensors, the range is approximately a sphere with a diameter of about $12 \mathrm{~m}$.

Measurements $70 \mathrm{~mm} \times 30 \mathrm{~mm} \times 25 \mathrm{~mm}$
Figure 3 Wireless

Tag Light Sensor.

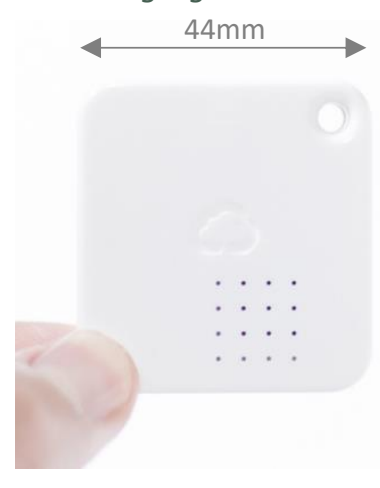

Figure 4 PIR Kumo Sensor.

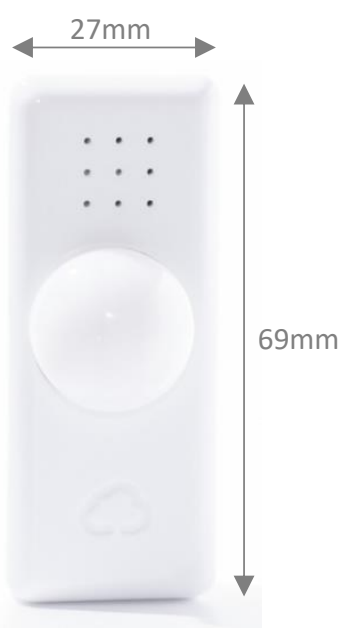

Figure 5 Tag Manager.

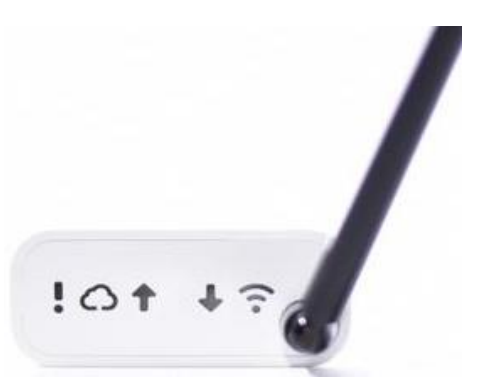

A recording interval shorter than five minutes would have been ideal to account for short use periods in some spaces - the hallways and stairwells. Due to software limitations and the quantity of sensors, a period of five minutes is the smallest recording interval available. 
The sensors are placed in pairs, one PIR sensor and one light sensor per space. Light switching is a behaviour determined by users which involves uncontrolled variables and can change over time. Therefore, is important that the spaces can be monitored simultaneously and for the same duration to minimise variables and account for any change in behaviour over time.

A limitation of the PIR sensors is that they cannot differentiate between a single user and a group of users, as both instances count as 'movement'. This is realistic of some occupancy sensors, however, advanced technology is developing sensors that can interpret how many people are in the space. As an example, Schneider Electric has been developing and testing an Advanced Occupancy Sensor (AOS) since 2016 (SchneiderElectric, 2016). This information is not required for this research as it does not consider number of people, but rather occupancy opposed to vacancy.

\subsubsection{QuALITY AsSURANCE}

The sensors were tested manually by documenting and timing intentional changes in light and occupancy. The light sensors were each tested first by covering with a hand to observe the change in light, and secondly by placing in a hallway with manual switch and recording observed use of the lights. The observations were compared to the data to contrast timing and accuracy. The light sensor data matched the observed data +/- four minutes (see Graph 1), which is within the five-minute recording interval. This is a limitation of the sensors, but not a restriction of the experiment. This difference is not considered an issue as lights are not expected to be turned on/off within that small period based on manual observations shown in Graph 1.

Graph 1 Light sensor data compared to manual light observation data.

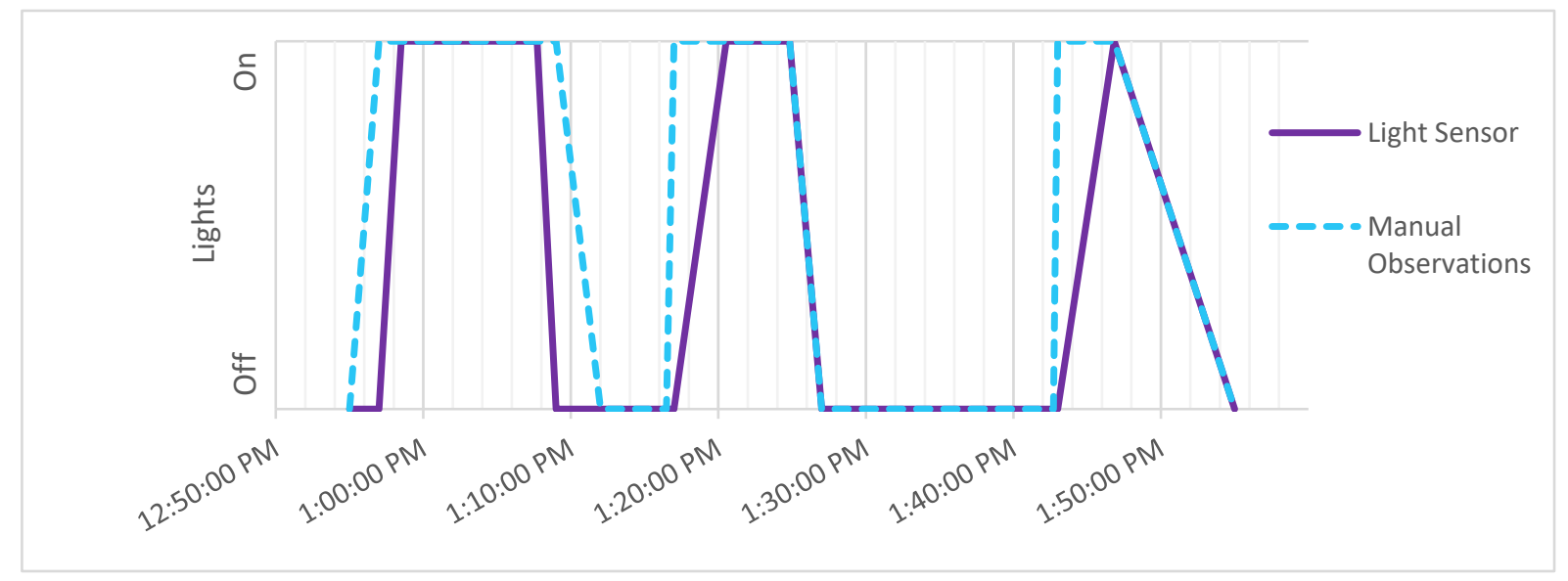

The reported light level of the sensors were calibrated against a light meter to avoid variations, and then the lights sensors were further calibrated to match each other. This process ensured that the light sensors are accurate representations of the lux levels in the space, and all calibrated against the same baseline. 
The PIR sensors were tested by monitoring and timing how often people walked down a hallway. The manually recorded data was compared with the sensor data. The two sets of data match every observation of occupancy with a timing difference of only four minutes. This is expected to be due to the time-out period of 30 seconds after detection. This is a very short time out period and allows the lights to be on for 30 seconds after no more movement is detected. This period is ideally short for the purpose of recording occupancy for the experiment but would need testing in practice in order to ensure minimal 'false offs' while users are present.

\subsection{Sensor Placement Guidelines}

Placement of the sensors was to be determined upon visual inspection of each space, observation of users and light locations. Guidelines were developed to ensure the same applications and restrictions are used consistently throughout the experiment. Inspection and observation of spaces identified potential sensor locations and weigh the benefits and negatives of each location. Including but not limited to, visual range of space, minimal/no obstructions and the likelihood of single user blocking sensor. The two sensor types will need to be considered separately, even in the same spaces as they are measuring different variables.

Light sensor placement needs to be especially conscious of any additional light circuits in the space and avoiding interference of daylight. The purpose of the light sensors is not to measure the light levels, but rather, if the lights are on/off. Therefore, it is not required to follow standard measurement guidelines for the purpose of lighting design. The light sensor need only be near or on a single light fitting (assuming single circuited space).

Sensors are to be attached to their final locations with 3M Velcro strips. This provides a semipermanent fixture, for ease of battery replacement during the experiment and ease of removal upon completion.

\section{SENSOR PLACEMENT GUIDELINES}

Guidelines were developed as a part of the preparation of the research. These guidelines to be followed as near as possible for each space and each sensor. The guidelines maintain consistency between spaces and aim to assess the artificial light only. Guidelines originate from site observations with reference to the Legrand (2014) Lighting Management Sensor Design and Application Guide. All sensors are required to be accessible during the experiment for battery replacement. 
1. Where possible, light sensors should be placed as close to a light fitting in the primary circuit as possible.

2. Light Sensors should be placed away from windows and away from direct sunlight.

3. Spaces that have more than one light circuit should determine a primary circuit and place sensor by this circuit.

4. Where lights are out of reach, light sensors should be placed as high as

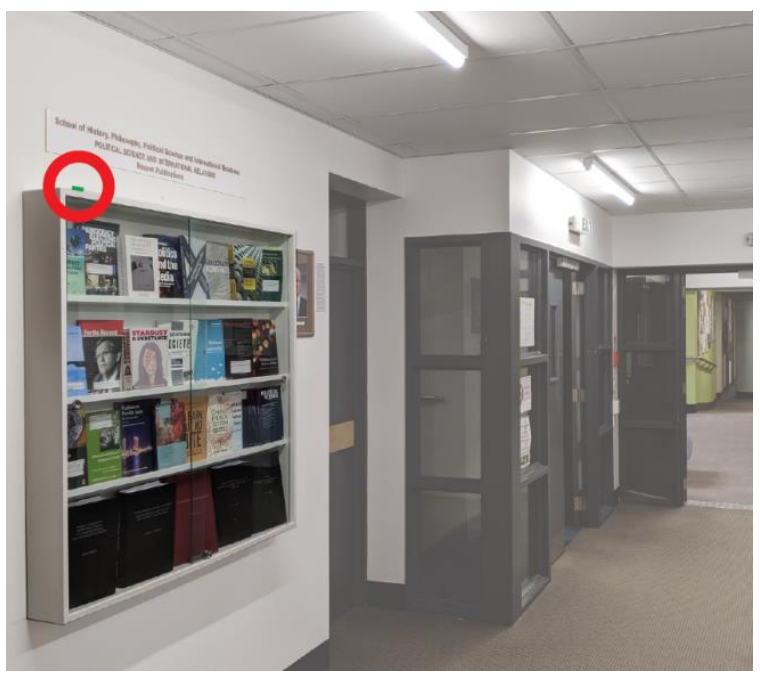
possible on the wall, on top of equipment or tall furniture. See Figure 6 for example.

5. Sunrise and sunset patterns should be considered to assess the time of day where any daylight influences could impact the light measurements

\section{PIR SENSOR PLACEMENT GUIDELINES}

1. PIR sensors should be placed where the field of range reaches as much of the space as possible.

2. Users of the space must be completely within the sensor field of range.

3. The majority of seating in seminar rooms must be within sensor range.

4. Place PIR sensors away from expected obstructions or locations with possible likelihood of users blocking the space. Use space observations and furniture layouts to assess where expected obstructions may occur e.g. avoiding walls adjacent to seminar room doors as students may wait here or any seating areas in hallways.

5. Placed mid wall height and along the middle of a wall where possible.

6. Where hallways are $1 \mathrm{~m}$ or less in width, the PIR sensor should be placed at the end.

7. Hallways longer than $12 \mathrm{~m}$ should place sensor in the middle if possible or use two sensors.

8. Hallways wider than $1 \mathrm{~m}$ should place sensors along the middle of the longer walls. 


\subsection{DATA COLLECTION}

Sensor data must be gathered, organised and translated into binary figures for comparison and analysis. Raw data is presented differently by each sensor type and needs to be manipulated into a linear timeline for comparison. The light sensor settings are set to a recording interval of five minutes. Motion data is not consistent, recording only when motion is detected, this could range from two minutes to many hours depending on time of day.

The raw results are grouped by each individual sensor and the results determined in five-minute intervals. The results for the pair of sensors in a room is compared and the results for each five minute period fall into one of four data categories noted in Table 1 Data Categories. Light data is represented by two options on/off, while occupancy is occupied/vacant.

Using this to provide a data comparison will highlight potential energy wastage of current use, and hence the potential for energy saving by using occupancy sensors. A single day of data provides 288 five-minute periods, thus 288 outcomes. The arranged data are totalled and converted to a percentage of time, in this instance one day. Data comparisons between light state (on/off) and occupant (occupied/vacant) can determine when lights use is justified or wasted. Ideally (shown in red in Table 1) the lights should not be on (and using energy) when the space is vacant. The percentage of energy waste is proportional to the amount of potential energy savings.

Table 1 Data Categories.

\begin{tabular}{|c|c|c|}
\hline & Lights on & Lights off \\
\hline Occupied & Justified energy use & No Energy use \\
\hline Vacant & Energy wastage & No Energy use \\
\hline
\end{tabular}

\subsubsection{Light MEASUREMENT METHOD}

The light data of each sensor was reviewed to assess the measured light levels and set a baseline. A baseline measure is required to make a distinction between daylight and artificial light to determine whether the lights are in use or not. It is expected that artificial light measurements will resemble a simple on/off patterns as opposed to the sunrise and sunset increase and decrease of natural light. The light use, types and quantities of artificial lights vary between the space types so each space must be assessed individually. 
The following image (Figure 7) shows an example of the light sensor data and how the baseline measure is determined for each individual sensor.

Three sensors were compared to differentiate daylight patterns from artificial light patterns. Two of the sensors (light sensor one \& two) were placed one meter and three meters respectively away from a large South facing window at desk height (approx. 0.7meters). A third light sensor (sensor three) was placed on a light fitting (Figure 7) in an adjacent hallway with no windows. The sensors were set to monitor their light levels for seven days in June 2019, results displayed in Graph 2.
Figure 7 Light sensor directly on light fitting. Wigan 5th Floor Hallway.

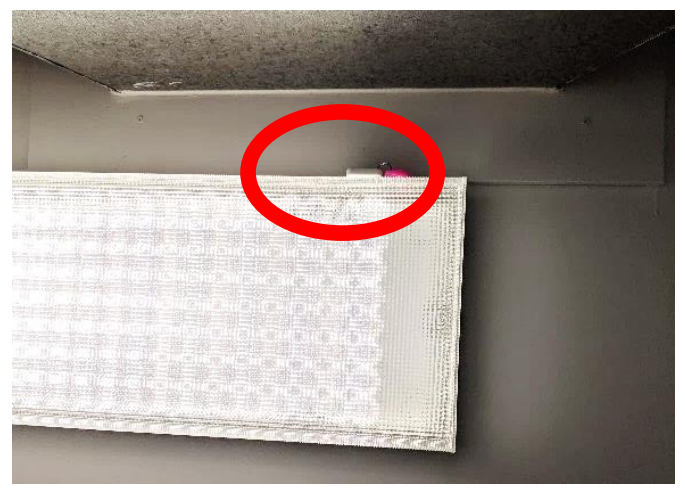

Graph 2 Daylight Vs Artificial Light.

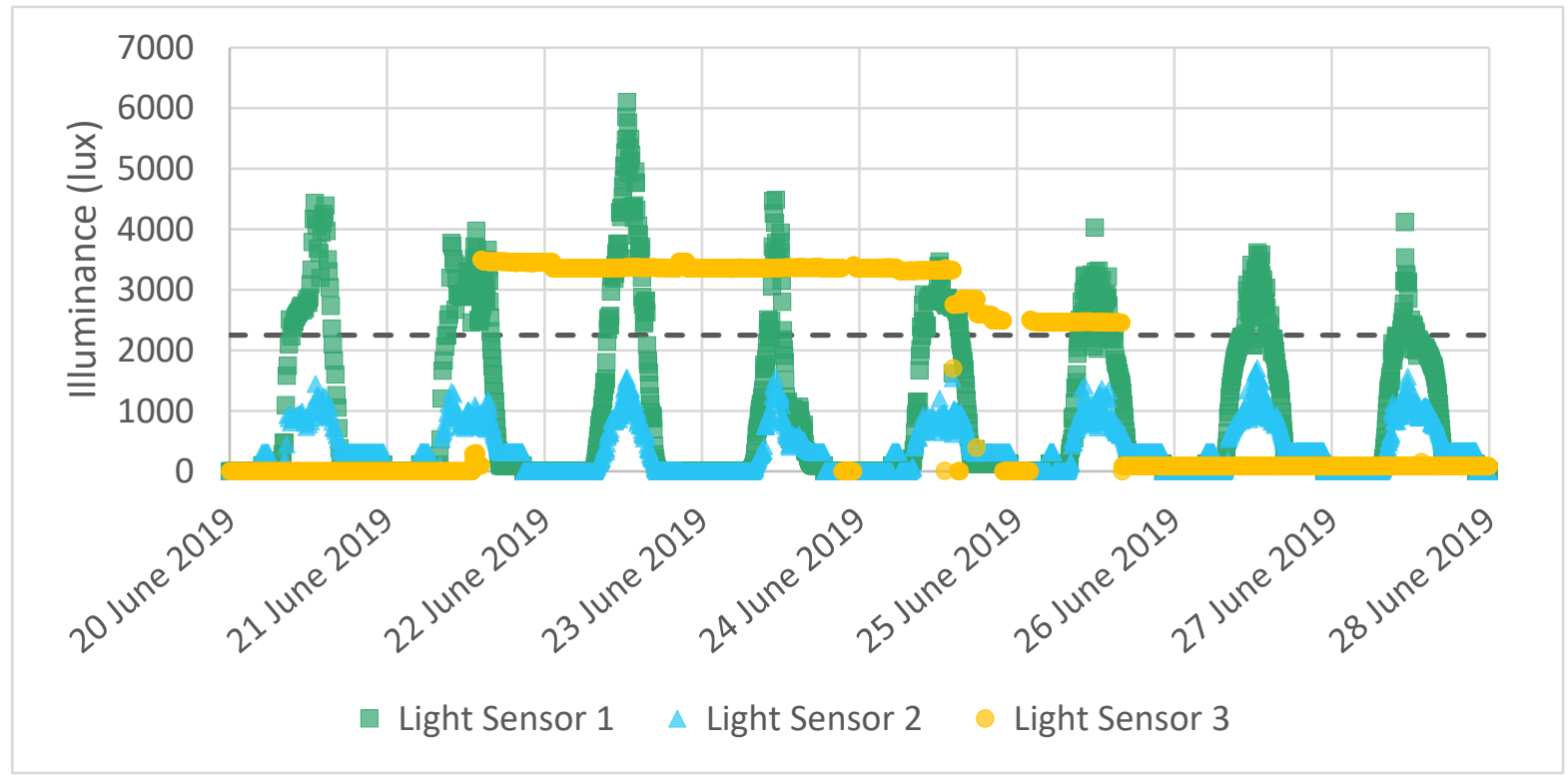

The comparison of these sensors shows two clear patterns. Light sensor one and two show distinctive patterns resembling sunrise and sunset across the seven days. The light sensor closest to the window records the brighter daylight. These patterns clearly identify daytime and night-time.

In contrast, light sensor three shows no daily daylight pattern, but steady periods. These periods at approximately 3500 lux and 2500 lux clearly suggests the lights are on. Light sensor three shows a decrease around midday on the $24^{\text {th }}$ of June, this is suspected to be due to a second light circuit being switched off. The dashed line, based on $70 \%$ the average artificial light value, indicates the selected baseline level for this space. $70 \%$ was chosen based upon measurements as this percentage would allow for the clearest determination of lights on versus lights off. This is the minimum lux level the sensor must reach to indicate that the lights on. 
This minimum requirement will differ as it is influenced by the sensor placement and the type of lighting. The situation illustrated in Graph 2 will not always be the case, as light sensors that are not able to be placed close to the light fitting will be more influenced by daylight reflected around the room. The baseline lux level allows the data to be simplified from a variable lux level to a binary value. If the measurement is above the baseline, it is represented by a one and below the baseline by a zero; one equals lights on, and zero equals lights off.

\subsubsection{Occupancy Measurement Method}

The PIR sensors measure on a vacant/occupied basis. They are continuously 'armed' to record when motion is detected upon someone entering the field of range. After 30 seconds of no motion the PIR sensors timeout. The sensor raw data provides simple vacant (0) or occupied (1) results. Results from the sensors are binary as shown in the nine-hour sample data in Graph 3, where one represents occupancy and zero represents vacancy.

\section{Graph 3 Sample Occupancy Data.}

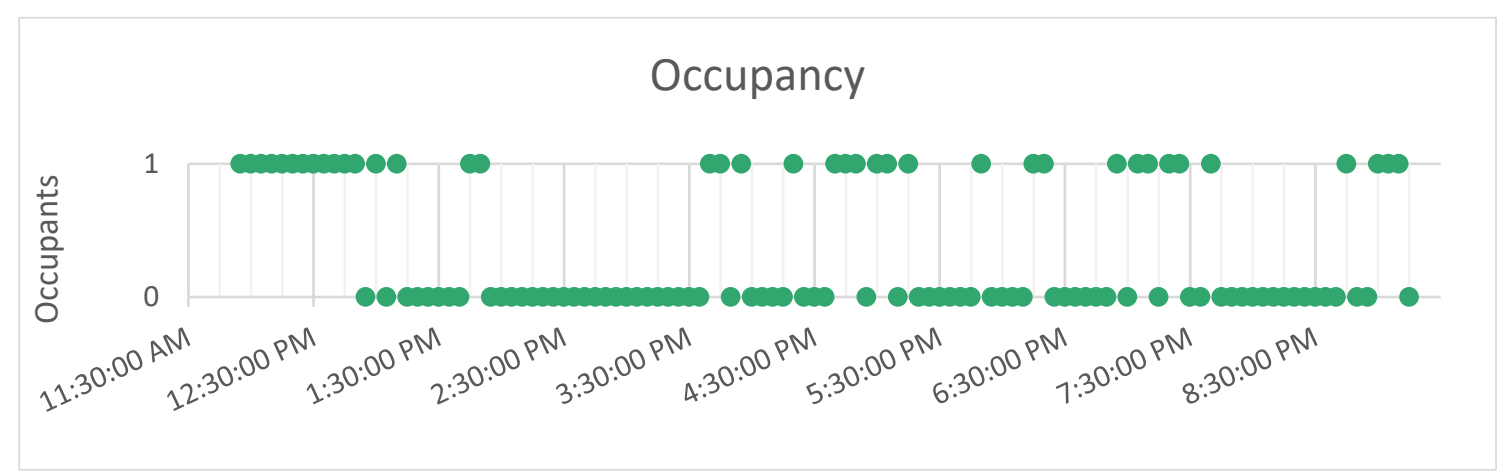




\subsection{SPACE DETAILED DESCRIPTIONS}

The following are used to determine consistent spaces for the experiment. The four space types are developed from literature discussed in Chapter 2. Details include use period, similarities, differences, lights and switching. There are no requirements for the type of light fitting or switching for any space in NZS1680 (2006).

Table 2 University Space Type Descriptions.

\begin{tabular}{|c|c|c|c|c|}
\hline & Hallways & Stairwells & Seminar Rooms & Lavatories \\
\hline $\begin{array}{l}\text { Use Period } \\
\text { (one user/ } \\
\text { one group) }\end{array}$ & $\begin{array}{l}\text { Un-specified and highly variable. one minute } \\
\text { - approximately } 30 \text { minutes. } \\
\text { Used frequently throughout the day with } \\
\text { peak periods between University schedule } \\
\text { slots. Most commonly short periods as users } \\
\text { move from one space to the next. } \\
\text { Long periods occupied for printing or } \\
\text { kitchenette amenities for users to idle or wait } \\
\text { between classes. }\end{array}$ & $\begin{array}{l}\text { Short; approximately less than } \\
\text { five minutes. } \\
\text { Access routes for short } \\
\text { periods. } \\
\text { The time it takes a user to } \\
\text { travel from one floor to the } \\
\text { next, or multiple floors. } \\
\text { Stairwells providing access to } \\
\text { other amenities such as } \\
\text { lavatories may see longer use } \\
\text { periods. }\end{array}$ & $\begin{array}{l}\text { Highly variable. five minutes - } \\
\text { whole day. } \\
\text { Users can utilise these spaces for } \\
\text { short to long periods. The } \\
\text { standard university lecture slot is } \\
50 \text { minutes with } 10 \text { minutes for } \\
\text { movement. These spaces can be } \\
\text { used for short 10minute } \\
\text { meetings, scheduled classes or } \\
\text { full-day workshops. }\end{array}$ & $\begin{array}{l}\text { Un-specified and variable. On } \\
\text { average approximately one to } 15 \\
\text { minutes. } \\
\text { The use period of lavatories can } \\
\text { vary in length between users. } \\
\text { It is expected that users of the } \\
\text { disabled lavatories may on } \\
\text { average take longer. }\end{array}$ \\
\hline $\begin{array}{c}\text { Commonalities } \\
\text { (Between } \\
\text { space type) }\end{array}$ & $\begin{array}{l}\text { Hallways allow access to multiple spaces and } \\
\text { amenities. It is uncommon for a hallway to } \\
\text { provide access to a single room. The simplest } \\
\text { hallway in the pilot experiment provides } \\
\text { access to five offices and a stairwell. The most } \\
\text { complex, access to lavatories, kitchen, printer, } \\
\text { seminar room, offices and stairwell. }\end{array}$ & $\begin{array}{l}\text { Stairwells are tall cells } \\
\text { between floors, for the } \\
\text { purpose of the experiment, } \\
\text { each floor is considered } \\
\text { individually. } \\
\text { By this definition, stairwells } \\
\text { can be near identical. }\end{array}$ & $\begin{array}{l}\text { Wide variety of use types, and } \\
\text { the spaces can be configured on a } \\
\text { use by use basis. Commonalities } \\
\text { between seminar rooms include a } \\
\text { variety of equipment and } \\
\text { furniture to cater for different } \\
\text { uses. }\end{array}$ & $\begin{array}{l}\text { The purpose does not differ } \\
\text { between lavatories. }\end{array}$ \\
\hline
\end{tabular}


The presence of amenities off hallways

impacts how they are used. A shorter, narrower hallway may provide access to more private spaces such as offices or fewer spaces.

Differences

(Between

space type) Longer and wider hallways are more likely to provide access to more amenities. Hallways are the only space type considered in this research to provide other amenities within e.g. printers and kitchenettes. Use of these amenities are expected to lengthen the use period.

Normally one primary circuit. Single and multiple light types.

Lights

(Per individual space)

Switching

Manual or automated switching.

Two-way switching may be used to control

lighting from two entrances. Switches are not necessarily at every entry to the hallway.
Stairwells are predominately

functionally similar. Some

stairwells access lavatories.

Another difference is the stair layout and height. The majority of layouts at the

University are straight stairs or U-shaped.

One circuit. Single light types. Lights are dictated by standards and codes to provide safe levels of light. The type of light differs between stairwells, and the quantity of fittings depends on stairwell shape.

Manual or automated.

Two-way switching may be used to control lighting from two (or more) levels.
The biggest differences are the size of the rooms which affects the variety of uses. At the University, the primary purpose of these seminar rooms is to

cater for seminars and tutorials.

\section{Multiple circuits. Multiple light}

types.

Variety of light types to cater for the changing uses. At minimum, these often include a separate circuit by the

whiteboard/projector for extra

light. The number of lights is

proportionate to the size of the room.

Typically, manual switching. Multiple switches for multiple circuits. Switches are typically located near the door for primary circuits.
Differences may include the size, for instance, how many people can use the facilities at one time and the use period. These differences could affect the space use. If a lavatory with fewer cubicles has a long queue, the overall use period will be longer than that of a lavatory with more cubicles.

One circuit. Single light types. Lights often cater for the same areas, mirror/sinks and the cubicles. Different sized lavatories may see a greater quantity of lights. The number of lights is proportionate to the size of the room.

Typically, manual switching. Switches are typically located near the door. 


\subsubsection{CRITERIA}

This section details criteria for what is included or excluded in each of the space types for this research. This is necessary to provide guidelines for the space types to avoid outlier spaces or similar spaces that are not appropriate for the study. This is intended to improve the repeatability of this research so that more experiments may be completed, more results gathered and compared to support the research question. The criteria include a simple inclusion and exclusion criteria to clearly show what is acceptable and what is outside the scope.

Table 3 Space Type Inclusion and Exclusion Criteria.

\begin{tabular}{|c|c|c|}
\hline & $\begin{array}{l}\text { Inclusion Criteria } \\
\text { Matches definition and additionally any } \\
\text { of the following. }\end{array}$ & $\begin{array}{c}\text { Exclusion Criteria } \\
\text { Spaces with any exclusion criteria are not } \\
\text { used, even if the definition matches. }\end{array}$ \\
\hline Hallway & $\begin{array}{l}\text { May include amenities such as } \\
\text { kitchenette or printer etc. }\end{array}$ & $\begin{array}{l}\text { May not include seating, workstations, } \\
\text { desks or open plan to atrium type spaces. }\end{array}$ \\
\hline Stairwell & $\begin{array}{l}\text { Includes access to amenities e.g. lavatory. } \\
\text { May be of any shape (straight, U, L). }\end{array}$ & Excludes stairwells in open plan spaces. \\
\hline $\begin{array}{l}\text { Seminar } \\
\text { rooms }\end{array}$ & Seating for $10+$. & $\begin{array}{l}\text { Technology or equipment-based spaces } \\
\text { such as labs or computers. Excludes } \\
\text { lecture theatres. }\end{array}$ \\
\hline Lavatory & $\begin{array}{l}\text { Any size. Included disabled cubicles if } \\
\text { other cubicles also present. }\end{array}$ & Single room disabled lavatories. \\
\hline
\end{tabular}


Masters of Architectural Science

Georgia Alexander

Chapter 4 PILOT StUdy 
The pilot study involved a number of tests which are a preliminary execution of the experiment to find and resolve any flaws or issues of the methodology or equipment. The pilot study is split into two sections, 4.1 Sensor Pilot and 4.2 Survey Pilot. The sensor pilot assesses the light use and occupant use of the space, whereas, the survey pilot assesses the perspective of the user of different light environments e.g. dimmed lighting. Each section covers the intent, design, results and limitations of each pilot.

DETAILS

The pilot tests were conducted at VUWs Faculty of Architecture and Design, Te Aro Campus in July 2019, a week-long test during the mid-year break at the University. Data from this period is specific to university holidays rather than usual term time. University holidays account for about $30 \%$ of the year and should be considered separate from term time due to different user numbers and behaviours from term time. For the purpose of the pilots, the holiday period is not considered a problem.

It is important to note the open times for VUW which may impact occupant use, the building access hours are Monday to Friday: $7.30 \mathrm{am}-11.30 \mathrm{pm}$, and Saturday, Sunday and public holidays: $9.00 \mathrm{am}-$ $10.00 \mathrm{pm}$. A security guard is on site during these hours. Access outside these hours is restricted only to postgraduate students and staff.

\subsection{SeNSOR PILOT}

The purpose of the sensor pilot is to test the sensors in the experiment environments to assess success or problems. These can then be revised and resolved before the full experiment. This pilot will test sensors locations, distance to the tag manager and battery life. These variables will be assessed for their performance and effectiveness. The two sensor types, light and occupancy must be considered individually as the sensors record different factors.

A total of 20 sensors were used in the pilot study. Sensor location assesses the effectiveness of placement differently for each sensor type. The sensors are located based upon the guidelines detailed in section 3.1.2. Light sensors were placed inside light fittings, directly on the light fitting or others appropriate nearby. PIR sensors were placed at the end of hallways and the middle of wide hallway. 


\subsubsection{SENSOR INTENT}

The intent of the sensor pilot is to assess the sensors in intermittent-use spaces and assess the expected results. The pilot is designed to represent the same situations expected in the experiment. Issues of concern include, the location of the sensors, the sensor connectivity range for uploading data and the battery life. Details are provided in Table 4.

\section{Table 4 Pilot Sensor Details.}

\begin{tabular}{|c|l|}
\hline Period & Monday $1^{\text {st }}$ July 9:00am to Sunday $7^{\text {th }}$ July 2019 5:00pm \\
\hline Location & $\begin{array}{l}\text { Victoria University of Wellington's Te Aro Campus } \\
\text { (Architecture and Design Campus) }\end{array}$ \\
\hline Sensor Location(s) & Three hallways, three stairwells and two seminar rooms. \\
\hline Equipment & 10 IR sensors and 10 Light sensors \\
\hline
\end{tabular}

\subsubsection{Space Selection}

The spaces used in the pilot study were selected to achieve a variety of space types and assess which, if any, space types may present restrictions or issues. The rational and space observations for each space are detailed in Table 5 (page 50). All hallways and stairwells are considered transitional spaces, seminar rooms are considered end-use spaces. 
Table 5 Space Information and Choice Rational.

\begin{tabular}{|c|c|c|c|c|}
\hline $\begin{array}{l}\text { Space } \\
\text { type }\end{array}$ & $\begin{array}{c}\text { Room } \\
\#\end{array}$ & $\begin{array}{l}\text { Sensor } \\
\text { Placement } \\
\text { Light/PIR }\end{array}$ & $\begin{array}{l}\text { Amenities and } \\
\text { Observations }\end{array}$ & Choice Rational \\
\hline $\begin{array}{c}\text { Hallway } \\
1.1\end{array}$ & $\begin{array}{l}2.44 \\
\text { North }\end{array}$ & $\begin{array}{l}\text { On wall/ } \\
\text { near light }\end{array}$ & $\begin{array}{l}\text { Kitchenette, printer, } \\
\text { lavatories and stairwell. } \\
\text { No windows. }\end{array}$ & $\begin{array}{l}\text { Northern end of a long hallway } \\
\text { with access to many amenities. }\end{array}$ \\
\hline $\begin{array}{c}\text { Hallway } \\
1.2\end{array}$ & $\begin{array}{l}2.44 \\
\text { South }\end{array}$ & $\begin{array}{l}\text { On Wall/ } \\
\text { On Light }\end{array}$ & $\begin{array}{l}\text { No amenities. } \\
\text { No windows. }\end{array}$ & $\begin{array}{l}\text { Southern end of a long hallway } \\
\text { with no amenities. }\end{array}$ \\
\hline $\begin{array}{l}\text { Hallway } \\
2\end{array}$ & 2.45 & $\begin{array}{l}\text { On Wall/ } \\
\text { On Light }\end{array}$ & $\begin{array}{l}\text { No amenities. } \\
\text { No windows. }\end{array}$ & $\begin{array}{l}\text { This hallway leads to staff offices } \\
\text { and a stairwell. }\end{array}$ \\
\hline $\begin{array}{c}\text { Hallway } \\
3.1\end{array}$ & $\begin{array}{l}5.55 \\
\text { North }\end{array}$ & $\begin{array}{l}\text { On Wall/ } \\
\text { On Light }\end{array}$ & $\begin{array}{l}\text { Route to lavatories, } \\
\text { stairwell, kitchenette and } \\
\text { lift. No windows. }\end{array}$ & $\begin{array}{l}\text { Northern end, assessing the open } \\
\text { plan kitchenette light circuit. }\end{array}$ \\
\hline $\begin{array}{c}\text { Hallway } \\
3.2\end{array}$ & $\begin{array}{l}5.55 \\
\text { South }\end{array}$ & $\begin{array}{l}\text { On Wall/ } \\
\text { On Light }\end{array}$ & $\begin{array}{l}\text { Route to lavatories, } \\
\text { stairwell lift and } \\
\text { kitchenette. No windows }\end{array}$ & $\begin{array}{l}\text { Southern end of a long hallway } \\
\text { assessing the bigger lighting } \\
\text { circuit in the hallway. }\end{array}$ \\
\hline $\begin{array}{c}\text { Stairwell } \\
1\end{array}$ & 2.71 & $\begin{array}{l}\text { On wall/ } \\
\text { near light }\end{array}$ & $\begin{array}{l}100 \% \text { internal. } \\
\text { No windows. }\end{array}$ & $\begin{array}{l}\text { Stairwell platform at level two. } \\
\text { Access to level three and fire exit. }\end{array}$ \\
\hline $\begin{array}{l}\text { Stairwell } \\
\quad 2\end{array}$ & 3.72 & $\begin{array}{l}\text { On wall/ } \\
\text { near light }\end{array}$ & $\begin{array}{l}\text { To other levels. } \\
\text { No windows. }\end{array}$ & $\begin{array}{l}\text { Stairwell platform at level three. } \\
\text { Access to workspaces on levels } \\
\text { four to two. Existing occupancy } \\
\text { sensor. }\end{array}$ \\
\hline $\begin{array}{l}\text { Stairwell } \\
\text { three }\end{array}$ & 4.72 & $\begin{array}{l}\text { On Wall/ } \\
\text { On Light }\end{array}$ & $\begin{array}{l}\text { To other levels. } \\
\text { No windows. }\end{array}$ & $\begin{array}{l}\text { Stairwell platform at level four. } \\
\text { Access to workspaces on levels } \\
\text { three to five. Existing occupancy } \\
\text { sensor. }\end{array}$ \\
\hline $\begin{array}{c}\text { Seminar } \\
1\end{array}$ & 2.05 & $\begin{array}{l}\text { On wall/ } \\
\text { near light }\end{array}$ & $\begin{array}{l}\text { Staff only, placed near } \\
\text { kitchenette/entry. } \\
\text { North facing windows. }\end{array}$ & $\begin{array}{l}\text { Similar use to a seminar room, } \\
\text { users enter for a period and leave } \\
\text { once finished. }\end{array}$ \\
\hline $\begin{array}{l}\text { Seminar } \\
2\end{array}$ & 2.36 & $\begin{array}{l}\text { On wall/ } \\
\text { near light }\end{array}$ & $\begin{array}{l}\text { Student room, windows } \\
\text { into atrium. }\end{array}$ & Enclosed seminar room. \\
\hline
\end{tabular}

\subsubsection{SENSOR LOCATION}

Considerations for sensor location involved an assessment following the guidelines in section 3.2

Sensor Placement Guidelines. Including, obstructions, likelihood of single user blocking sensor and the amenities in/through the hallway.

Observations must account for any natural light and place the light sensors accordingly where natural light will not affect the measurements. The Light Measurement Method section 3.3.1 discusses how the artificial light data results are differentiated from daylight patterns. 


\subsubsection{SENSOR MONITORING}

On-going monitoring of the sensors is necessary to check that they were all recording data as expected. Prior to the sensor pilot the sensors were all tested for connectivity and ability to upload data. This involved sending commands to the sensor such as turn on/off LED and refreshing signal periodically throughout the day to monitor lux levels and occupancy data.

Although the light sensors were set to record every five minutes, the raw data intervals varied between three minutes to seven minutes, averaging across the week to five minutes.

\subsubsection{SENSOR PILOT RESULTS}

This section provides the results from the pilot studies. The following graphs in this section and the graphs in Chapter 6 refer to the four data categories mentioned in section 3.3, Table 1. The results are graphed as a percentage of time ( $y$ axis) and the space across the $x$ axis. Although all the results are relevant, particularly to assess space use, the 'vacant and lights on' category is the most important to determine potential energy savings. The right most column for each space type shows how the average of that space type performs. The other columns show each space individually, the space types are grouped together. Considering the colour key (Figure 8) and the data categories, it is possible to group the results. As an example, red and dark green grouped shows all vacant results which can be compared to light green and yellow grouped, the occupied results. The same can be done for lights on and lights off.

Figure 8 Data categories key as graphed.

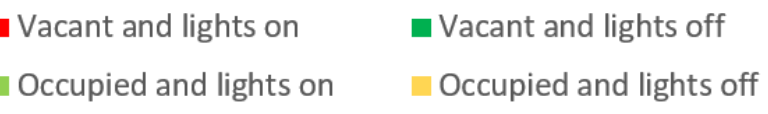




\section{Hallways}

Graph 4 Pilot Study Hallway Results.

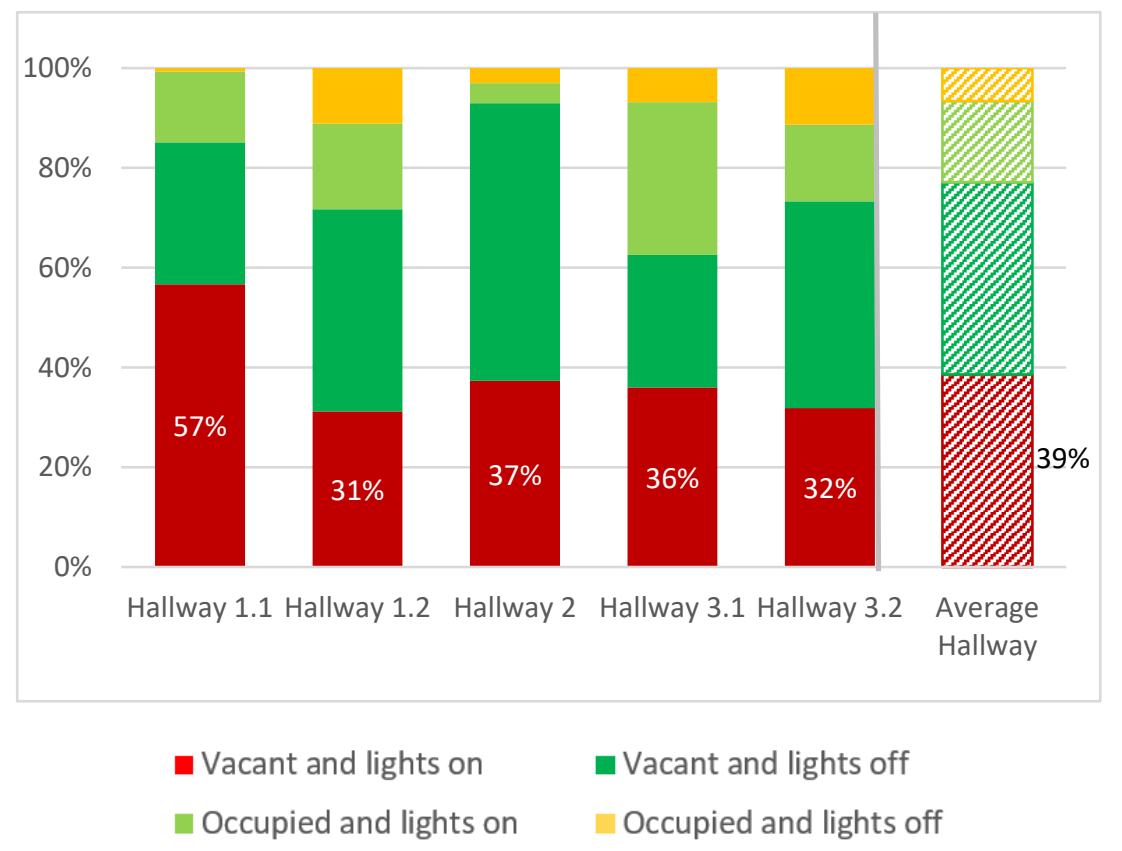

Hallway results show both similarities and differences across the hallways. Notably the worst performing hallway is number 1.1 at $57 \%$, this hallway has the second highest percentage of vacancy (85\%), exceeded by hallway two (93\%). There is little variation of hallways 1.2, 2, 3.1 and 3.2 for 'vacant and lights on'; only $6 \%$ difference.

There is an average of $12 \%$ difference of vacancy/occupancy between the monitored ends of the hallways $1.1 \& 1.2$ and $3.1 \& 3.2$. Interestingly hallway 1.1 has access to all the amenities but is vacant for longer than the opposite end of the hallway. In contrast, hallway $3.1 \& 3.2$ have very similar amenities, yet are used differently.

On average, $7 \%$ of the time lights are off and the hallway space is occupied, this could be due to nightly security guard. 
Seminar Rooms

Graph 5 Pilot Study Seminar Results.

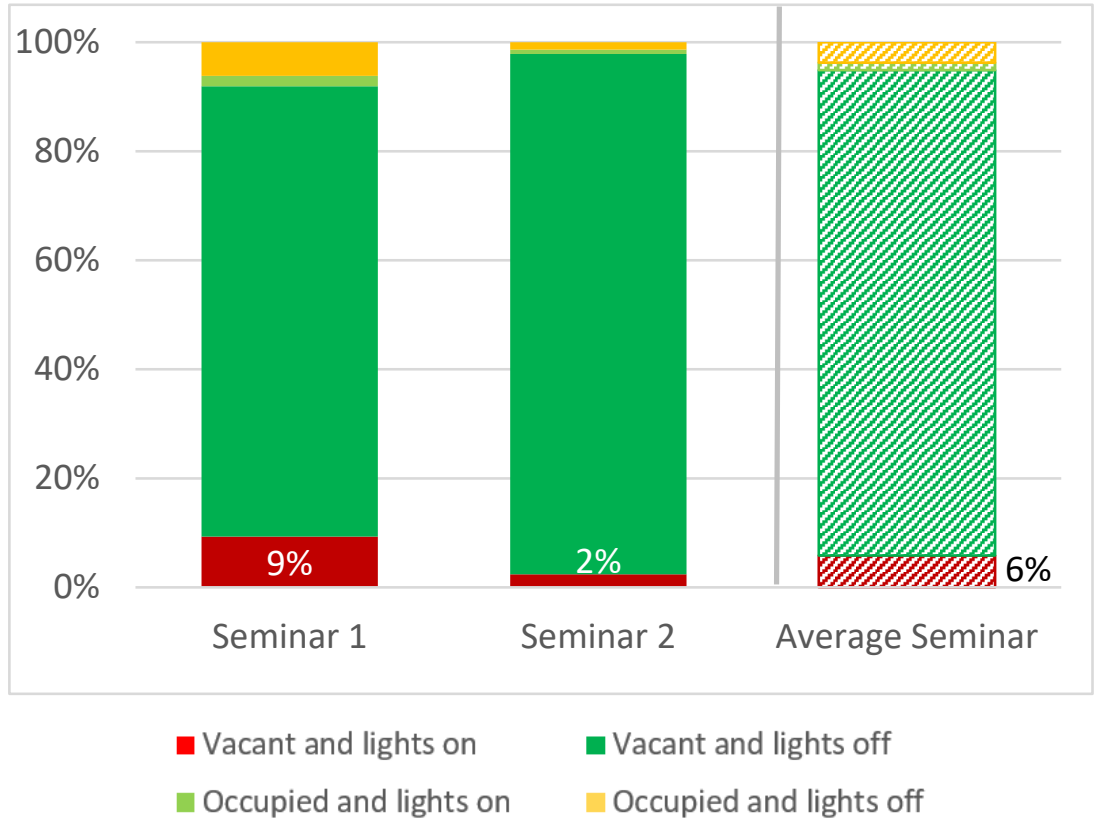

The seminar rooms have very similar trends and show efficient light use. The percentage of 'occupancy and lights off' is not surprising as both spaces have windows, seminar one North facing, and it could be assumed that the users are efficiently using daylight.

At $9 \%$ and $2 \%$ vacant and lights on, there is little room for improvement. The large percentage of vacancy is not surprising and is likely due to the holiday time period of the pilot test. 


\section{Stairwells}

Graph 6 Pilot Study Stairwell Results.

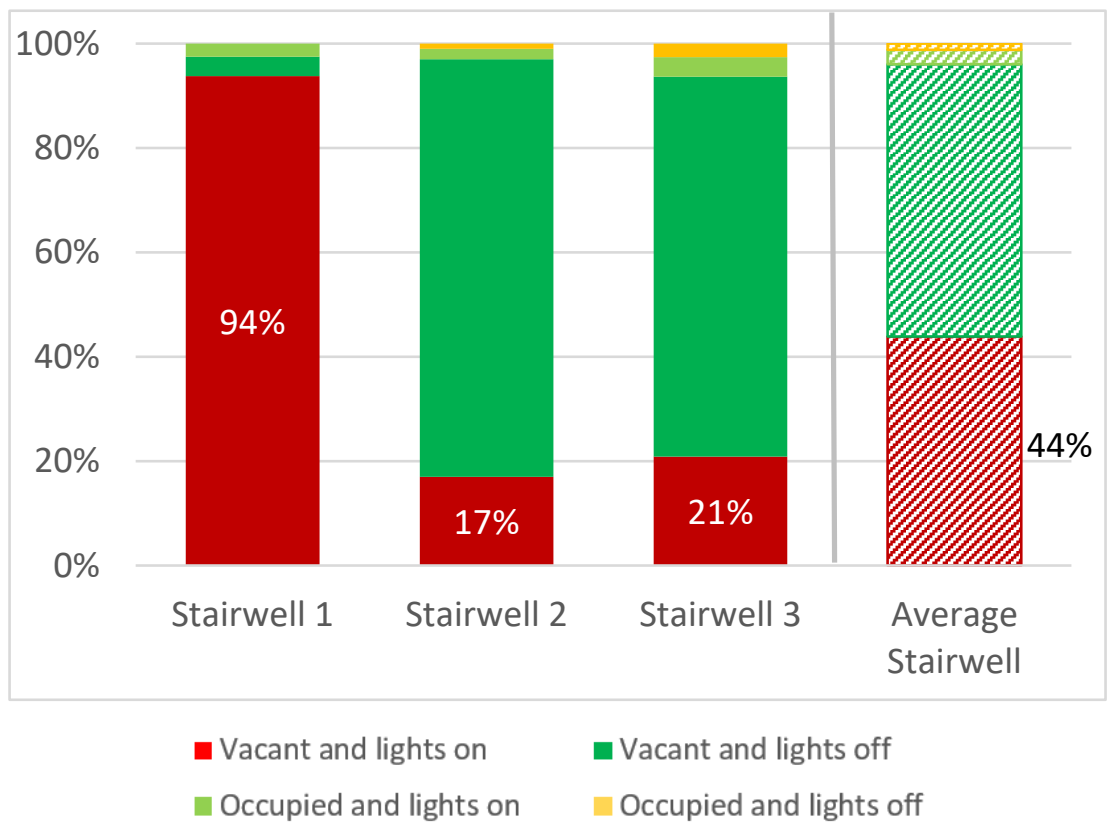

Stairwell two and three have existing occupancy sensors (noted in Table 5) and show the likely benefits of these sensors. In contrast, stairwell one shows a stairwell without occupancy sensors and the significant improvement in energy efficiency that occupancy sensors can provide. The period stairwell two and three are 'occupied with lights off' is likely the period between sensing people and the lights turning on. This can be improved through tuning or improved sensors as the existing sensors could be older technology.

Stairwell one has very high 'vacant and lights on' compared to stairwells two and three, but as noted in Table 5, stairwells two and three have existing occupancy sensors. Stairwells two and three average about $20 \%$ 'vacant and lights on' which could be due to either time delay or entry to the stairwell on other levels consequently turning the lights on, for 'all' the levels. This could be a restriction of stairwells. If a stairwell has a single light circuit, then entry on any level would trigger the occupancy sensors to turn all the lights on, this is the case at VUW. 
Pilot Study Cost Savings per fitting

Graph 7 Pilot Study Annual Cost savings per fitting.

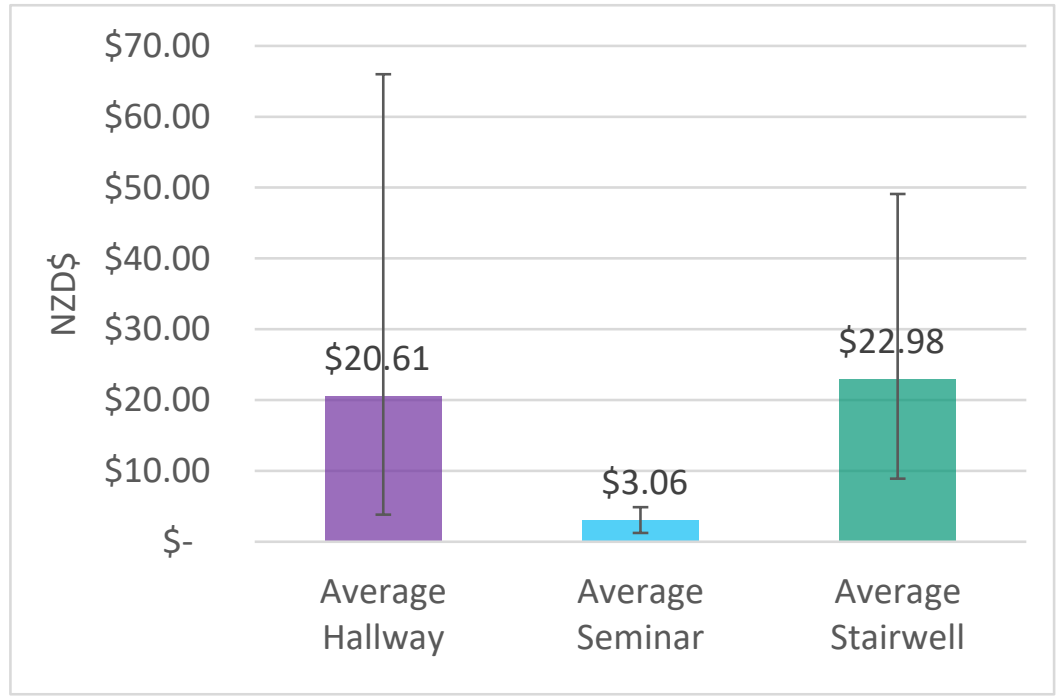

The cost savings use the percentage 'vacant and lights on' to calculate the cost savings per fitting. The percentage of 'vacant and lights on' is converted to kWh per year using the quantity of fittings and wattage to calculate the $\mathrm{kW}$ load. The annual cost savings uses the $\mathrm{kWh}$ per year multiplied by the Genesis electricity rate of $\$ 0.10$ per kWh (Genesis, 2020). The annual cost savings are then divided per fitting to account for the different fitting quantities in the different space types.

The pilot results from the pilot study show that there are potential cost savings for both hallways and stairwells through the use of PIR sensors. On average, these hallways and stairwells can save $\$ 21$ and $\$ 23$ respectively per fitting. Seminar rooms are much lower at only \$3. Although stairwells should produce the greatest cost savings per fitting, hallways typically have more lights and therefore would produce greater savings in the whole space. Hallways also have the greatest variation across all the space types, with some as low as the seminar room average and some reaching up to $\$ 66$ per fitting. 
Pilot Study Payback period (years)

Graph 8 Pilot Study Payback period (years).

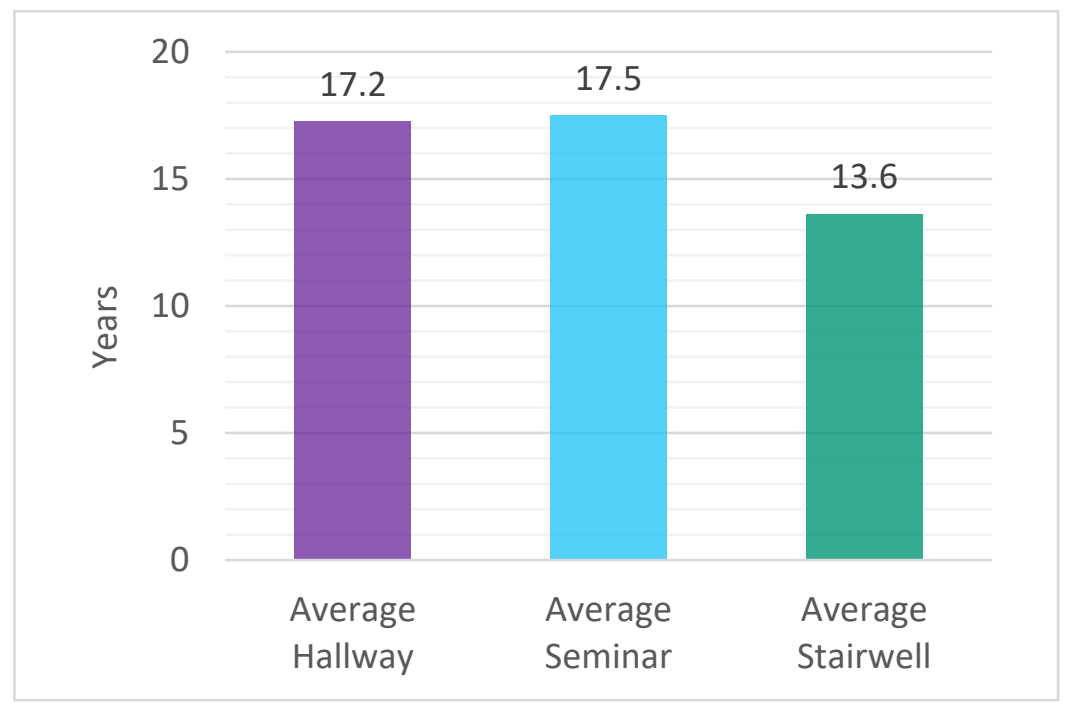

Payback results calculation takes the annual cost saving and divides the savings by the cost to buy and install an occupancy sensor. All the spaces are within the size range to only require one occupancy sensor. Pricing is provided by Advance-Electrical (2019).

The payback periods for each space are somewhat similar. On average Hallways and seminar rooms have near identical payback periods with only a few months difference at 17.2 and 17.5 years. Stairwells are the lowest at 13.6 years. These are long and not financially attractive payback periods.

\subsubsection{SENSOR PILOT ANALYSIS AND DISCUSSION}

Pilot study results show no obvious anomalies or errors of the process that cannot explained by space differences and or user behaviours. These results give an initial insight into results we may expect from the full experiment. A review of the battery use post sensor pilot investigates potential causes driving varied battery use, however, no strong correlation is found. The measurement methods, organisation and collection of data worked well to produce binary results for comparison. No anomalies, missing data or outliers were found, providing confidence for the full data collection process.

Lessons from the data include a lack of differentiation between a single user or a group of people and the varied recording intervals of the light sensor averaging to five minutes. While these lessons are good to know, they have no impact on the intended use of the data for finding energy saving potential. 


\section{SENSOR BATTERY LIFE}

No batteries required replacing during the sensor pilot, but the battery use varied significantly. The sensor battery voltage was recorded before and after the pilot experiment to assess the factors that influence battery use. This analysis was to find if there was a pattern between external factors and the battery use. All batteries were replaced in May 2019 and are expected to last for 12 months according to the manufacturer website. It became obvious that the manufacturer battery life recommendation does not apply to the settings used for this experiment. In an attempt to simplify the on-going battery monitoring process throughout the full three-month long experiment the battery decrease over the period of the pilot test is compared to distance, obstructions and data collected as shown in Figure 9 and results graphed in Table 6.

An example of one particular sensor used an internet router to gain height and be closer to the lights. It was presumed that this could have had an effect on the sensor by interfering with the signal. This sensor was one of the furthest away from the tag manager at $32 \mathrm{~m}$, although the remaining battery (72\%) and quantity of recorded data (651) are average (bearing in mind large variability). The results do not suggest any apparent interference due to the location of the particular placement of this sensor.

Figure 9 Factors that may influence battery life.

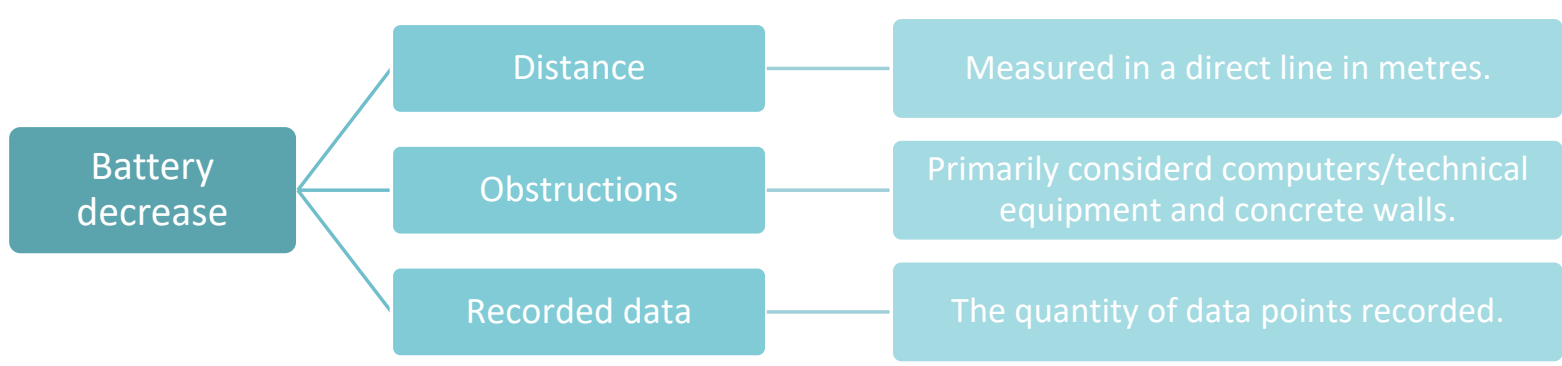

Distance and obstructions consider physical instances between sensor and tag manager that may have affected the battery life. Recorded data considers how much power it consumes relative to the amount of data measured, i.e. a lot of occupancy detection. 
Table 6 Battery Life Analysis (Pilot data).

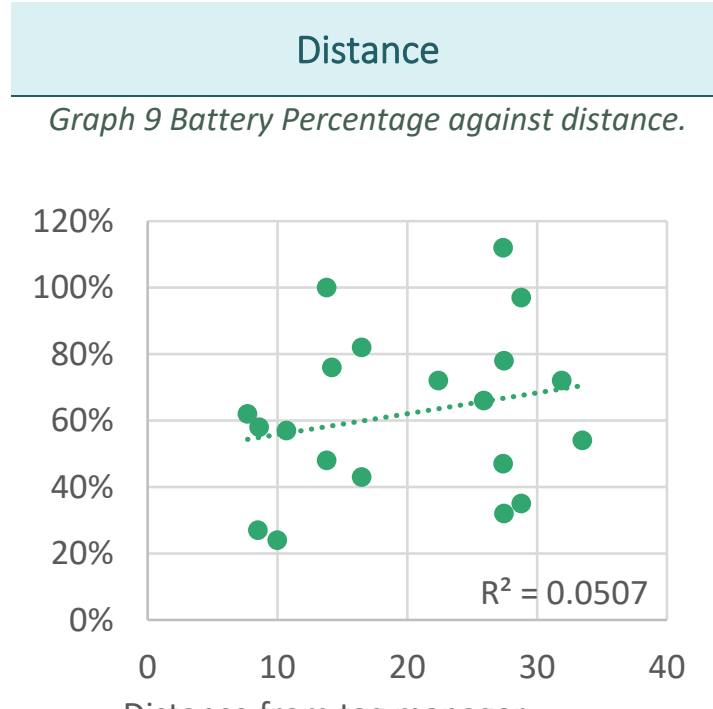

Distance from tag manager (meter)

The data presented in Graph 9 suggests that there is very little correlation between 'distance to the tag manager' and battery use.

The $R^{2}$ value of the trendline indicates that only $5 \%$ of the points are represented by the trendline, which is a weak relationship.

\section{Recorded Data}

Graph 10 Battery Percentage against Quantity

$$
\text { of data }
$$

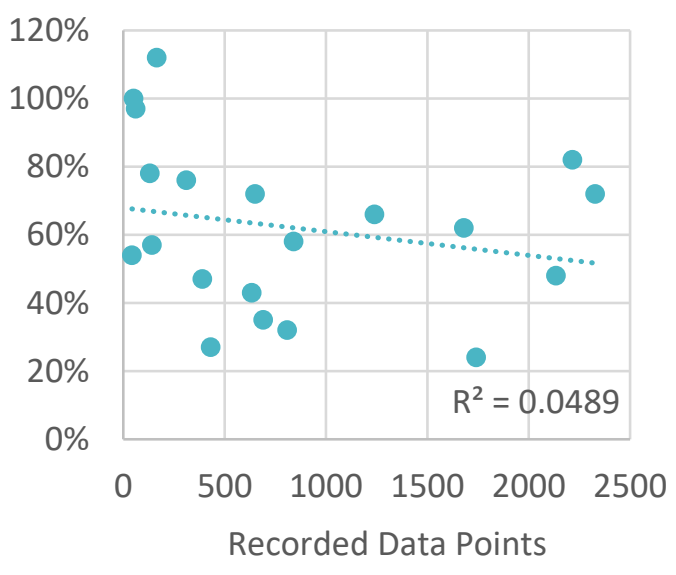

Quantity of data considers a sensor that may be working harder recording more data and using more battery. Graph 10 data points suggest that this is not the case.

Another weak relationship of only $5 \%$ of the points represented by the $R^{2}$ value.

\section{Obstructions}

Graph 11 Battery Percentage against obstructions

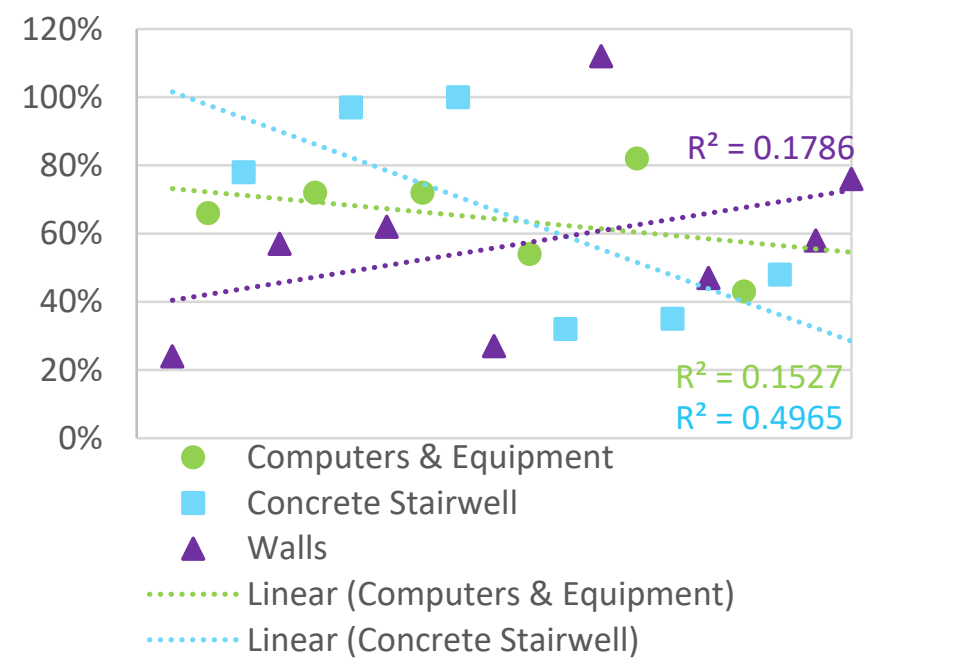

Graph 11 considers the battery percentage compared to physical obstructions. The colours represent different obstructions that may affect the battery life of the sensors. A correlation between a certain obstruction and a sensor would be expected to show the colours grouped together at similar percentages, which is not the result shown.

The $R^{2}$ value for concrete stairwell indicates that the data points are a $50 \%$ match of the trendline, a stronger relationship than all the other aspects. The trendlines for walls and 'computers \& equipment' are represented by $18 \%$ and $15 \%$ respectively. 
The trendlines for obstructions, specifically concrete stairwells (see Graph 11), are higher than either distance or 'data quantity'. The $\mathrm{R}^{2}$ values for obstructions are the highest of all aspects. The values for walls and 'computers \& equipment' are reasonably low still. A possible future analysis of the battery life of these sensors may group these aspects and investigate combinations which may lead to worse battery performance, e.g. long distance AND concrete walls. These comparisons do not deduce an obvious factor that influences the battery use of the sensors.

\section{SENSOR LIMITATIONS}

There were no issues with the running, monitoring and extracting of data from the sensors.

Difficulties around timing and access for setting up the sensors and tag manager did occur, but only during the set up, and these were dealt with by ensuring enough time and back up days to place sensor ahead of the pilot study. Once the equipment is all in place, the sensors run without issue. As the battery life analysis found no conclusive results for tracking the battery life, the sensor battery life must be continuously and closely monitored throughout the experiment.

It was not felt necessary to monitor lavatories during the pilot study for ethics reasons. These are small size rooms and the stairwells tested in the pilot are similar in size. There appeared to be no issues with the small size of the stairwells, sensor placement and sensor effectiveness.

\subsection{SURVEY PILOT}

The purpose of the survey pilot is to test the survey tablet location, survey software and ease of answering questions. These intend to assess any problems that may occur to resolve any issues where possible before the full experiment. Feedback on the survey design was provided from colleagues for the pilot study.

The survey aim is to determine an initial insight on user perspective of proposed lighting changes in hallways. It is an investigation of the correlation between psychological comfort and lighting. The survey asks anonymous users their thoughts on turning the lights off in empty hallways, and how they would respond to different situations. It is simple to suggest turning lights off to save power, but it is important to also consider the user's perceptions. 


\subsubsection{SURVEY INTENT}

The intent of the survey was to assess user perception on the acceptance of adjustments to lighting design. If lights could be turned off or dimmed when a hallway is not in use, they could save more energy. The survey is designed to gain knowledge of how users feel about these scenarios. According to NZS 1680.2.1 Table D Recommendations for circulation spaces and other general areas, hallways and circulation spaces are required to provide 160-40lux while in use (2006). While maintaining requirements, hallway and circulation spaces could turn the lights off or dim them when not in use, as currently circulation spaces are fully illuminated for long periods while vacant, particularly overnight (Papamichael, 2017).

This part of the research begins to gather knowledge on how to best ensure user comfort on approach of a vacant space. This survey is focused solely on hallways. It is expected of an empty office or empty classroom to have the lights turned off. It is also expected that empty or not, transitional spaces always have the lights on, consequently wasting energy. If this proposed change were implemented; how would it affect users? If lights are off, are people less likely to use that route? If they are familiar with the hallway, would they not mind? The survey starts to investigate the surface level of these questions to provide preliminary answers and encourage future research in this area. It is hypothesised that users may feel less comfortable to enter a space with lights off, somewhat inclined with lights dimmed and comfortable with lights on.

Table 7 Pilot Survey Details.

\begin{tabular}{|c|l|}
\hline Period & Monday $1^{\text {st } J u l y ~ 9: 00 a m ~ t o ~ S u n d a y ~} 7^{\text {th }}$ July 2019 5:00pm \\
\hline Location & $\begin{array}{l}\text { Victoria University of Wellington's Te Aro Campus } \\
\text { (Architecture and Design Campus) }\end{array}$ \\
\hline Survey Location & $\begin{array}{l}\text { Wall Mounted. } \\
2^{\text {nd }} \text { floor hallway at the North end near a printer and routes to kitchenette, } \\
\text { lavatories, stairwell and seminar rooms. }\end{array}$ \\
\hline Equipment & University provided IPad Air, with wall mount. \\
\hline Software & University provided; Qualtrics. \\
\hline Ethics & Human Ethics Committee approval \#27765 \\
\hline
\end{tabular}




\subsubsection{SURVEY DESIGN}

The questions focus on the hallway where the tablet is located to provide responses of the users using the hallway. This is based on a similar citizen participation theory approach previously mentioned with the work of Hebert and Chaney (2012),(see 2.22.6 User Perception) where they used the approach to influence facility design regarding sustainability in an institutional setting.

The survey questions are shown in Table 9 Survey Questions and Results. A wall-mounted tablet was set up to display one question per day, to work through all the questions within the pilot week. The full survey would display one question per week to reach all users throughout the work week. In the pilot, the first image was set up for three days, the second and third for one day each. This format allowed all three images to be on display throughout the working week.

The complete survey across three weeks would ask users about three perceptions of lighting in the hallway, lights off, lights dimmed or lights on. Users were asked how comfortable they felt to enter the space seen in an image on the survey. The survey was completely optional, anonymous and takes less than one minute to complete. The three images in Figure 10, Figure 11 and Figure 12 (page 62) represent three weeks of the survey. One image per week 
Figure 10 is the 'lights off' image to be used in the survey. The benefits of this change would provide the greatest energy savings (of the three scenarios) if occupancy sensors were used to turn lights off in vacant spaces.

Figure 11 is the 'lights dimmed' image to be used in the survey. It represents the space if occupancy sensors dimmed the lights upon vacancy. Benefits of this scenario would be less than 'lights off', but greater than no change; 'lights on'.

Figure 12 is the image used in the survey to represent 'lights on', no change. No energy savings, but continued energy waste if lights are left on in vacant spaces.
Figure 10 Survey Image: Lights off.

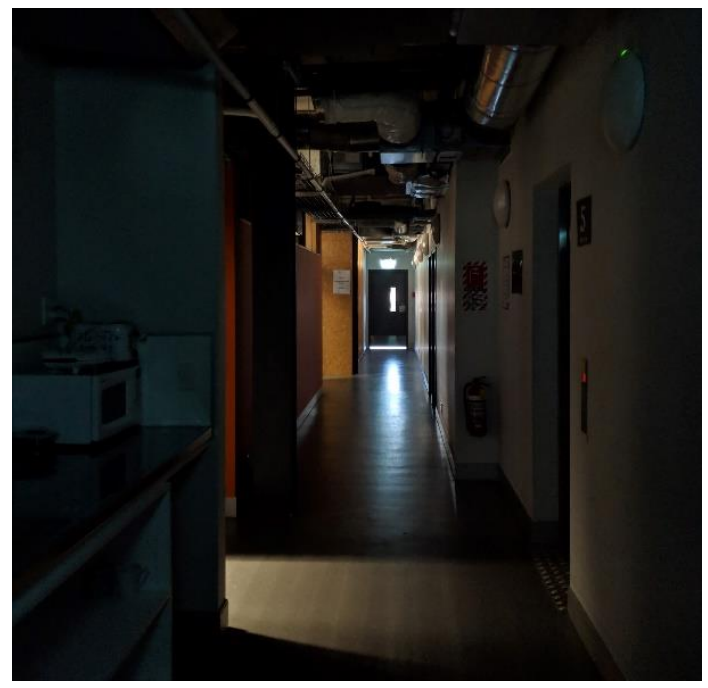

Figure 11 Survey Image: Lights dimmed.

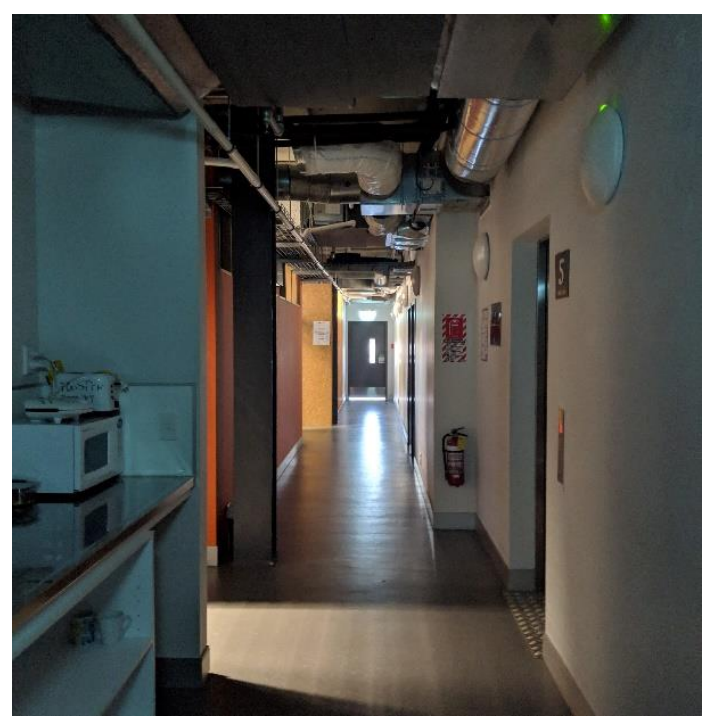

Figure 12 Survey Image: Lights on.

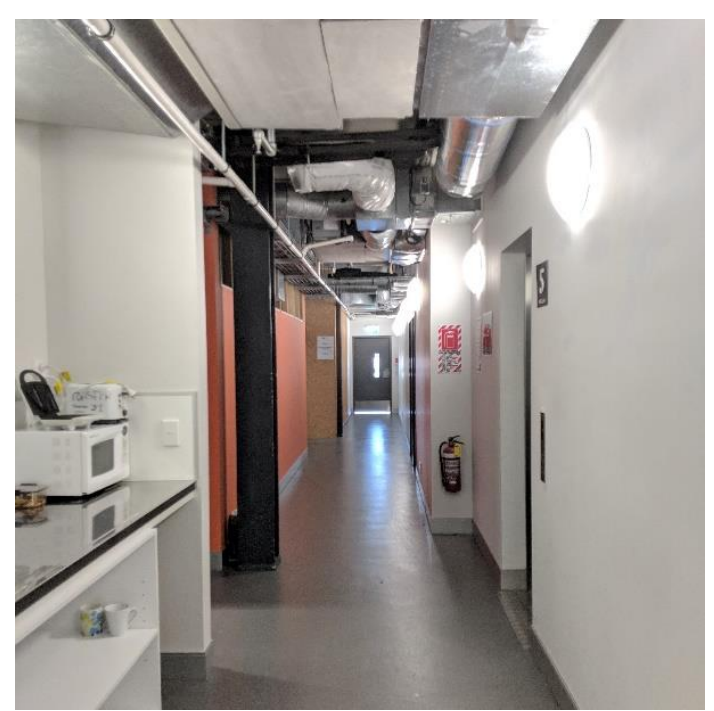


Figure 13 Survey Question example from Pilot Survey.

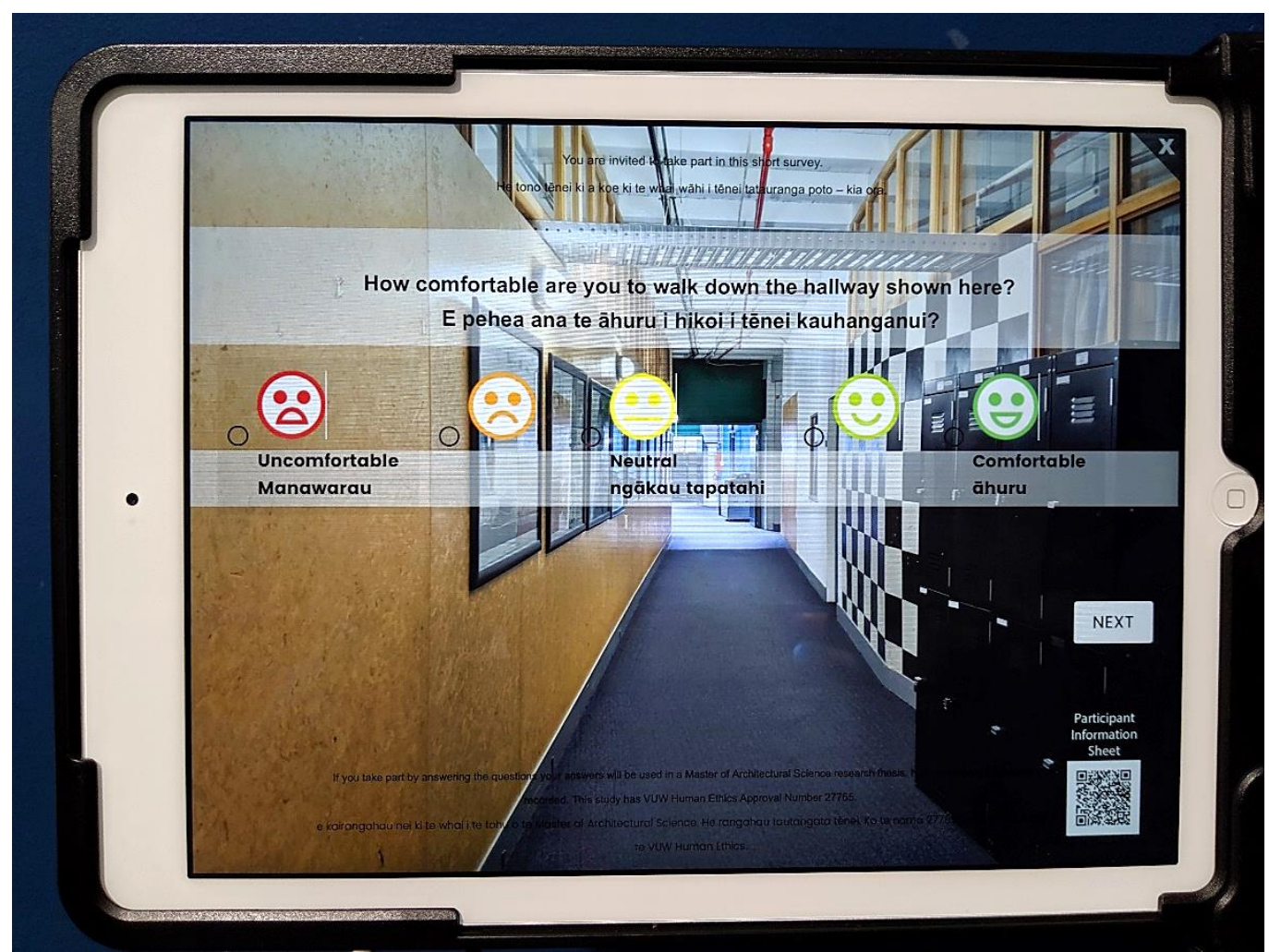

Figure 13 shows one of the questions used in the pilot test (all text is provided in both English and Maori). The answer options are presented in a five-point Likert scale from uncomfortable to neutral to comfortable. A follow-up question was asked for responses uncomfortable - neutral as shown in

Figure 14. The follow up question (2) asked if they would find an alternate route, intending to determine if their level of discomfort would influence their behaviour and use of the hallway.

Figure 14 Question Distribution.

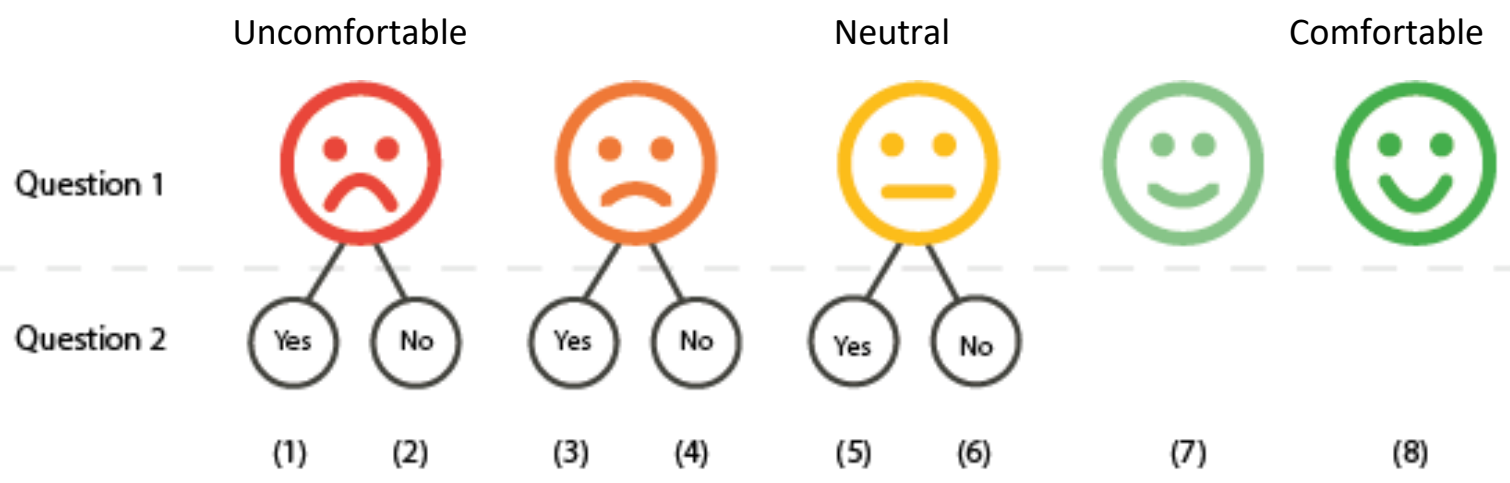

There were eight possible answers, detailed in Table 8, and illustrated in 
Figure 14. User responses and rational for their choices can only be speculated as there are many behavioural and cultural variables that are uncontrollable in this type of survey. Different personalities, ages, ethnicities, cultures and genders are likely to all feel different in the same space. To minimise these variables from influencing the survey responses, it is important that the survey reaches a range of personalities, ages, ethnicities, cultures and genders. However, these questions were not asked to reduce the time taken to complete the survey and hopefully increase the number of people providing a response. The survey is completely optional and anonymous, there is no way to know if the survey respondents are from any group. The higher the number of respondents reduces the likelihood of any single variable group, but it cannot be confirmed. These variables are not considered a hindrance to the research as the survey is intended as supplementary knowledge to make supported and guided recommendations for future research around the user of occupancy sensors. The survey will help provide information on user perception of lighting, to determine if this is an energy saving area that should be investigated in more detail.

Table 8 Survey Answers.

\begin{tabular}{|c|c|c|c|c|}
\hline Outcome & $\begin{array}{l}\text { Question one } \\
\text { Response }\end{array}$ & $\begin{array}{c}\text { Question two } \\
\text { Response }\end{array}$ & Speculated Rational & $\begin{array}{l}\text { Positive/ } \\
\text { Negative }\end{array}$ \\
\hline 1 & Uncomfortable & Yes & $\begin{array}{l}\text { Uncomfortable, enough to } \\
\text { find an alternate route due to } \\
\text { lighting }\end{array}$ & Negative \\
\hline 2 & Uncomfortable & No & $\begin{array}{l}\text { Not affected enough to find } \\
\text { alternate route }\end{array}$ & Negative \\
\hline 3 & Uncomfortable/Neutral & Yes & $\begin{array}{l}\text { Uncomfortable/neutral } \\
\text { enough to find an alternate } \\
\text { route due to lighting }\end{array}$ & Negative \\
\hline 4 & Uncomfortable/Neutral & No & $\begin{array}{l}\text { Not affected enough to find } \\
\text { alternate route }\end{array}$ & $\begin{array}{l}\text { Somewhat } \\
\text { Negative }\end{array}$ \\
\hline 5 & Neutral & Yes & $\begin{array}{l}\text { Neutral but would find an } \\
\text { alternate route due to lighting }\end{array}$ & $\begin{array}{c}\text { Somewhat } \\
\text { Positive }\end{array}$ \\
\hline 6 & Neutral & No & $\begin{array}{l}\text { Not affected enough to find } \\
\text { alternate route }\end{array}$ & Positive \\
\hline 7 & Neutral/Comfortable & N/A & Not affected & Positive \\
\hline 8 & Comfortable & N/A & Not affected & Positive \\
\hline
\end{tabular}




\subsubsection{SURVEY PILOT RESULTS}

The pilot survey consisted of the same format for three different hallway images, dark, dimmed and lights on. The results for each of these are below in Table 9. The reason that there was a lack of responses for the third and final image with all lights on (Figure 12) is not known. It is speculated to be due to reasons including software issues, the turning off of the screen, the short one-day period, the day of the week (Friday) or little/no knowledge of new question. These reasons are all discussed further in the section Lessons from the Survey, page 67.

Table 9 Survey Questions and Results.

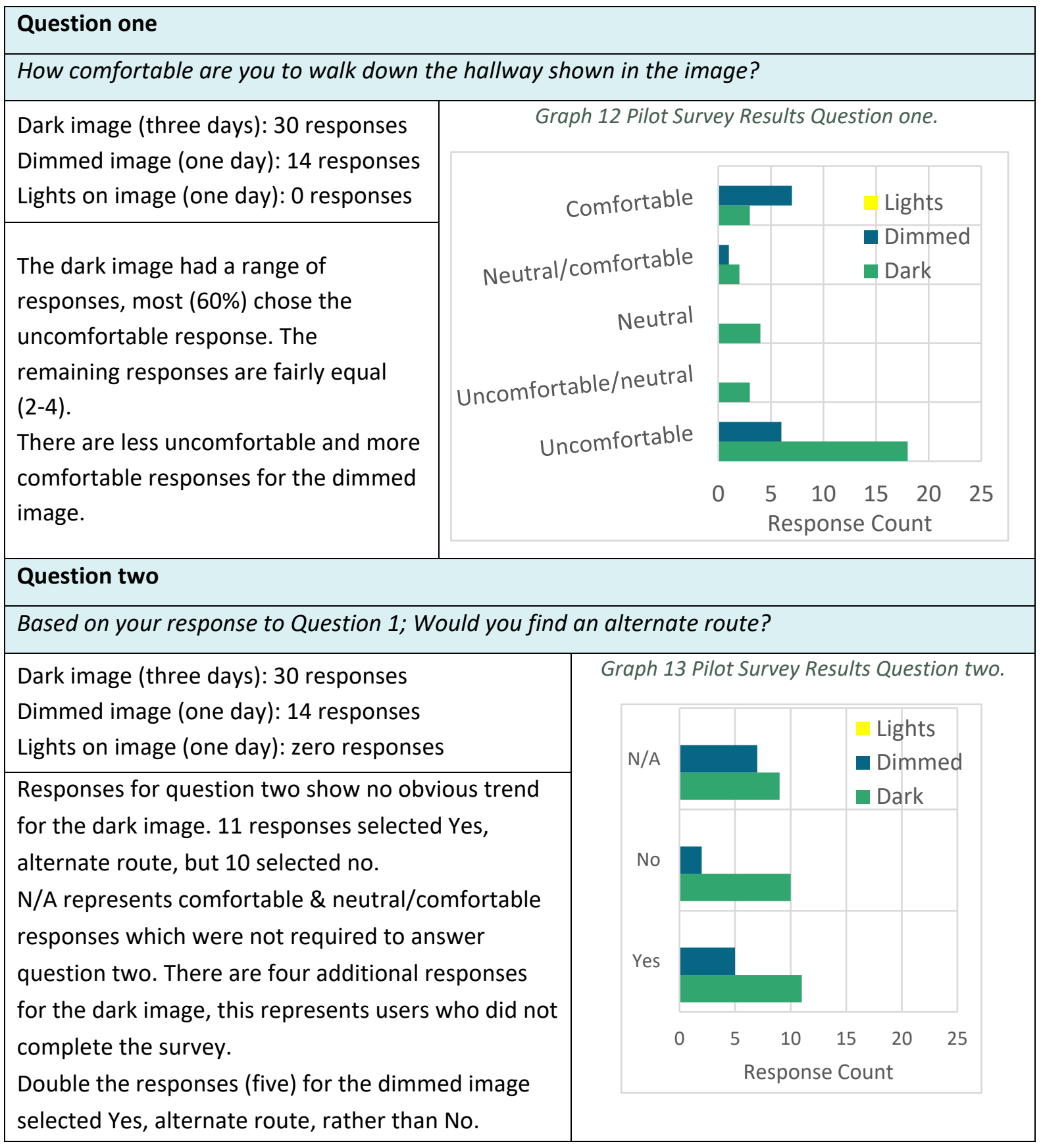




\section{FEEDBACK AND DISCUSSION}

The surveys provided initial results and gave insight as to how the full experiment survey outcomes may perform. It is possible to compare the motion data against the survey response quantities to see approximately how many responses could be received had everyone answered the survey. Table 10 shows a comparison of the survey responses against the count of motion detected.

Table 10 Survey responses compared to motion count.

\begin{tabular}{|c|c|c|c|c|}
\hline Survey Question & Date & $\begin{array}{c}\text { Survey } \\
\text { Responses }\end{array}$ & $\begin{array}{l}\text { Motion } \\
\text { Count }\end{array}$ & Percentage \\
\hline \multirow{3}{*}{$\begin{array}{l}\text { Dark image } \\
\text { (three days) }\end{array}$} & Monday, $1^{\text {st }}$ July 2019 & \multirow{3}{*}{30} & \multirow{3}{*}{126} & \multirow{3}{*}{$24 \%$} \\
\hline & Tuesday, $2^{\text {nd }}$ July 2019 & & & \\
\hline & Wednesday, $3^{\text {rd }}$ July 2019 & & & \\
\hline $\begin{array}{l}\text { Dimmed image } \\
\text { (one day) }\end{array}$ & Thursday, $4^{\text {th }}$ July 2019 & 14 & 77 & $18 \%$ \\
\hline $\begin{array}{l}\text { Light image } \\
\text { (one day) }\end{array}$ & Friday, $5^{\text {th }}$ July 2019 & 0 & 75 & $0 \%$ \\
\hline
\end{tabular}

These results suggest that lest than a quarter of hallway users responded to the survey. This is an estimate as the sensors can only give an indication of how many groups of people walk through the hallway. A large group (e.g. four people) would be counted as one motion while an individual who uses the hallway 10 times a day would register as 10 instances of motion. The sensors and analysis software cannot differentiate between multiple people or repeat users.

\section{University colleagues provided the following feedback:}

- 'Smiley face' design was easy to understand.

- Screen was found off on more than one observation.

- Software pop-ups such as 'survey session halting'.

- The location was thought to be too busy, nearby amenities (e.g. printer) detracted from noticing the tablet.

- Text and smiley faces covered the image in the question.

Issues such as location and adjusting the image/text layouts were easily resolved. The problem was the survey software and the screen turn off. The survey was designed to be used throughout the entire workday, for the whole workweek across several weeks. It was found after experimenting that using the Qualtrics software the tablet would not remain on for longer than 30minutes. This could not be resolved as easily. Ultimately, the Qualtrics survey software engineers were unable to resolve this issue within the timeframe of the experiment. As a consequence, it was not possible to implement the user survey into the final research. 


\section{LESSONS FROM THE SURVEY PILOT}

The pilot survey identified a number of limitations including survey design, length of pilot test, survey software, location of tablet and time of pilot test.

Due to the nature of the survey intent, it was important for the tablet to be within the hallway. This had an influence on the type of survey chosen (smiley face) and the likely voluntary participation. As hallways are transitional, the survey needed to be brief to encourage higher participation. Often in this context, short one-question smiley face surveys are used, for user feedback situations, such as following airport security screening. This also limited the number of follow-up questions. For ease of answering, the question(s) needed to be closed with provided answers for simple 'click of button' answering, rather than typing a comment or response. To provide a range of options, a Likert scale was selected for the answers.

The short nature of the survey meant that more in-depth answers could not be attained. Ideally, the survey would have gathered some insight into the variables that may have affected their answers on the key question.

For instance, if a user is uncomfortable with the suggested lighting but selects 'no' alternate route. The speculated rational is that they were 'not affected enough to find an alternate route'. But what are the reasons for this choice? Are they a regular student/staff and are familiar with the building and the hallways? Perhaps they don't know any alternative routes or perhaps this is the quickest route. Without additional questions, there is no way to know the rationale behind the selected answers. The intent of this survey is to gain preliminary knowledge to support future work in this area.

Figure 15 Survey Poster to show 'New question today'.

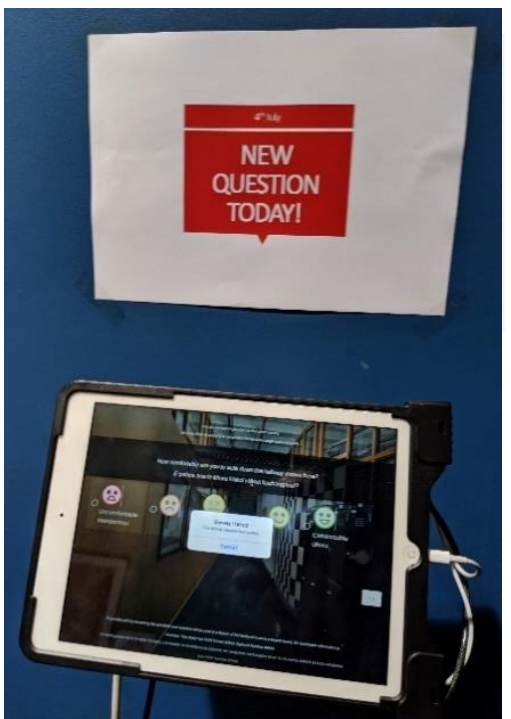


The software selection was a limitation that could not be avoided. It was required that the selected survey software was the VUW supported Qualtrics software. Qualtrics survey software does not specialise on 'smiley face' surveys, although this option was available and appeared to be suitable for the intended use. The graphics and design were customised to match the desired aesthetic. It was unfortunately found that the Qualtrics software was not designed to function in a setting that sees the survey continuously active and available on a tablet (refreshing after every entry). The largest issue with this was that the survey software would halt the survey session automatically and consequently turn the screen off after 30minutes, whereas the survey design required the tablet to be on and active $100 \%$ of the time. The software and tablet settings were checked by colleagues, the conclusion was that the issue was the software as it was not designed for this context. The issue was elevated to Qualtrics software engineers but could not be resolved within the timeframe of the proposed research.

Location requirements limited the placement of the tablet. The wall mount required wall screws, the hallway needed to be wide enough to avoid obstructing access and the tablet needed to be within reach of both power supply and something to attach to for security. Due to the screws, the tablet was restricted by the walls it could be attached to. The tablet was required to be within reach of a power supply for the tablet charger (on extension cord), but there were few hallways which had accessible power supply. On top of those requirements, the tablet needed to be within reach of any kind of pole, pipe, structure or rail to attach a security wire. There were few hallways that provided security, fewer that had power, an acceptable wall for screws as well as a hallway that was wide enough to not obstruct access.

Placing the survey in a hallway limited some aspects that would have been helpful to expand upon, such as the questions. However, within the constraints, the survey choice has been seen to work well and software issues aside, the responses for the survey could have been successful in gathering a preliminary understanding of user perception and lighting in hallways. Unfortunately, the software issues could not be overcome, and the pilot survey was not continued with the full experiment. 
Masters of Architectural Science

Georgia Alexander

Chapter 5 EXPERIMENT 
The experiment is detailed in this chapter dealing with the building and space selection process, sensor placement process, monitoring and limitations. Location, time and equipment details are provided in Table 11. As mentioned in the survey limitations (section 4.2.3), the user perception survey is not continued into the experiment due to software issues. The following experiment focuses solely on the results of the sensors. A section is provided in Chapter 7 to discuss the significance of the survey outcomes and how the results would have complimented the sensor analysis (see section 7.4 Survey Significance).

Table 11 Experiment Details.

\begin{tabular}{|c|l|}
\hline Period & $1^{\text {st }}$ of August to $13^{\text {th }}$ October 2019 (74 days total). \\
\hline Location & Victoria University of Wellington's Murphy Building at Kelburn Campus. \\
\cline { 1 - 2 } Space locations & $\begin{array}{l}\text { See appendix 9.3 (from page 125) for descriptions and images of sensor } \\
\text { locations and plans of each space. }\end{array}$ \\
\cline { 1 - 2 } Sensor locations & 20 PIR sensors and 20 Light sensors. A pair of each in 20 space \\
\cline { 1 - 2 } Equipment & $\begin{array}{l}\text { Wireless tag.net - online database to access data for continuous } \\
\text { monitoring and to download for analysis. }\end{array}$ \\
\hline
\end{tabular}

\subsection{BUILDING SELECTION PROCESS}

The building selection process was required to ensure that there were enough of each space type within the chosen building, and that each of those space types met the space definitions and inclusion criteria. As part of this research, a building survey undertaken on Monday $6^{\text {th }}$ May 2019 surveyed 10 of VUW Kelburn campus buildings. The survey identified buildings that include all four space types, hallways, stairwells, lavatories and seminar rooms. Only three of ten buildings surveyed included of all four space types within the criteria, so these were selected for a more intensive survey and observation.

Excluded buildings include, sports facilities, lecture theatre buildings, communal areas, libraries, science labs and postgraduate or staff buildings. Buildings included in the survey were required to be accessible by all students and staff. 


\subsubsection{BUILDING SCOPE SURVEY}

The building survey identified the quantity of each space type in the three buildings, Table 12 lists these as they meet the definition in section 3.4 Space Detailed Descriptions. The criteria (section 3.4.1) are used to determine consistent spaces for the experiment. Table 2 (section 3.4) details the four space types gathered from the literature discussed in Chapter 2, including use period, similarities, differences, lights and switching.

Table 12 Building Survey Space Type count.

\begin{tabular}{|c|c|c|c|c|c|}
\hline & Address & Hallway & Stairwell & Seminar & Lavatory \\
\hline Kirk Building & 16 Waiteata Road, Kelburn, & 21 & 10 & 2 & 10 \\
$\begin{array}{c}\text { Wellington } \\
\text { Murphy }\end{array}$ & 21d Kelburn Parade, Kelburn, & $\mathbf{3 8}$ & $\mathbf{2 4}$ & $\mathbf{1 3}$ & $\mathbf{1 8}$ \\
$\begin{array}{c}\text { Wellington } \\
\text { Von Zedlitz } \\
\text { Building }\end{array}$ & $\begin{array}{c}\text { 28 Kelburn Parade, Kelburn, } \\
\text { Wellington }\end{array}$ & 18 & 18 & 3 & 18 \\
\hline
\end{tabular}

The clear choice was Murphy Building as it had of the most seminar rooms which appeared to be the scarcest space type. Many seminar rooms in Kirk and Von Zedlitz buildings were computer or science labs and therefore did not meet the selection criteria. The number of spaces within Murphy Building allowed more refinement when selecting the individual spaces. Murphy building consists of two Towers, North and South. Both Towers have all space types. The South Tower has the majority of seminar rooms and the North Tower has the majority of hallways. Two identical stairwells run up the North Tower, whereas, the South Tower has only one stairwell.

Part of the survey assessed the floor area space of the whole building and of all the space types. The results are shown in Table 13 (For data see appendix 9.3.2). On average, nearly half the floor areas of these buildings are identified as intermittent-use spaces. Individually these spaces are small, but when added together across all the levels, are a significant proportion of floor area. Particularly significant, as lights are often left on in these spaces, suggesting significant potential for energy savings.

Table 13 Floor area percentage of intermittent-use space types.

\begin{tabular}{|c|c|}
\hline Kirk Building & $63 \%$ \\
\hline Murphy Building & $46 \%$ \\
\hline Von Zedlitz Building & $39 \%$ \\
\hline Average & $49 \%$ \\
\hline
\end{tabular}




\subsection{Space Selection Process}

The selection process consisted of a more detailed observation survey (reported in Appendix 9.2) and planning within the constraints of the technology to refine the space list down to 20 . There were 93 individual intermittent spaces counted in the building survey (Table 12). Many of these spaces, were identical across the floors, particularly the lavatories, stairwells and hallways. 30 spaces in Murphy building are compared to find a range of space type variants within the criteria. Observation comments and details of these spaces can be found in Appendix Section 9.2 including light quantity and type, windows, orientation, amenities, irregular shapes and comments including occupancy size, observed behaviour and amenities within the space.

Although of 30 spaces were assessed, only 20 sensor pairs were available. The selection rational considered similar spaces, tag manager connection range and potentially obstructing architectural aspects. Stairwells, lavatories and hallways were repetitive across the floors which was convenient to achieve a range of space types within the constraints of the tag manager range. The selection and distribution of space types in Table 14, show how the 20 sensor pairs are allocated across the space types for the Murphy Building selection.

Table 14 Observation Space Type Distribution.

\begin{tabular}{|c|c|c|} 
& Building Survey & Murphy Selection \\
\hline Hallway & $7+$ & 7 \\
Stairwell & $5+$ & 2 \\
Seminar & $12+$ & 7 \\
Lavatory & $6+$ & 4 \\
Total & 30 & 20 \\
\hline The "+" represents identical spaces on other levels. \\
E.g. stairwells which are consistent up the building.
\end{tabular}

Across the two Murphy Building towers, there are only two different stairwells, one of each of these is monitored. Similarly, there are four different lavatory space arrangements, all four of these are monitored. Due to the similarities of lavatories and stairwells, there are more sensors available to monitor the hallways and seminar rooms. This is ideal as these rooms have greater variability than lavatories and stairwells as noted in the Sensor Pilot Results. Seven hallways and seminar rooms were selected which achieved the tag manager requirements, a range of variety within the space type, while all meeting the space type criteria outlined in section 3.4.1. All images and plans for the 20 spaces in the experiment are found in Appendix 9.3. 


\subsection{Sensor PLACEMENT PROCESS}

Once the spaces were selected the placement of each sensor needed to be considered to achieve consistent and accurate results, so space observations were essential for this process. The Sensor Placement Guidelines (page 39) were followed as a basis which considered lights in the space, windows, coverage of room, minimal blocking of sensor and access throughout the experiment. Observations of the spaces found common ideal locations across the space types. There was greater variation in the placement of the motion sensors than the light sensors. Sensor were placed nearby other equipment including light switches, whiteboards, or flat wall objects to minimise user attention being drawn to the sensors and any potential resultant change in behaviour. The location and placement of the sensors varies between the different rooms and space types providing variation of measurement. These measurement variances are accounted for as best as possible through a consistently used Light Measurement Method as detailed in section 3.3 Data Collection.

Users loitering was the largest inconvenience noted from observations. Potentially blocking a sensor and not gathering full occupancy data. This is accounted for in the guidelines and was followed through by placing sensors immediately next to doorways and whiteboards where users were seen to not loiter or block access as detailed in appendix 9.2 Space Observational Survey Details. A space that may encounter loiters would still register enough information for this experiment as the space is deemed occupied. Whether that is two people having a chat in a hallway or 10 people passing through, the space is occupied. User behaviours appeared consistent across the variety of spaces. The definition and criteria in section 3.4

Table 2 and Table 3, section 3.4 provided a way to select a range of hallways and excluded common atrium spaces where seating encourages users to stay and loiter. This allowed all spaces to be considered intermittent-use spaces and provide a consistent comparison baseline. During the workday there were periods of high use and no/low use, but these aligned with the university timetable with peak user traffic between classes and low user traffic during classes.

\subsubsection{Light SENSOR PLACEMENT}

The placement of sensors in internal spaces without windows were simpler choices. These include the stairwells, lavatories and all hallways aside from hallway seven. All seminar rooms had windows which required a more considered placement to avoid daylight interference.

In most cases, light sensors were placed above objects or doors to minimise drawing attention to the sensors. This worked well in most cases aside from stairwell one. This stairwell originally had the sensor placed on top of a shelf midway up the wall at the turn of the $U$ shape. 
This was not an ideal location as two weeks into the monitoring, the sensor went missing. The sensor was in direct eyesight of any user travelling down the stairs. The sensor was replaced, and the new location was the underside of the staircase above, which was closer to the light fitting and out of user eyesight but still within easy access. Another case was hallway four where a tall shelf was utilised, as the top was out of eyesight and not used. This kind of sensor placement was suggested as an example in the guidelines.

Seminar room light sensors were placed as close to the lights as possible, although this meant high on the walls close to the ceilings and away from windows. In two seminar rooms light sensors were placed at the top edge of columns to be closer to the light fitting and seminar room six placed the sensor directly on the light. Seminar room six received the most natural light with North facing windows and none of the lights were close enough to the walls to justify wall placement. Figure 16 shows the sensor taped to and facing the light fitting.

\subsubsection{MOtion SEnSOR PLACEMENT}

The lavatories and stairwells PIR sensors were placed on a case by case basis as each had a different layout. The U-shaped stairwell placed the PIR sensor at the turn of the $U$, whereas the Straight stairwell placed the sensor at the top of the stairs facing downwards. The lavatories were U-shaped or L-shaped, so like the stairwell, the best motion sensor location was at the turn of the space.

Five out of seven hallways were straight, less than 12 meters in length and narrower than two meters. Following the guidelines, the motion sensors in these hallways were all placed at one end. Hallway five was wider than two meters so the motion sensor was placed midway and the seventh hallway angled halfway (see plans in appendix 9.3), the sensor in this hallway was placed midway at the change in angle to best cover each end.

Assuming seminar room users would need to visual access of the centrally placed whiteboards/screens, the PIR sensors were placed above the white boards in all the seminar rooms. This provided a central and consistent location across all seminar rooms. 


\subsubsection{INSTALLATION, TESTING AND MONITORING}

All sensors were installed on the morning of Monday the $29^{\text {th }}$ of July 2019. The full experiment commenced after final sensor checks on Thursday the $1^{\text {st }}$ of August 2019 and ran for two and a half months until Sunday the $13^{\text {th }}$ of October 2019. The monitoring period included a two-week midtrimester break from the $19^{\text {th }}$ August until the $1^{\text {st }}$ of September. This period is included in the final analysis to include all behaviour types present across the year for the purpose of annual cost savings and payback periods.

Sensors were attached using $3 \mathrm{M}$ Velcro strips for ease of battery replacement throughout the monitoring period and to allow for clean removal from the wall post experiment. All 40 sensors were tested prior to the pilot test to check that they had connection and could upload data. Connection testing was checked by sending commands to the sensor (turn on/off LED) and refreshing signal periodically throughout the day to check recorded lux levels. Occupancy sensors were checked by cross-checking time and date of access to each space with the data output. Sensors were left for two days to assess this connection and continuous data uploading. All sensors were either recording light data or motion (as necessary) and connecting to the database without trouble.

Throughout the experiment sensors were checked every day, and battery levels recorded every second day to track performance and replace batteries before sensors died. Batteries were replaced when the percentage recorded below $10 \%$.

\subsection{LIMITATIONS AND ASSUMPTIONS}

For unknown reasons, not all the sensors continuously recorded for the full two-and-a-half-month period. Instead, there were seemingly random periods where individual sensors would register out of range. The reason is not known why this occurred as the sensors were permanently in the same place throughout the whole experiment. Some considerations as to what the cause could be was, low battery, making the connection weaker or strain on the wireless network. There was one recorded instance where all the sensors lost internet connection due to a University wide network outage. There do not appear to be any trends in the failures between the space types or distance to tag manager. 
The result of these issues were 'loss of data days'. Each sensor's percentage performance is displayed in Graph 14. The worse sensor (PIR Lavatory three) managed to record only $36 \%$ of the time, and more than half the light sensors recorded $100 \%$ of the time. There was a noticeable difference between the sensor types as light sensors seemed to be more reliable. On average light sensors recorded $95 \%$ of the time in contrast to the motion sensors at $67 \%$ of the time.

Graph 14 Sensor Performance Percentage.

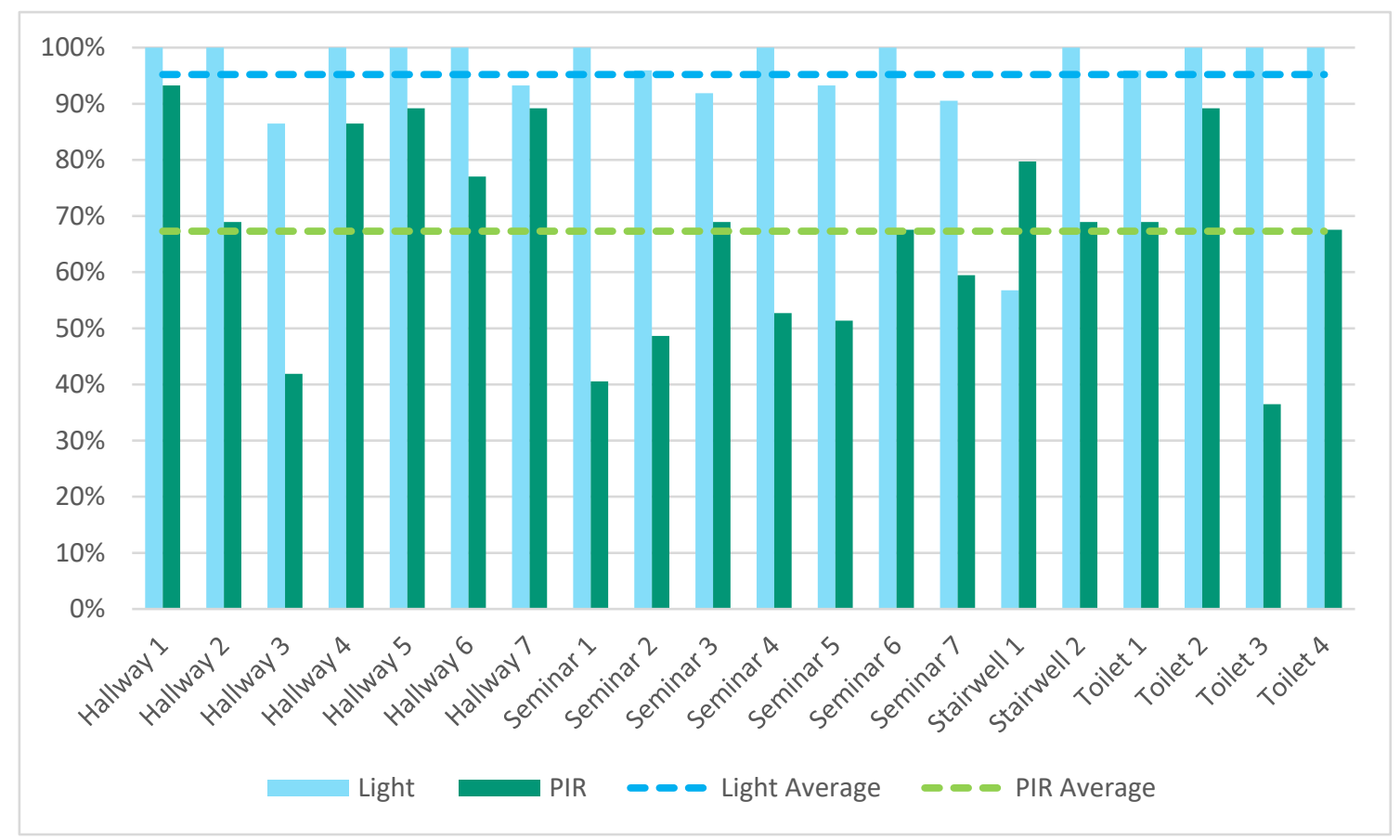

The results for each pair are based upon the lowest amount of data for either sensors. In the case of Lavatory three, the light sensor recorded $100 \%$ of the time, but the motion sensor was only $36 \%$ of the time. Rather than being averaged, only the light data for the matching $36 \%$ of the time is used in the results and analysis. 


\section{Chapter 6 RESULTS}

The accompanying results discussion and analysis may refer to the shape, fittings or features of individual spaces, the details for each of the 20 spaces, are located in appendix section 9.3. All result data is provided in appendix section 9.4. 
This chapter is split into three sections, individual results, space type results and 'time of day' results. The individual results compare each space within the space type groups, focusing on the four data categories as per Table 1. Space type results compares the average of each space type, against the four data categories, as well as the range across the space types, calculated energy savings, cost savings and payback periods. The 'time of day' results compare the energy saving potential of each space type against weekday/weekend and different periods of the day such as daytime/night-time. These perspectives of time and space types provide a broad view of the use of lighting and the energy saving potential across the different intermittent-use spaces

\subsection{INDIVIDUAL SPACE RESULTS}

This section shows the results per space as the data categories previously mentioned in section 3.3. These compare light use to vacancy/occupancy for four possible categories, lights off and occupied, lights off and vacant, lights on and occupied, lights on and vacant. The last category is the focus as it highlights energy waste, however, all categories provide perspective of space performance.

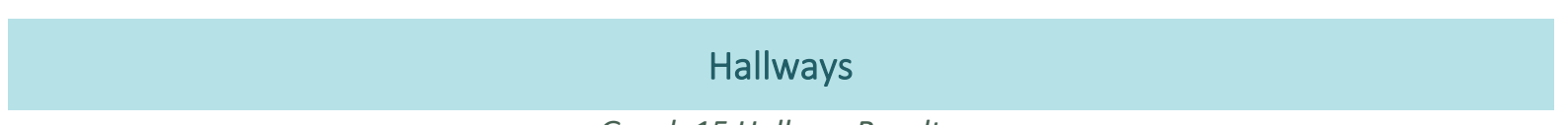

Graph 15 Hallway Results.

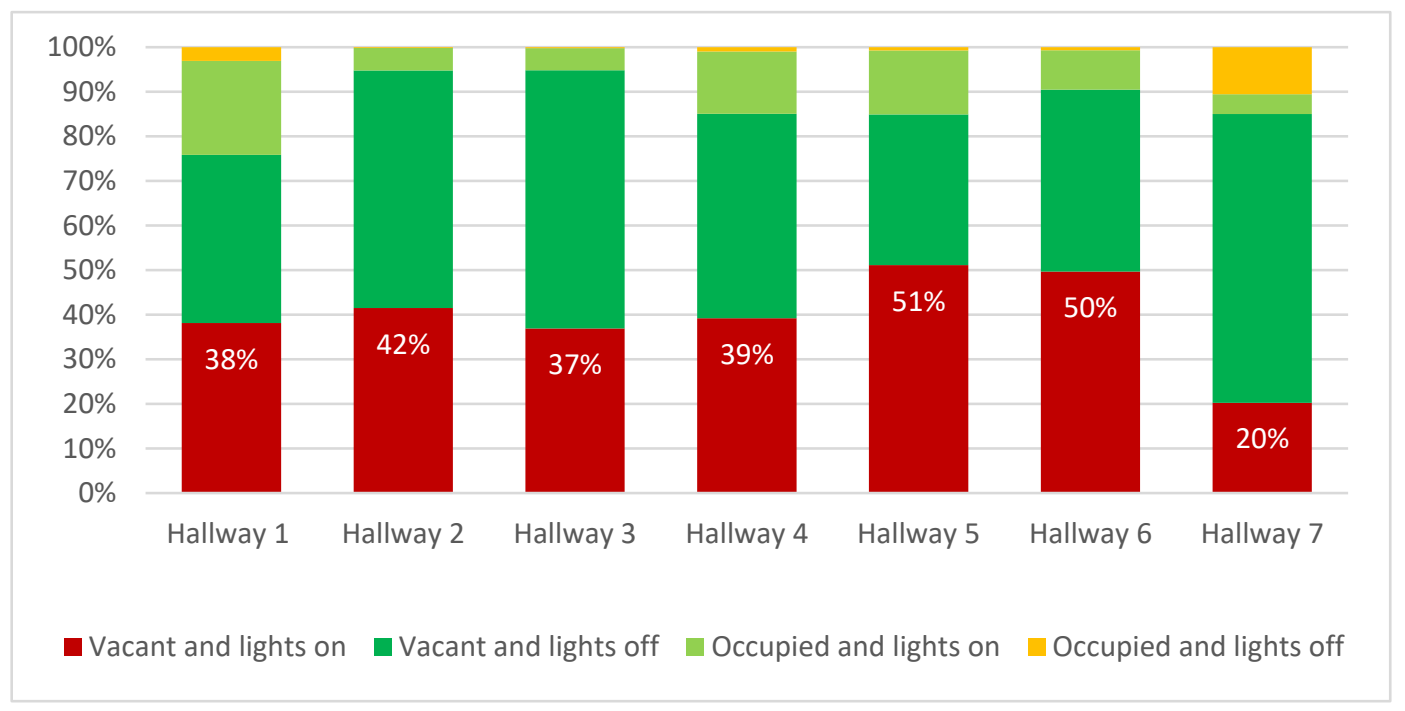

The results (Graph 15) for hallways show some similarities between the seven hallways, although no two are the same. The most similar hallways are five and six, which across the four categories, show the least variation while they also have the highest energy saving potential. These two hallways are similar in size and shape, and as they are on the same floor it is likely with the same or similar users' similarities are not unexpected.

Hallway one shows the highest percentage of time occupied at $24 \%$ overall, $21 \%$ with lights on and $3 \%$ with lights off. 
Hallway one is on ground floor and includes direct access to the lifts, users would be most likely to enter the building from this level, resulting in a higher occupancy for this hallway.

Hallway one and seven are the most irregular shaped hallways, one has another hallway crossing it, and seven is not straight. Due to the different shape, it is possible that users would pass through the intersecting hallway, or the angle portion, not directly using the hallway in question, but still being picked up on the sensors, this could be a cause of the higher figure for occupied and lights off in these spaces. Hallways one, four, five and six use lights more than $50 \%$ of the time, at $59 \%, 53 \%$, $65 \%$ and $59 \%$ respectively, but most of this time the spaces are vacant. An ideal opportunity for occupancy sensors.

\section{Stairwell}

Graph 16 Stairwell Results.

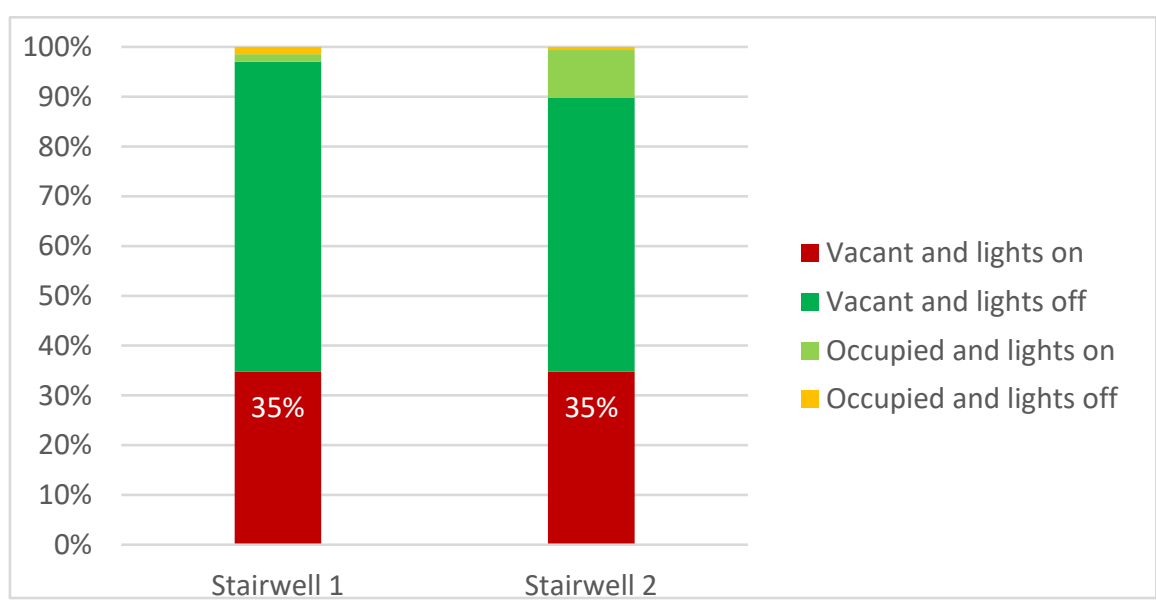

The results for the two stairwells are very similar considering the spatial variances. The percentage potential for energy savings are identical at $35 \%$. The two stairwells have similar times with no one using the space, but a difference of $9 \%$ occupancy results. The largest difference between these two spaces is stairwell two has a higher percentage of occupancy with lights on, of $10 \%$ compared to stairwell one at $1 \%$. Both stairwells have noticeably high vacancy, with stairwell one $97 \%$ and stairwell two $90 \%$.

These two stairwells are physically quite different, stairwell one is closed-in on the bottom level and open to the floor at the top, whereas stairwell two is completely enclosed with doors. The light levels in stairwell one are significantly lower than any other space in this research at an average of 40 lux, this is simply a result of the type of light fittings in this space. The similar vacant and lights on results suggests that these spaces could be on the same light schedule where for the same period of time the stairwells are not being used e.g. after hours. 


\section{Seminar}

Graph 17 Seminar Results.

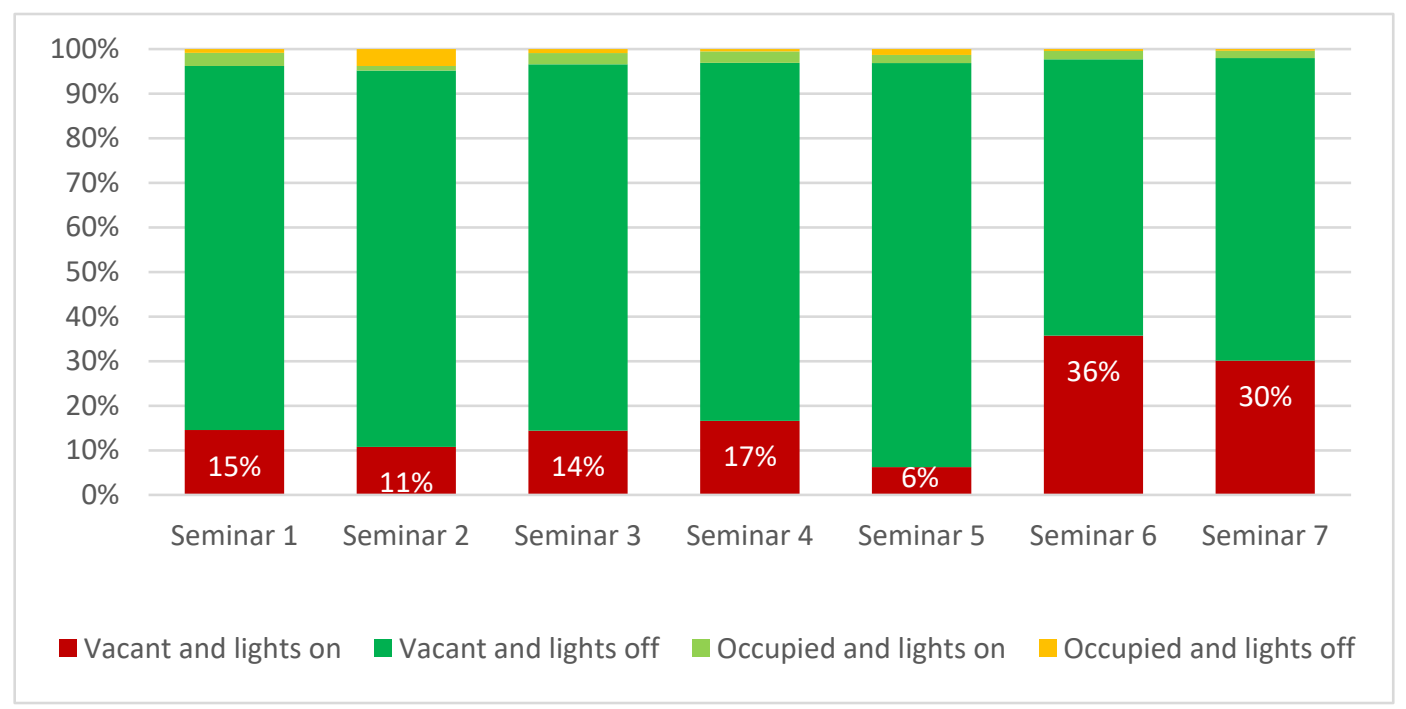

The seminar room with the highest energy saving potential is seminar six with $36 \%$, closely followed by seminar seven with $30 \%$. The remaining seminar rooms are reasonably similar, ranging from $17 \%$ to $6 \%$. Seminar five has the lowest energy saving potential and is about $5 \%$ lower than any other seminar room. Noticeably all the seminar rooms have a large percentage of time with vacant and lights off and very little percentage of time occupied. The percentage of occupied time ranges from $5 \%$ to $2 \%$, which is rather small, especially considering five of the seminar rooms have $1 \%$ of the time occupied and lights off. Seminars one, two, three and four have the most similar results, this is somewhat surprising as these rooms were all very similar in size and layout with the exception of seminar one which was about double the size. Seminar rooms three and four were spatially identical rooms, one with east windows and one with west windows across the hallway. Seminar room five also has similar results, though lower, and the space is quite different with North and east facing windows.

While all precautions were taken to minimise daylight effecting the light sensor measurements, seminar rooms six and seven had North facing windows where daylight was significantly more difficult to avoid, the higher vacant and light on percentage could be due to daylight interference. This could happen when daylight might reflect off tables or desks onto the sensors. Any daylight interference is expected to be verifiable based on the light level data and discounted as per section 3.3.1 Light Measurement Method. 


\section{Lavatory}

\section{Graph 18 Lavatory Results.}

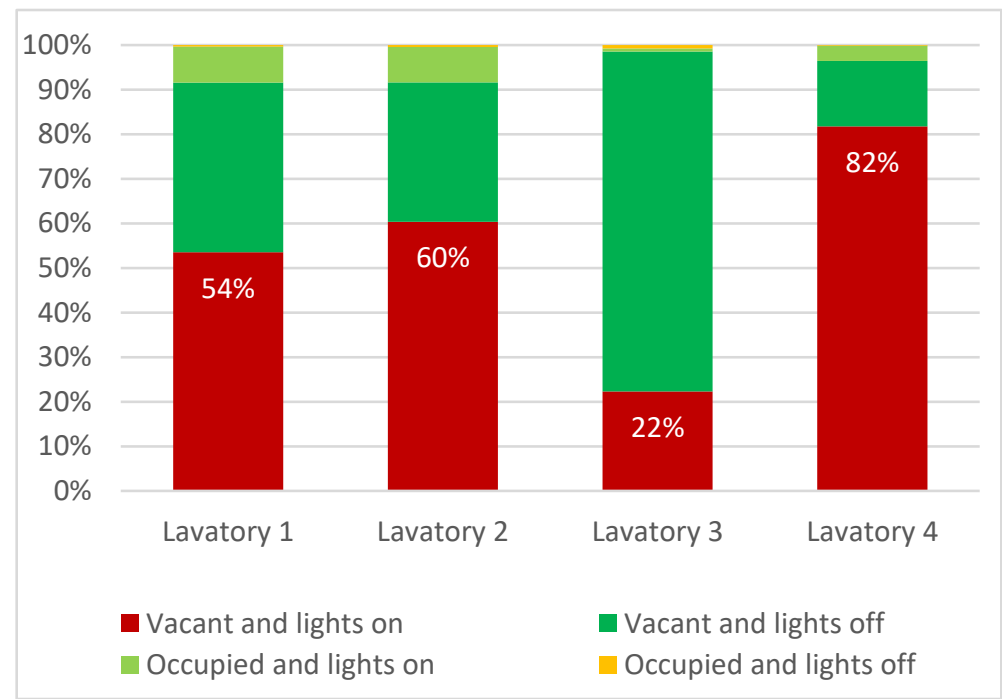

On average, the lavatories provide high potential for energy savings, three of four lavatories are above $50 \%$. There is a lot of variation across the four lavatories, though all had low/no occupancy with lights off. Physical differences between each of these lavatories may or may not influence light use, including number of lavatories, gender, students and staff. The sample size in this research is too small to determine.

Lavatory one and two were the larger lavatories and had $54 \%$ and $60 \%$ potential energy savings respectively. These two larger lavatories also have similar occupancy percentage, each of $8 \%$. Lavatory three and four were the smaller staff lavatories. Lavatory three is female and has a percentage potential energy savings of only $22 \%$ in contrast to lavatory four, males with $82 \%$ potential. One possible explanation of these results could suggest that female staff are more efficient at turning lights off when leaving the lavatory. Lavatory three has the lowest occupancy of all the lavatories at $1 \%$, while lavatory four has $4 \%$ total occupancy. 


\subsection{SPACE TYPE RESULTS}

The percentage of energy saving potential considers the percentage of time throughout the two and a half months experiment that lights were left on and no users were in the space. This percentage is the potential to turn lights off and save energy. It is considered potential savings as neither humans nor technology are perfect and could not turn lights off $100 \%$ of the time when the space is unused. It is possible for users to achieve this efficiency, but requires responsibility and intentional habits, which literature suggests are not abundant in these intermittently used public space types. Occupancy sensor technology relies on the time-delay setting which reduces the potential for perfect energy savings, this is discussed in more detail in section 7.3 Sensor Technology.

\section{Energy Saving Potential Percentage}

Graph 19 Space Type Results.

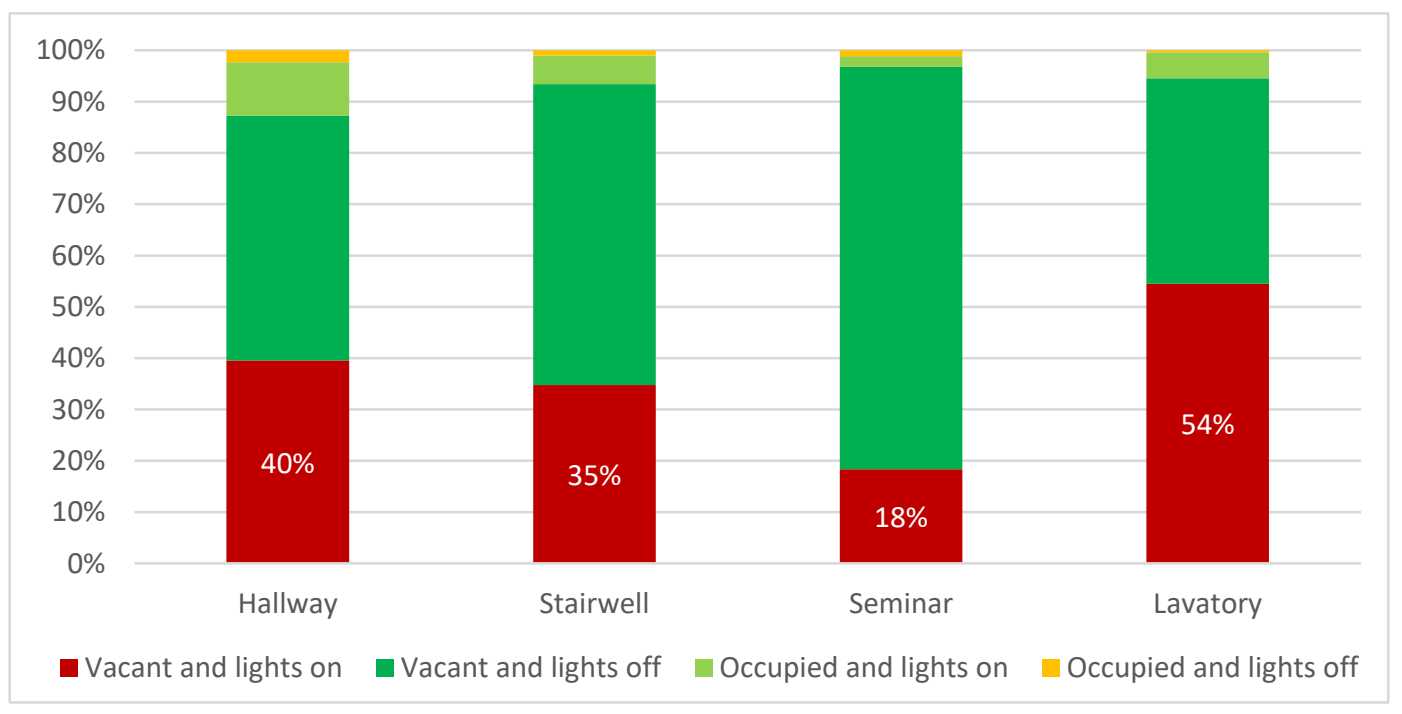

Lavatories have the highest energy saving potential at $54 \%$, followed by hallways (40\%), stairwells (35\%) and notable lower, seminar rooms (18\%). In all these four intermittent use spaces the majority of the time they are vacant, either with lights on or lights off. 'vacant and lights off' is the highest category for hallways, stairwells and seminar rooms, whereas the highest category for lavatories is 'vacant and lights on'. Hallways are the most occupied of the spaces at $13 \%$ occupancy compared to stairwells at $6 \%$, seminar rooms at $3 \%$ and lavatories at $5 \%$.

Seminar rooms receive the most energy efficient behaviour from users turning lights off more than any other space similar performance to the female staff lavatory. Results show the percentage of time when lights were in use; lavatories used lights for $60 \%$ of the time, hallways $50 \%$, stairwells $40 \%$ and seminar rooms $20 \%$. Efficient light use would see this predominantly consist of 'occupancy and lights on' which is not the case. 
Lavatories and seminar rooms are both end-use rooms, but the results suggest the nature of the seminar room encourages users (perhaps sub-consciously) to turn lights off more often than in the lavatories. The responsibility of controlling the light switch is more evident in seminar rooms than lavatories.

\section{Energy Saving Potential Percentage}

Graph 20 Percentage Potential Available Savings.

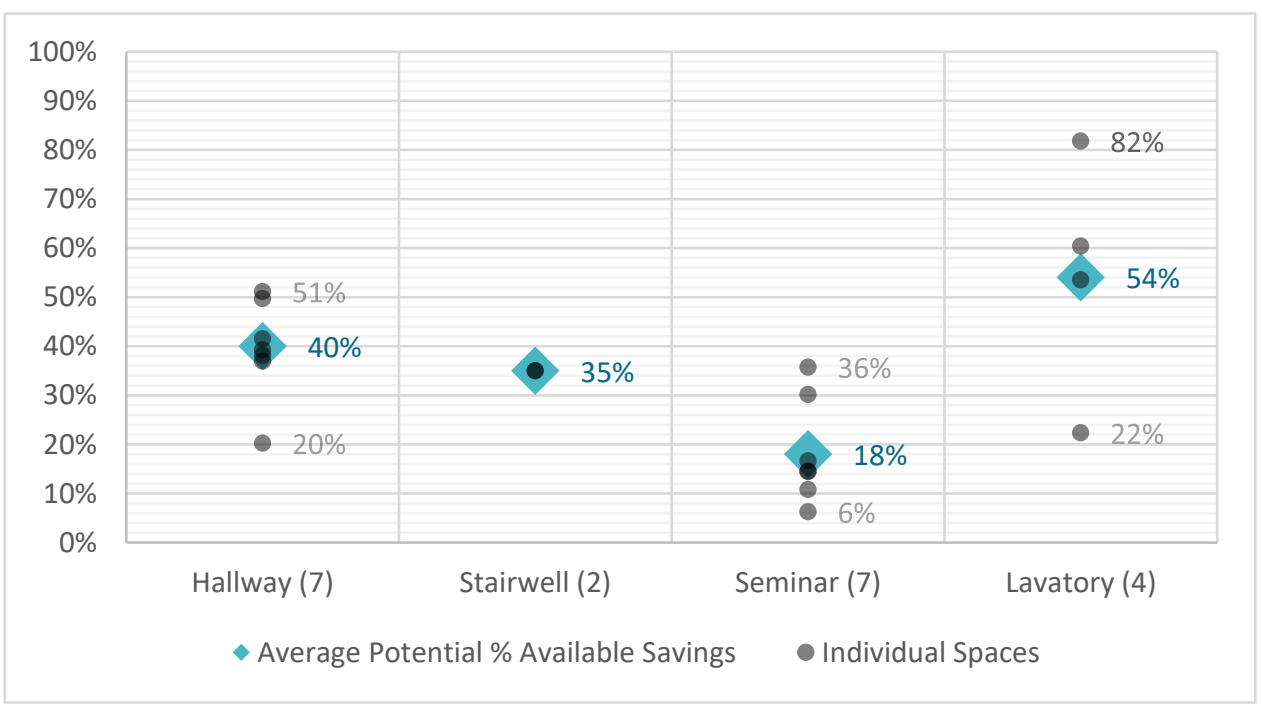

All Space types have potential to save energy with the addition of an occupancy sensor. Graph 20 shows the percentage potential energy savings for each of the 20 spaces, grouped by the space types. The large diamond represents the average of each space type, and the dots are the individual spaces. This arrangement shows how the results vary across the 20 spaces in this experiment and the range of each space type. Graph 21, Graph 22 and Graph 23 use the same format to display the results. In the case of the hallway results there are seven dots for the seven hallways, as noted in brackets beside the column, there are a bunch of dots around the average and a couple overlapping near the top.

The average energy saving potential for lavatories (54\%) is higher than all other results from any other space. The next highest result is a hallway at $51 \%$. Hallways and Stairwells are similar with an average of $40 \%$ and $35 \%$ respectively although hallways have a range of $31 \%$ and stairwells didn't have a range. Seminar rooms are significantly lower on $18 \%$ and a range of $30 \%$ between top and bottom seminar room result.

Lavatories have the greatest variability with a range of $60 \%$ between the highest and lowest, the two stairwells have identical potential energy saving percentages and the Hallways and Seminar rooms have very similarly sized ranges of results. Hallway performances are closely bunched together with four of seven hallways within $3 \%$ of the average. 
Seminar room percentage of potential energy saving results were more varied. Across the seven measured, two seminar rooms with higher percentage of potential energy savings at $36 \%$ and $30 \%$ pushed the average higher, whereas the other five seminar rooms were below the average, all between $6 \%-17 \%$. The most efficient hallways, stairwells and lavatories are not as efficient as the average seminar room with a low average of $18 \%$ and all other space types $20 \%$ or greater.

\section{Annual Energy Performance.}

Graph 21 Energy (kWh) performance of the Space Types.

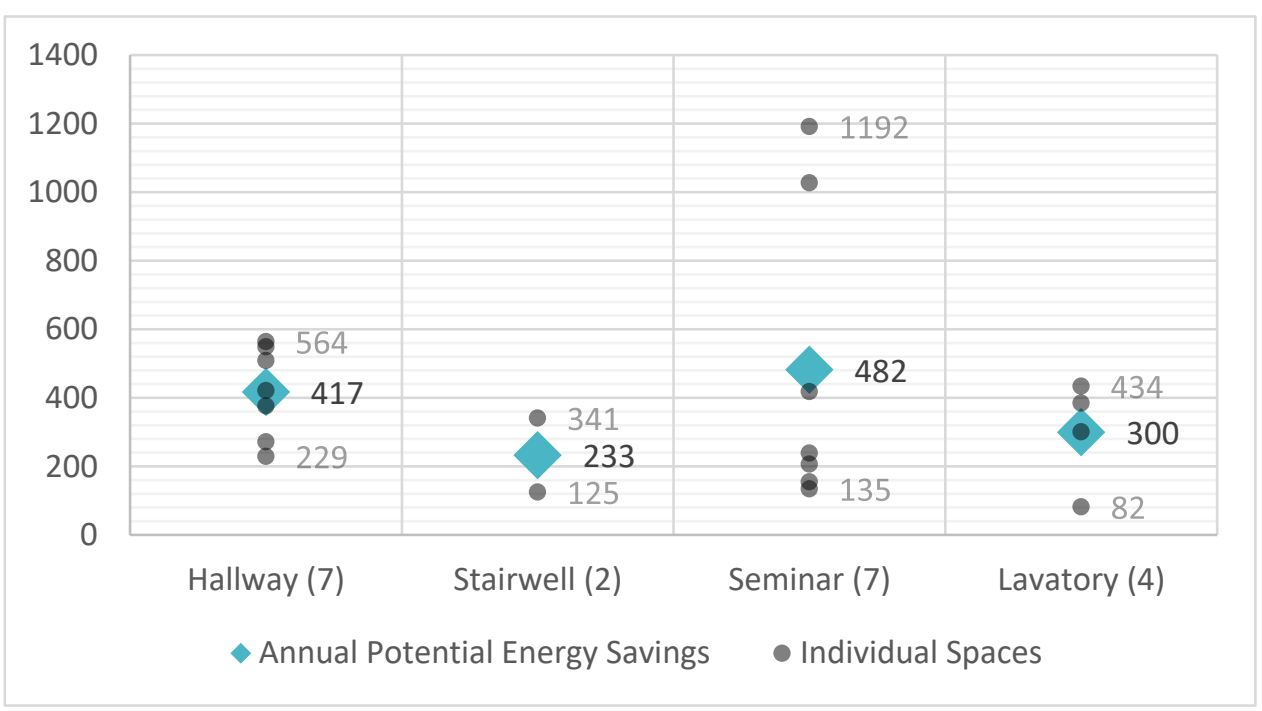

Graph 21 shows all 20 spaces, grouped by their space types and the average for each space type, a total of 24 points. The kWh are calculated by taking the percentage potential energy savings and the wattage of fittings to calculate the annual energy savings, this is calculated individually per space.

Assuming perfect energy saving potential is achieved, the annual kWh energy savings are presented in Graph 21. The average annual energy savings range from $482 \mathrm{kWh}$ to $233 \mathrm{kWh}$, which is a range of $249 \mathrm{kWh}$. The energy savings for the seminar rooms are double that of the stairwells. This is likely due to a higher number of lights. On average the stairwell lighting average light fitting power was $48.5 \mathrm{~W}$ compared to the seminar rooms with an average of $41 \mathrm{~W}$. The stairwell lighting used more power, though there were about one-third the number of lights. Hallways have similarly high potential energy savings of 417kWh annually, though on average the lights had lower power of 26.7W.

The seminar rooms had the greatest variability of energy savings from $1192 \mathrm{kWh}$ to $134 \mathrm{kWh}$. All the seminar rooms had the same $41 \mathrm{~W}$ fittings, the two seminar rooms that are significantly higher than the other five are the same two seminar rooms with double the energy saving potential (Graph 20). 
The other spaces have a more even distribution across the individual spaces. There is one lavatory which is pushing the average down, with significantly lower energy saving potential (Lavatory three). The difference between the stairwells is the most likely due to the different quantity and type of light fittings.

\section{Annual Cost Saving Results per Fitting}

\section{Graph 22 Annual Cost Savings per Fitting.}

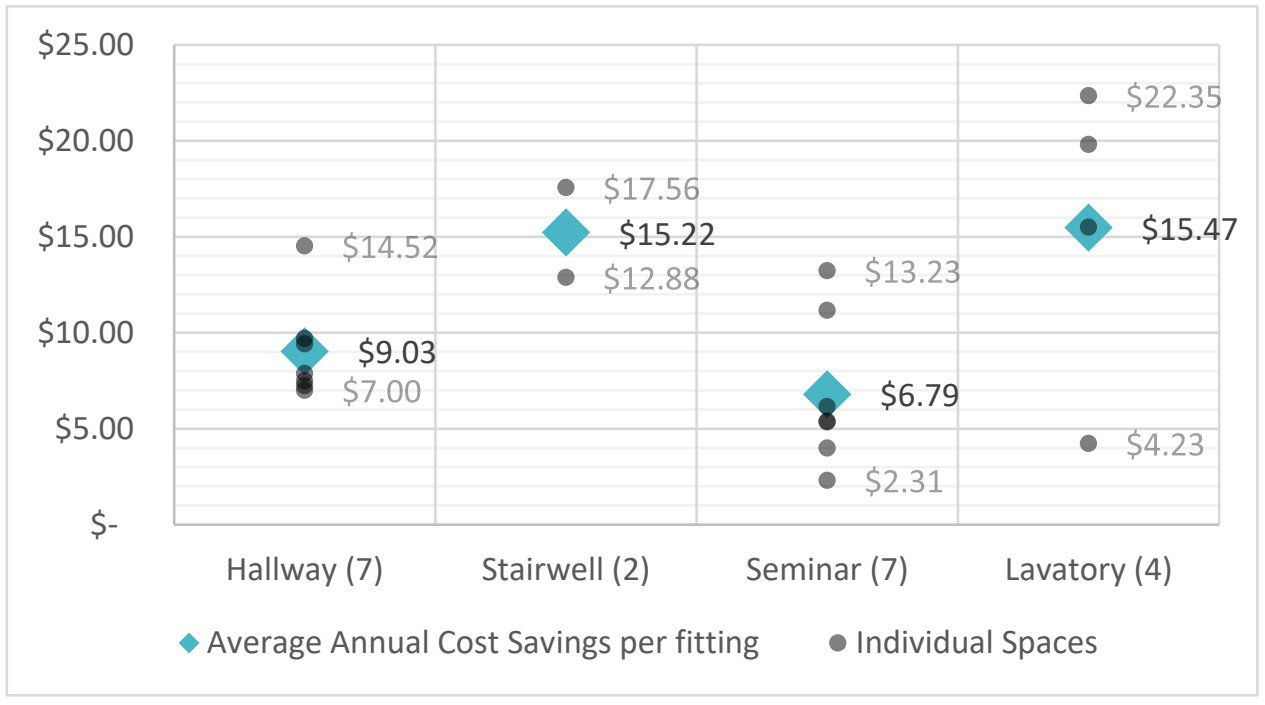

This graph shows all 20 spaces and the average per space type. The annual cost saving per fitting results convert the annual potential cost savings (kWh) to cost savings by multiplying by the VUW electricity rate. The annual cost savings are then further divided by the number of fittings in each individual space. Fitting refers to a whole light fitting which may include more than one lamp or bulb.

The greatest cost savings per fitting are Stairwells and Lavatories, with $\$ 15.22$ and $\$ 15.47$. Both lavatories and stairwells have the least number of fittings compared to hallways and seminar rooms. Seminar rooms have the lowest annual cost saving per fitting at $\$ 6.79$, though on average have triple the number of fittings compared to hallways and stairwells. There is variance across all space types, stairwells have the smallest range of $\$ 5$, hallways a range of $\$ 7$, seminar rooms a range of $\$ 11$ and lavatories a range of $\$ 18$.

The majority of hallways are sitting around $\$ 7$ to $\$ 9$ savings with the highest increasing the overall average. Seminar rooms are more spread out with five below the average and two higher results. Three of four lavatories have above $\$ 15$ while one lavatory has $\$ 4$, decreasing the average. 


\section{Payback Results}

Graph 23 Payback Period (years).

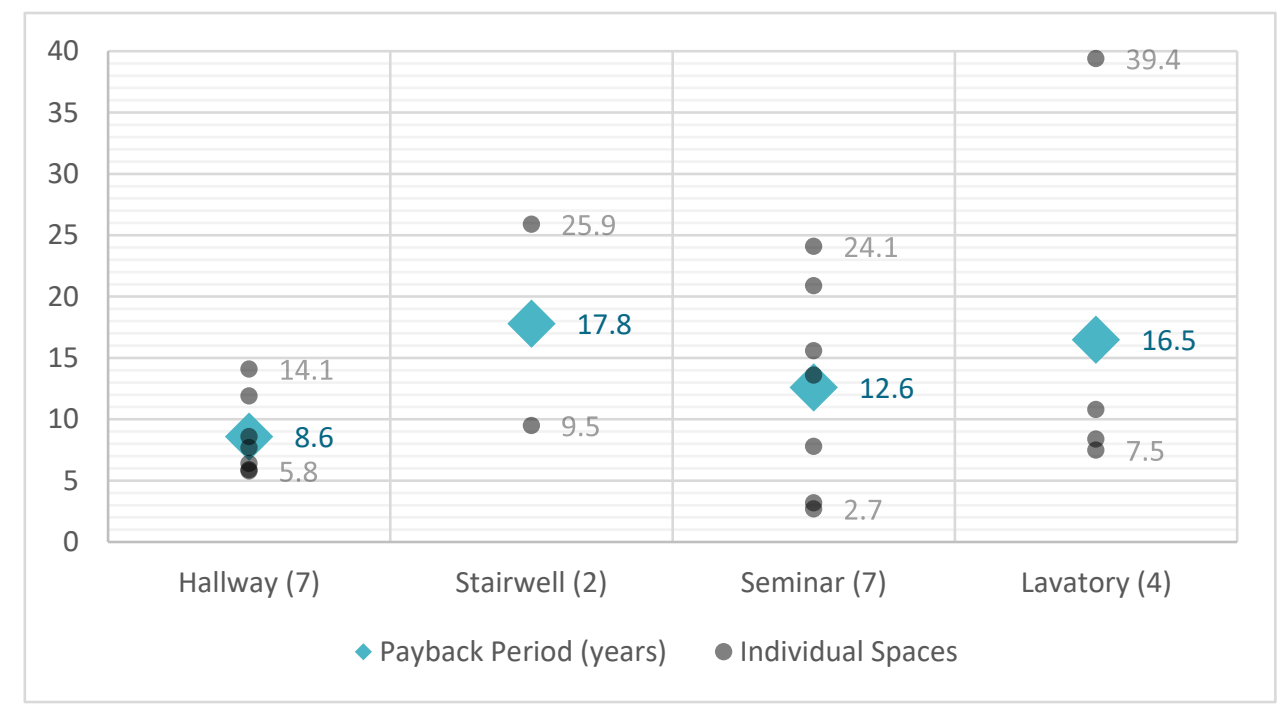

The payback period includes cost + installation of one sensor per space.

Graph 23 compares the payback period of all 20 space types and the average for each space type. These results are grouped per space type and calculated by dividing the cost savings by the cost to purchase and install one sensor (per space). A notable part of the cost of these sensors is in integrating them to work with existing fittings. There are luminaires with integrated occupancy sensors which could be integrated gradually as existing fittings reach the end of their life. As this could be a long process of replacement, the use of their integrated occupancy sensors may not occur until all fittings in a space are replaced.

Manzoor et al. (2012) and Fernandes et al. (2014) found payback periods of one year in open-plan offices. As this kind of research has not been experimented before, there are few baseline figures to compare the payback specifically for intermittent-use spaces. Tolat (2016) claims that in a laboratory space, occupancy sensors typically have a one-to-two-year payback. The payback period results for all space types is long in contrast to the expected one to two years as seen in other space types.

The shortest payback period on average is hallways at 8.6 years. The highest average payback period is 17.8 years for Stairwells. The best average payback is the hallways at 8.6 years, but the best individual space payback is one of the seminar rooms at 2.7 years. The payback periods are considered long as they are over one year and are closer to a decade or longer. Secondary spaces likely do not have such intensive lighting requirements as laboratories so can be expected to have longer payback periods. The NZBC states that the life of a building may not be less than 50 years (MBIE, 2019). The life span of an occupancy sensor depends on the product, though as per the NZBC they classify as building elements which must be at least five years, (NZBC clause B2 $2.3_{(\mathrm{C})}$ ). 
To comply with the NZBC occupancy sensors must be able to last at least five years, which is less than most payback periods of the 20 spaces in this research. Although an occupancy sensor may pay itself back within the building's required life span, the technology has no obligation to last as long.

\subsection{TIME OF DAY RESULTS}

The time-of-day results consider the percentage of time 'vacant and lights on' for each variable, as shown in Graph 24. The percentage energy saving potential of $37 \%$ for a hallway weekday is used here as an example.

\section{Weekday Vs Weekend Potential Energy Savings}

Graph 24 Weekday potential compared to Weekend potential.

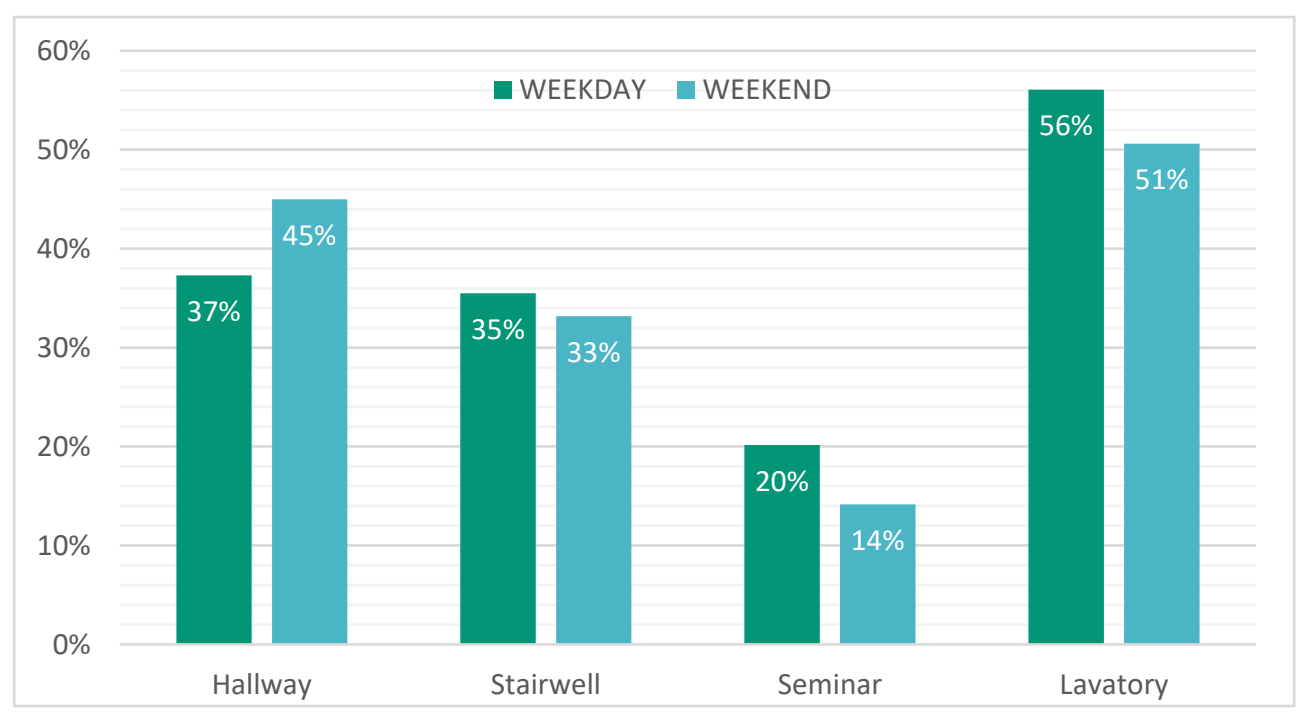

All spaces show greater potential energy savings over the weekdays except for hallways. The difference between weekday and weekend does not differ more than $8 \%$ for any space type. The potential energy savings for hallways increases by $8 \%$. Hallways are the exception as they increase in potential energy savings from $37 \%$ to $45 \%$, possibly due to less users over the weekend, but same light schedules. The other spaces decrease at the weekend implying a slight improvement to turn lights off over the weekend. The difference between weekday and weekend is only small, the largest difference is $8 \%$ increase of hallways, whereas the other spaces decrease by $6 \%$ or less. The behaviour of turning lights off at the end of the workweek is only very small if this is indeed the mentality driving the behaviour. 


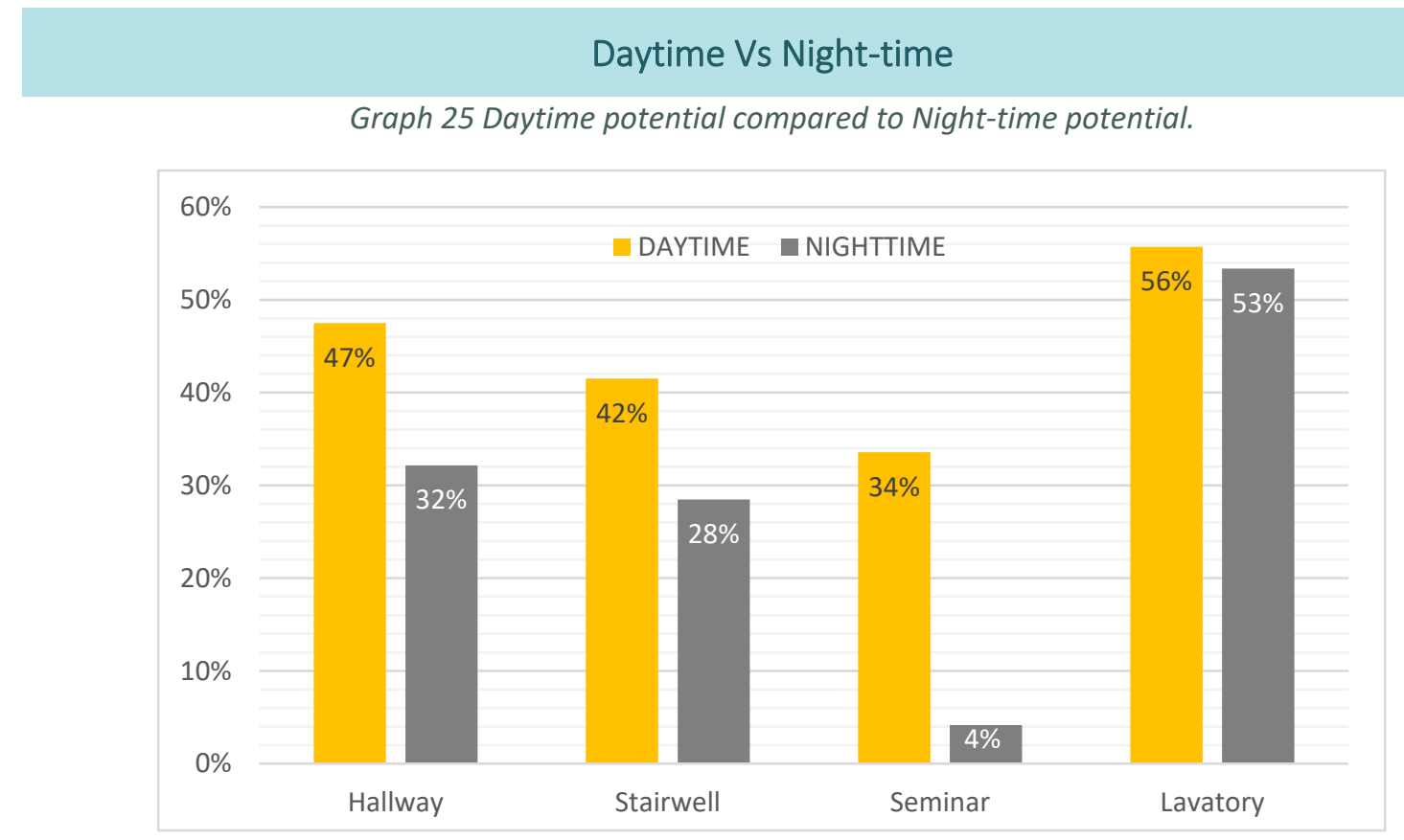

Daytime and night-time are based upon sunrise and sunset hours for each month.

All spaces show greater potential for energy savings during the daytime as results suggest that users are more competent at turning lights off at night-time. Seminar rooms are noticeably the best performing space at night-time with only $4 \%$ energy saving potential, suggesting that further energy savings can be achieved by changing light-switching behaviour. There is still much room for improvement at night with research suggesting there is considerable time when lights are unnecessarily left on. Night-time potential energy savings of the other space types measuring $32 \%$ for hallways, $28 \%$ for stairwells and $53 \%$ lavatories. Lavatories are the worst performing spaces as they have the highest energy saving potential during the daytime and with very little change at night-time. Hallways and stairwells show a similar decrease by about $14 \%$ from daytime to nighttime. 
Time of Day Results

Graph 26 Comparing the potential at different times of the day.

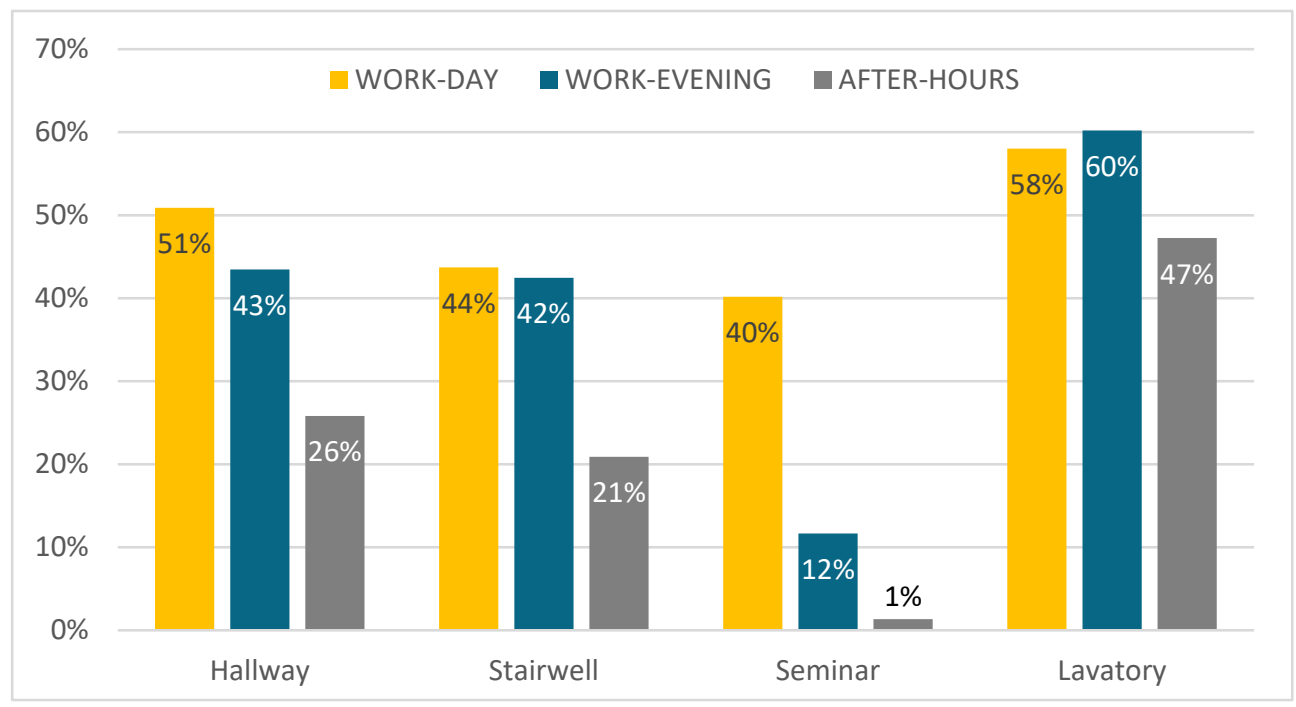

Workday matches regular VUW classroom schedules. Work-evening is from the end of the workday until close at $11 \mathrm{pm}$. After hours is the remaining time.

This graph elaborates upon the daytime and night-time split and considers the university timeline of workday, work-evening and after-hours. It is expected that the majority of users are at university during the workday, less during the work-evening and almost no users after hours. This comparison shows some similarities between hallways and stairwells, likely due to the similar transitional use. These two spaces decrease slightly from workday to work-evening to $43 \%$ and $42 \%$ respectively, followed by a larger decrease after hours to $26 \%$ and $21 \%$ respectively. Whereas the seminar room energy saving potential decreases from $40 \%$ during workday to $12 \%$ during work-evening and further decrease down to only $1 \%$ energy saving potential after-hours.

Lavatories are the least efficient but offer the largest energy saving potential across all three time periods. The lavatories are the only space to increase energy saving potential during the workevening which could be due similar light use as daytime but less users.

From workday to after-hours, seminar room energy saving potential decreases by $39 \%$, the most of any space. This is potentially due to efficient light switching behaviour around night-time and close. The Hallways and stairwells have a similar pattern but with less change. $1 \%$ is the lowest potential energy savings across all space types and all time periods. This suggests that there may be a general understanding of seminar room users that lights should be turned off at the end of the day and upon leaving, contrary to the other three space types, and typical use found in the literature review. 

Masters of Architectural Science

Georgia Alexander

Chapter 7 DISCUSSION 
This chapter provides various perspectives of the results provide an overarching view of the space types and the energy saving potential of each. The experimental results suggest occupancy sensors could make a positive impact to reduce energy and increase cost savings. Savings are positive, but it is important to also consider the value and worth of the situation.

Occupancy sensors in intermittent-use spaces as a monetary investment must be considered as a long-term investment. This payback period is one aspect that influences the judgment of the worth of occupancy sensors. Other aspects include, the type of lamp and retrofit versus new build. Alternative options explored included schedules and the potential for additional daylight savings by using daylight sensors. The imperfections of occupancy technology are reviewed regarding the results and how the industry adapts with the restriction.

Though the user survey did not proceed past the issues of the pilot test, the limited understandings and assumptions of the results are combined with the experiment results to discuss how the survey would have provided supplementary knowledge for future research.

\subsection{Potential ANd Actual SaVings}

This section discusses the primary influential factor driving the potential energy saving of these spaces. The most influential and least manipulative factor is user behaviour. It is likely that light switch position and other spatial factors such as furniture layout also play a small part.

This research investigates how successful occupancy sensors would be in intermittent-use spaces. The success of occupancy sensors in intermittent-use spaces is based on improving the existing light use behaviour with technology. This is a case of the 'most improved award', where the space that is most improved; or has the most energy saving potential is the space that currently performs the most inefficiently. Therefore, the space type with the worst energy savings behaviour, i.e. Lavatories, has the greatest energy saving potential use of occupancy sensors. The type of lamp and the quantity of light use will impact the actual energy saved, but the energy saving potential percentage remains the same. The light type and quantities in this experiment are the cause of the difference between the ranking of potential and the ranking of energy savings. 


\subsection{ECONOMIC AND ENERGY ANALYSIS}

Occupancy sensors can save energy and money, but are they worth it? The primary theme of this section is to assess the worth of occupancy sensors in intermittent-use spaces. The worth and effectiveness of occupancy sensors depends largely on the intent and perspective. Comparing the performance of some key categories: energy saving potential, annual energy saving, annual cost saving, and payback period to help form a judgement on which space type provides the best opportunity for occupancy sensors. The section first presents the best performing space type in each of the categories (Table 15) and then looks at the performance of all the space types (Table 16).

The experimental results of this research can provide some general recommendations for occupancy sensor use and which aspects they will benefit the most. The small sample of spaces from this experiment is used to make judgements about each average space type in each category. These recommendations are recommended for education buildings, for the intermittent use space types in this research and other similar space types that may match the criteria (section 3.4.1).

The categories are intended to provide an overall view of the performance of occupancy sensors in the space types. There may be different reasons for considering occupancy sensors. The categories provide an overview so judgement can be formed based upon their individual reasons or goals, be it energy savings, cost savings or otherwise.

All space type average results are provided in Table 16 to show the performance and ranking of each space type. The order ranking is simply based on the performance, and opportunity for energy savings, in each category. The overall ranking takes the category rankings and adds them together, the lowest result is the space type with the best performance in the categories spaces. This ranking assessment assumes equal value in the ranking, which is a valid comparison, but assumes the interested party is equally interested in all category benefits which will not always be the case. This assessment averages the cost saving per light fitting to allow a facilities manager or interested party the opportunity to count the number of fittings in a space and thereby estimate cost saving.

An example of the overall ranking calculation for hallways is $2^{\text {nd }}+2^{\text {nd }}+3^{\text {rd }}+1^{\text {st }}=8$. Compared to stairwells with $3^{\text {rd }}+4^{\text {th }}+2^{\text {nd }}+4^{\text {th }}=13$. The lower the total number, the better the overall ranking. Hallways and lavatories both totalled eight which was the lowest overall, hence, first equal. 
Table 15 Recommendations and Worth.

\begin{tabular}{|c|c|c|}
\hline Category & Best Ranked & Worth \\
\hline $\begin{array}{l}\text { Energy } \\
\text { Saving } \\
\text { Potential }\end{array}$ & $\begin{array}{l}\text { Average } \\
\text { Lavatories } \\
\text { at } 54 \% \text { potential } \\
\text { energy savings }\end{array}$ & $\begin{array}{l}\text { If the focus is to save energy, all space types will successfully } \\
\text { save energy with occupancy sensors, although lavatories and } \\
\text { hallways will save the most. These spaces were wasting light } \\
\text { close to half the length of the whole two-and-a-half-month } \\
\text { experiment. Stairwells should also be considered as they can } \\
\text { save } 35 \% \text { which is more than a third of the time. }\end{array}$ \\
\hline $\begin{array}{l}\text { Maximum } \\
\text { Energy } \\
\text { Savings }\end{array}$ & $\begin{array}{c}\text { Average } \\
\text { Seminar rooms } \\
\text { At } 482 \mathrm{kWh} \\
\text { annual savings }\end{array}$ & $\begin{array}{l}\text { The average seminar room from this experiment achieves the } \\
\text { highest energy savings annually. The higher number of light } \\
\text { fittings is the biggest factor influencing the higher energy } \\
\text { savings. } \\
\text { Results from this experiment suggest seminar rooms will } \\
\text { provide the greatest energy savings annually. Energy savings } \\
\text { are attributed to quantity of lights, therefore, other } \\
\text { intermittent use spaces with lots of lights may provide good } \\
\text { energy savings. }\end{array}$ \\
\hline $\begin{array}{l}\text { Maximum } \\
\text { Cost Saving }\end{array}$ & $\begin{array}{c}\text { Average } \\
\text { Seminar rooms } \\
\text { at } \$ 49.63 \text { annual } \\
\text { cost savings }\end{array}$ & $\begin{array}{l}\text { The annual cost savings are positive for each space. Seminar } \\
\text { rooms and hallways would be the best options for cost savings } \\
\text { but still have significant payback periods. } \\
\text { To achieve the highest cost savings with occupancy sensors in } \\
\text { intermittent use spaces, results imply that seminar rooms will } \\
\text { likely achieve the most cost savings. }\end{array}$ \\
\hline Payback & $\begin{array}{l}\text { Average } \\
\text { Hallways } \\
\text { at } 8.6 \text { years } \\
\text { payback. }\end{array}$ & $\begin{array}{l}\text { Hallways have the shortest payback period of } 8.6 \text { years which } \\
\text { is close to a decade. The payback is over a decade for three of } \\
\text { the spaces, getting closer to two decades for stairwells. } \\
\text { If the focus is energy savings with a quick payback period, } \\
\text { average hallway results imply that hallways would be the best } \\
\text { choice. }\end{array}$ \\
\hline
\end{tabular}

Table 16 Performance of Space Types.

\begin{tabular}{|c|c|c|c|c|c|c|c|c|}
\hline \multirow[b]{2}{*}{$\begin{array}{l}\text { Energy Saving Potential } \\
\text { (Vacant and Lights on) }\end{array}$} & \multicolumn{2}{|c|}{ Hallway } & \multicolumn{2}{|c|}{ Stairwell } & \multicolumn{2}{|c|}{ Seminar } & \multicolumn{2}{|c|}{ Lavatory } \\
\hline & $40 \%$ & 2nd & $35 \%$ & $3 r d$ & $18 \%$ & 4 th & $54 \%$ & 1st \\
\hline $\begin{array}{l}\text { Annual Energy Savings } \\
\text { (kWh) }\end{array}$ & 417 & 2nd & 223 & 4 th & 482 & 1st & 300 & $3 r d$ \\
\hline $\begin{array}{c}\text { Annual Cost Saving per } \\
\text { fitting (NZD) }\end{array}$ & $\$ 9.03$ & $3 r d$ & $\$ 15.22$ & 2nd & $\$ 6.79$ & 4 th & $\$ 15.47$ & 1st \\
\hline $\begin{array}{l}\text { Payback Period } \\
\text { (years) }\end{array}$ & 8.6 & $1 s t$ & 17.7 & 4 th & 12.6 & $2 n d$ & 16.5 & $3 r d$ \\
\hline Overall Ranking & \multicolumn{2}{|c|}{ 1st } & \multicolumn{2}{|c|}{$3 r d$} & \multicolumn{2}{|c|}{ 2nd } & \multicolumn{2}{|c|}{ 1st } \\
\hline
\end{tabular}


When occupancy sensors are being considered to improve efficient light use, it is important for the interested party to determine if there are factors more important than others. Such as cost savings or the payback period. Where there is one primary intention, the results in Table 15 provide the best average space type results for each category. Where two or more categories are deciding factors, Table 16 becomes more helpful as it provides an overview of all the space types. The following discussion and overall ranking assumes all four categories are of value.

Hallways and lavatories have the best overall ranking at first equal, though lavatories performed best in more categories. Hallway results show second best potential energy savings of $40 \%$ behind lavatories of $54 \%$, but second-best annual energy savings of $417 \mathrm{kWh}$ ahead of lavatories at $300 \mathrm{kWh}$ energy savings. Where hallways calculated annual cost saving per fitting of $\$ 9$, lavatories calculated about $\$ 15$, though the average hallway in this research had approximately five fittings compared to the average lavatory with two fittings. The difference could also be due to the difference of lamp types. A higher quantity of fittings in hallways compared to lavatories could arguably conclude hallways as the best potential space type for use of occupancy sensors. A similar comparison of the seminar rooms would consider the lowest annual cost saving per fitting of about $\$ 6.80$, but the highest average quantity of fittings of approximately eight fittings in this research. Seminar rooms measured the highest potential annual energy savings of $482 \mathrm{kWh}$ for second place, and stairwells third based on these rankings. Stairwells were the lowest performing of the space types, though did achieve reasonable annual cost saving per fitting of about $\$ 15$. However, with only one to two light fittings in a stairwell, the overall cost saving doesn't increase much compared to spaces with lots of light fittings like seminar rooms.

Victoria University of Wellington is working towards a more efficient, carbon neutral future and would likely be more focused on the achievable energy savings, the recommendation for this scenario would be seminar rooms first, then hallways and lavatories. Although stairwells had high energy saving potential of $35 \%$, with only one to two fittings, there is not as much opportunity for energy savings. Despite having the lowest energy saving potential, seminar rooms have the highest potential energy savings. It could be suggested to a facilities manager to simply install occupancy sensors in locations with many light fittings operating off a single switch rather than measuring energy waste.

Occupancy sensors have the potential to reduce lighting energy use in all the intermittent-use spaces investigated in the experiment, ranging from $54 \%$ to $18 \%$ potential energy savings. The categories discussed provide a range of areas for interested parties to assess and choose the most appropriate space types for their intentions. 
Occupancy sensors are expected to make a positive impact on intermittent use space types that match the criteria in this research. Retrofitted occupancy sensors can provide energy savings and cost savings but have a long and not financially attractive payback period.

\subsubsection{LAMP TYPES}

LEDs have become widely used within the last decade or so and are fast becoming favourites, but older light fittings are commonly used where lighting may not have been updated e.g. halogen or fluorescent lamps. Some light types such as fluorescent battens, halogen and incandescent are less energy efficient than LEDs, so would provide higher energy/cost savings if an occupancy sensor was introduced to the system.

Occupancy sensors are advantageous to all light types, and in most cases energy savings may be greater with older, less efficient lighting. A comparison of the light types using results from the experiment to predict performance, shows greater cost savings may result from the use of sensors with older less efficient fittings. Light fitting information was gathered from the VUW Te Aro Campus building for calculations, comparison results are shown in Graph 27.

Different light fittings used at VUW are used here as a representation of the different light types used in the building industry. The comparison uses lights achieving the same output of 2000 lumens per light fitting. The same cost saving calculation is used as in Graph 22. The average energy saving potential of hallways (40\%) is used to calculate the annual cost savings (see Graph 20 Percentage Potential Available Savings).

Graph 27 Comparison of Light Types Annual Cost Savings.

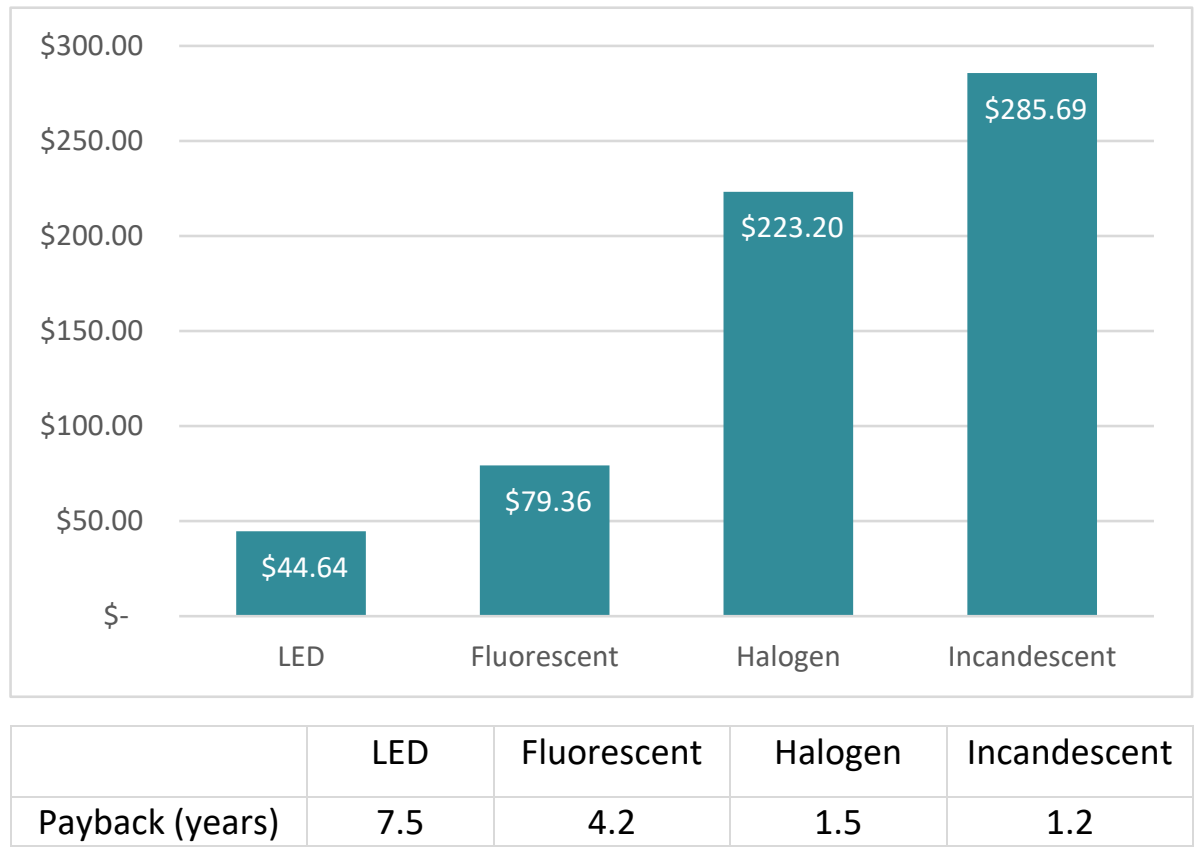


A comparison of common light types from the last two decades show significant differences and potential cost savings. Occupancy sensors are energy effective for efficient LED lighting but will save even more energy with less efficient fittings.

This is positive for buildings that don't use LED's as they will have greater cost and energy savings, and as a result a quicker payback. Incandescent fittings can achieve six times the cost savings than LEDs and the payback is six times quicker. This is a convenient solution where replacing all the light fittings is not a feasible option. Akrasakis and Tsikalakis (2018) performed an experiment in an education building corridor and found higher energy savings with T8 lamps and occupancy sensors, than changing to LED. The combination of LED and occupancy sensors will provide the greatest savings.

If a building is considering ways to save energy through lighting, two demonstrated successful options are to switch to LEDs and/or install occupancy sensors. If the existing light fittings are not at the end of their life, or if there isn't enough budget to change all the lights, occupancy sensors are a great solution to save energy. Additionally, LEDs could be retrofitted in the future to minimise energy use when lights are in use. The best of these two options depends on the quantity of lights and spaces. If there are lots of small spaces, the quantity of sensors increases. Alternately, if there are lots of lights over few spaces, occupancy sensors are a good option. Hence the widely accepted use of occupancy sensors in open plan spaces.

\subsubsection{Retrofit VS NeW BUILD}

This research measured the light use and motion performance of an existing building and, therefore, considers the cost of retrofitting existing light circuits. It is assumed that a new build would be able to integrate occupancy sensors in a more cost-efficient solution.

Installing occupancy sensors requires electrical work to connect the sensors to the circuits. Electrical work is required regardless of when the sensors may be installed, however, it would be more intrusive and less straightforward in an existing building. It may require searching for electrical plans or accessing the ceiling space to find circuit wires. In a new build, this could all be done at the time of light installation and is less intrusive. Regardless of retrofit or new build, each scenario would need to consider the planning for the placement of sensors. Alternately, occupancy integrated light fittings could be used as replacements over time. Noting that these fittings are more expensive than a replacement lamp. 


\subsubsection{SCHEDULES}

Building schedules, if used with suitable management and user specific knowledge can be an efficient way to reduce energy consumption. Efficient schedules often require tuning and adjustments as building spaces and occupants change over time. Lights could be set to turn off everywhere upon building lock up at the end of the day. This is not necessarily applicable for education buildings, as some tertiary institutes such as VUW do allow 24-hour access to postgraduate students and staff. Implementing schedules to control lighting would reduce some of the light energy waste at night, but not during the day where the biggest waste occurs.

Existing time of day, light use patterns could be improved with schedules and could save up to $26 \%$, $21 \%, 1 \%$ and $47 \%$ for hallways, stairwells, seminar rooms and lavatories respectively as seen in Graph 26 for work-evening and after-hours.

Schedules are easy to implement or refine in an already existing BMS but are less easy if lights are manually switched. Schedules are most effective for controlling lighting when they are based upon thorough observations, as no one wants the lights to turn off while they are still in a room working. Schedules can often require regular refinement due to changing occupant use, though in practice are often not refined and can end up wasting energy. Delgoshaei et al. (2017) set up a case study to investigate BMS schedules and lighting control without occupant access to light switches. Their work of a specific building found that the lighting schedule operated for more than two hours after the typical workday and occupants couldn't turn the lights off, the conclusion was that BMS schedules have the potential to compromise occupants ability to turn off lights when they are poorly tailored to the occupants. Schedules, much like the sensor time delay setting requires space observations and refinement for best use. In some instances, such as after-hours when spaces should be empty, schedules could provide better light energy use than occupant switching, however, they also allow for opportunities of energy wastage when users cannot turn the lights off if they try to. User controls are important for users to turn lights off if they need to. Schedules are likely not the best options in intermittent-use spaces where occupancy patterns are less predictable. Alternatively, occupancy sensors will turn the spaces off regardless of time and schedules, but based upon space use, minimising for unintended light use. 


\subsection{SENSOR TECHNOLOGY}

Results at a glance show the success of occupancy sensors as an energy savings method in intermittent use spaces. However, technology, like ourselves is imperfect, and cannot reasonably be expected to achieve $100 \%$ of the 'energy saving potential' dictated by the results. This section discusses the potential of the results, the impact of time-delay on the experiment results and the potential for daylight sensors.

The energy savings produced by the experiment in this research are always discussed as potential, assuming perfect performance with $100 \%$ efficient light use as controlled by the sensors. The experiment results do not account for time-delay or sensitivity settings, the impact of these can change on a case-by-case basis and there is no definite figure to determine how much they may affect the 'perfect' potential assumed by the experiment results. Industry research encourages finetuning of the time delay setting to minimise unnecessary energy waste (section 2.3), however, this is not often the reality in practice.

For example, consider the average lavatory results from the experiment with an energy saving potential of $54 \%$. It is correct that $54 \%$ of the time the lights are on while the space is vacant, it is misleading to claim that an occupancy sensor will resolve $54 \%$ of the wasted light use. Real life scenario could provide up to $54 \%$ savings, but time-delay negatively affects this energy saving potential and decreases the real-world scenario savings. Sensitivity settings if not set appropriately for the space use may under-detect small motions and cause false offs.

The difference between potential and actual energy savings is not explicitly known. This would be the difference of 'measured occupancy and light data' compared to 'measured performance of occupancy sensors' in the same spaces. This difference could be blamed upon time delay, but without comparing these the two types of measurements, it is not known if this difference is solely due to time delay or whether there are other aspects, such as sensitivity or space use. The following Time Delay section uses the measured occupancy and light data from the experiment and adds a time delay period to each instance of occupancy to see the impact time delay would cause, the results are shown in Table 17.

\subsubsection{TIME DeLAY}

As described in the definitions (page XIII), time delay is the amount of time between sensed vacancy and the light turning off. This time interval is in place to reduce the amount of false-offs while users are still present, but stationary for a period as discussed in section 2.3. The time interval restricts light use, perfectly aligning with occupant use. 
Time delay can be seen to restrict energy savings, but the purpose is to maintain user comfort. It is a built-in measure of all sensors to account for imperfect PIR technology. This has improved within the last decade allowing the time-delay periods to decrease. Originally these could be about 30minutes or more (Dilouie, 2017, Guo et al., 2010) and some codes and sustainability tools still recommend this duration as they have not been updated to keep up with advances in technology. Some research suggests time-delay periods of 20 to five minutes are possible, shorter periods especially with professional commissioning and sensitivity adjusting (Guo et al., 2009).

PIR data from the experiment can be arranged to count the duration of use in each space type, this information is graphed in Graph 28 and begins to give an indication of a possible time delay period for the space types. Graph 28 takes each instance of occupancy from the whole experiment for each space type and groups the instances by their duration of one minute to 10 minutes. For instance, across the whole experiment hallways were used approximately 10,000 instances for a period of two minutes. Graph 29 is part two of Graph 28 showing the remaining data for durations 11 to 60 minutes. The data is split across the two graphs for ease of reading against two different $y$ axis scales.

Graph 28 Duration of recorded occupancy periods. One to 10 minutes shown (part one).

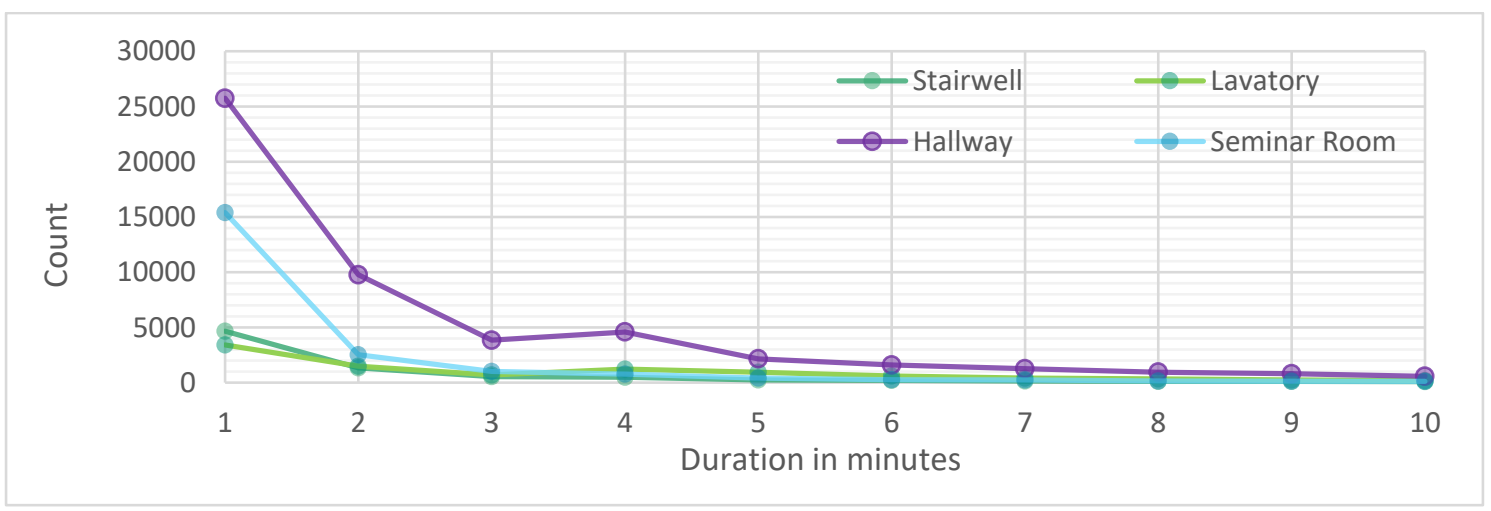

Graph 29 Duration of recorded occupancy periods. 11 to 60 minutes shown (part two).

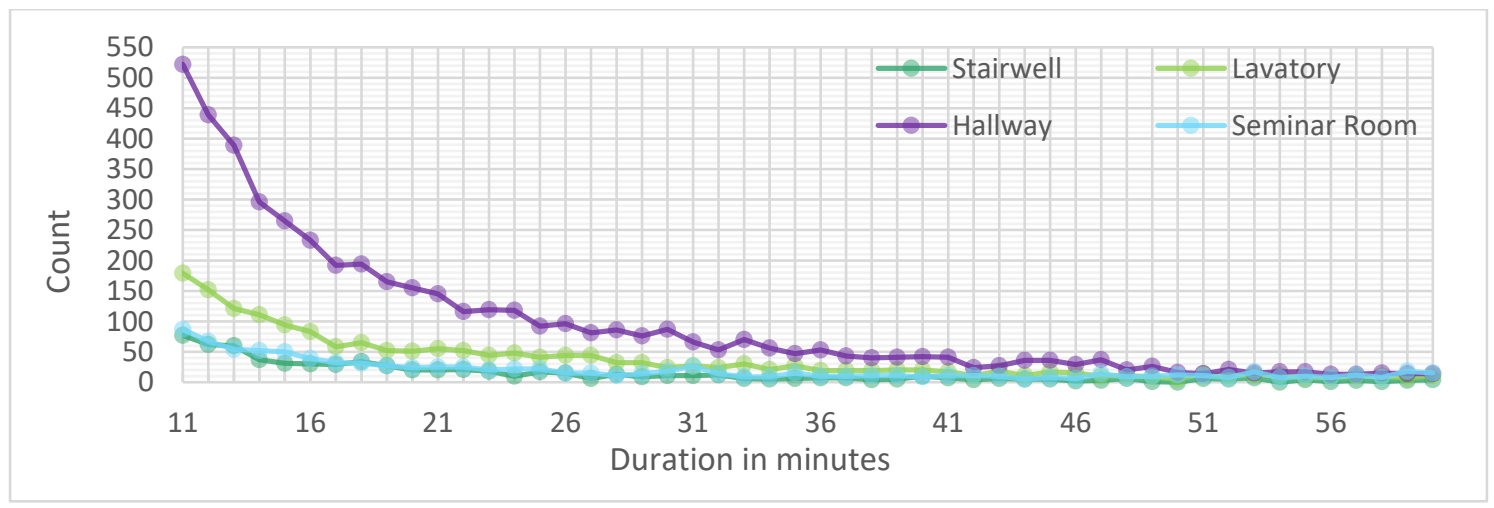


Graph 28 and Graph 29 shows the use durations for each space type, highlighting hallways as the space type used the most, for shorter durations. The majority of recorded instances of occupancy occur within a duration of one minute to four minutes. The most common duration for each space is one minute. This is expected of transitional spaces, hallways and stairwells, but somewhat surprising of seminar rooms. The one-minute period of lavatories could be due to cubicles obstructing the sensors, recording occupants upon entry, mirror/basin use and exit. Use periods of seminar rooms as noted in section 3.4 Space Detailed Descriptions were less specific due to varied use, five minutes to whole day. The broad space use description allowed for various activities within the space, although the most common use was thought to be tutorials and seminars which are approximately one hour to two hours long.

The surprising seminar room data prompted further review and a closer look at the data. Graph 30 shows a closer look at four hours of data from the $2^{\text {nd }}$ of August 2019, 9:00am to 1:00pm. This graph shows each instance of recorded occupancy as individual dots.

Graph 30 Instances of Occupancy in the space types. Data excerpt from 2/08/2019.

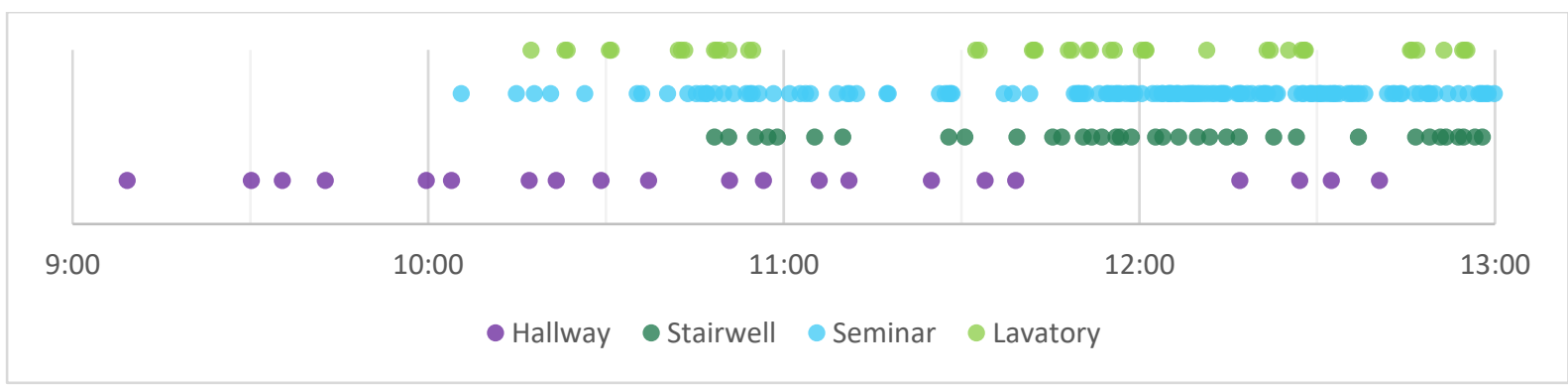

The seminar room pattern shows the most distinctive use across the four hours. 9:00am to 10:00am no one in the seminar room. 10:00am to 11:00am some occupants start to appear, particularly closer to the end of the hour. 11:00am to 12:00pm occupancy drops in the middle of the hour and increases again at the end of the hour. 12:00pm to $1: 00 \mathrm{pm}$ consistent occupancy suggesting a seminar in progress. As the graph implies, the quantity of blue dots between $12: 00 \mathrm{pm}$ and $1: 00 \mathrm{pm}$ suggests many occupants and/or constant occupancy. The sensors used in this experiment are set to time-out every 30 seconds (discussed in 3.1 Monitoring Equipment), so when triggered record a new instance of occupancy. This likely explains the high number of one-minute periods for seminar rooms in Graph 28 and explains why there were no durations representing the length of a seminar. Graph 28 and Graph 29 do not accurately represent the use of seminar rooms but the short durations of use of hallways, stairwells and lavatories align with the differences in expected use of the intermittent spaces. 
Hallways have the most intermittent use with occupancy sporadically across the whole four hours. The stairwells and lavatory use can see a slightly concentrated pattern of use preceding and, on the hour, likely between lectures or classes.

Due to the way the sensors in this experiment record occupancy, the data output does not provide enough information to form recommendations of time delay for seminar rooms. The sensor data for seminar rooms suggests that the sensors used in this experiment are not appropriate for long use spaces. Although seminar rooms were classified as intermittent use, but have long use periods unlike hallways, stairwells and lavatories, which is not accurately recorded by the sensors. For the purpose of measuring the length of use, these sensors are not ideal for space types of long use periods. However, these sensors can accurately measure occupant use for the purpose of detecting occupancy to turn on lights.

This duration data from the PIR sensors can be used to form time delay recommendations for hallways, stairwells and lavatories. Though the data can't help form time delay recommendations for seminar rooms, the data can confirm that a time-delay period of 30 seconds (the time-out setting) is too short in long-use spaces like seminar rooms.

The data from Graph 28 and Graph 29 is totalled within the space types and each duration is turned into a percentage of the total instances of occupancy per space type. The percentages for the first 10 durations are graphed in Graph 31 as a stacked column graph. This shows how much occupancy in the experiment is within these durations and leads to possible time delay recommendations.

Graph 31 The percentage of the 'duration of occupancy'.

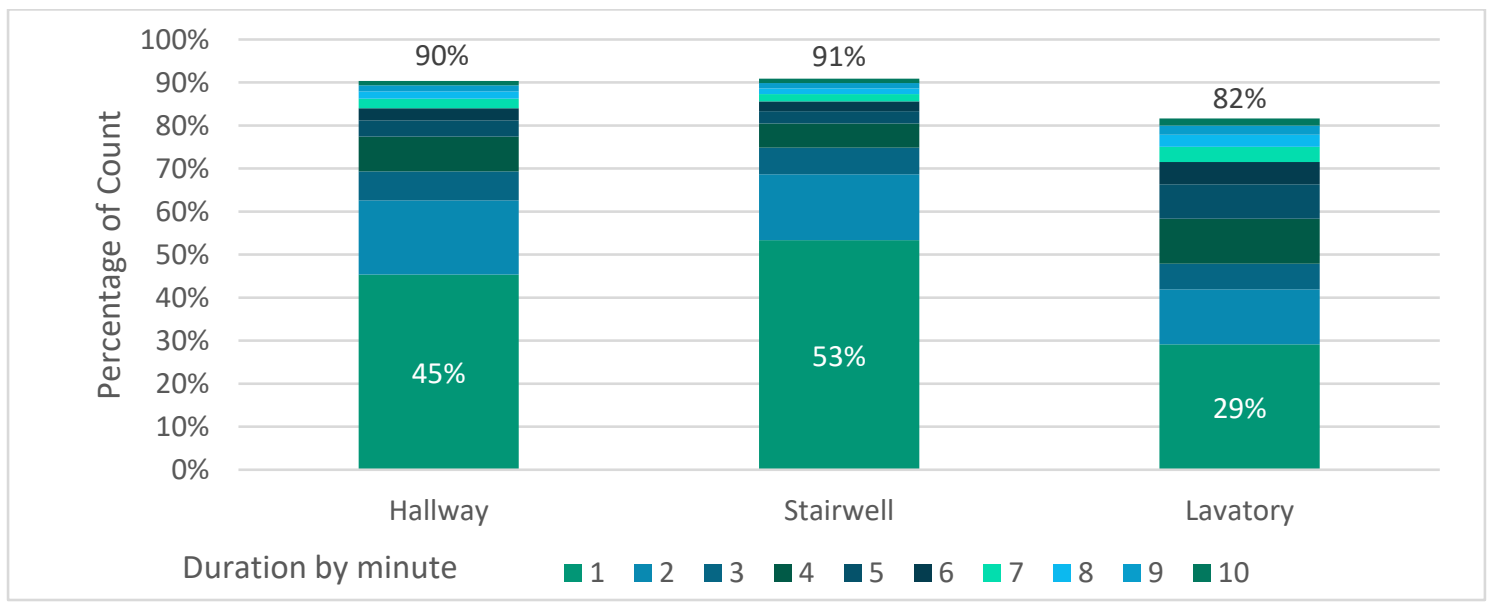

(Data: Table 28, Appendix 9.5.2)

There are two notable points from this graph, firstly, the large percentage that falls within one minute, and secondly, the large percentage that falls within 10 minutes. Nearly half of the measured instances of occupancy account for just one minute of space use for hallways and stairwells. 
One-minute use of lavatories is nearly one third of the measured instances of occupancy. A large percentage of these spaces is used for only one minute at a time. About $15 \%$ for each of these three space types is used for two minutes. Altogether, one-minute durations through to 10-minute durations form $90 \%, 91 \%$ and $82 \%$ respectively for hallways, stairwells and lavatories. Which means that these spaces could a use time-delay setting of 10 minutes and significantly reduce the potential for false off's when users are still in the space. The consequence of time delay period is the time between the shorter occupant use durations and the 10-minute time delay. Hallways and stairwells are used nearly half the time for one-minute periods, yet each time, the lights would remain on for a further 10 minutes after detecting vacancy. A shorter time period could be beneficial particularly for transitional spaces as the primary use is to transition through the space, an area for future work. Based upon the results from this experiment, a recommended time delay setting of 10 minutes for hallways and stairwells could cover $90 \%$ of occupant use. The other $10 \%$ of users occupying the space for longer than 10 minutes would simply trigger the lights again to stay on while they are still in the space.

According to the data, the recommended setting for lavatories would be 20 minutes to achieve $90 \%$ of occupant use. A higher time delay period for lavatories allows for cubicle use without lights turning off, when the sensor field of view is obstructed (if wall mounted). There is still potential for sensitivity settings to impact false offs, but the data from this research is not detailed enough to provide recommendations on sensor sensitivity.

A simple calculation added 10 minutes of light data after every instance of occupancy data to determine the possible impact of a 10 minute time delay in hallways and stairwells, the results are displayed in Table 17 for stairwells and hallways.

Table 17 Time Delay Calculation.

\begin{tabular}{|c|c|c|c|c|}
\hline & \multicolumn{2}{|c|}{ Stairwell two data } & \multicolumn{2}{|c|}{ Hallway one data } \\
\hline & $\begin{array}{l}\text { Experiment } \\
\text { results }\end{array}$ & $\begin{array}{l}\text { 10min time } \\
\text { delay results }\end{array}$ & $\begin{array}{l}\text { Experiment } \\
\text { results }\end{array}$ & $\begin{array}{l}\text { 10min time } \\
\text { delay results }\end{array}$ \\
\hline Vacant and lights on & $35 \%$ & $29 \%$ & $38 \%$ & $26 \%$ \\
\hline Vacant and lights off & $55 \%$ & $55 \%$ & $38 \%$ & $35 \%$ \\
\hline Occupied and lights on & $10 \%$ & $10 \%$ & $21 \%$ & $21 \%$ \\
\hline Occupied and lights off & $1 \%$ & $1 \%$ & $3 \%$ & $3 \%$ \\
\hline $\begin{array}{c}\text { Vacant and Lights on due } \\
\text { to Time Delay }\end{array}$ & $\mathrm{n} / \mathrm{a}$ & $6 \%$ & $\mathrm{n} / \mathrm{a}$ & $15 \%$ \\
\hline
\end{tabular}


The time of day results from this calculation show the percentage of time where spaces would be 'vacant and lights on' due to a 10 -minute time delay. The percentage is $15 \%$ for hallways and $6 \%$ for stairwells. Compared to the original data also shown in Table 17, the majority of the time delay percentage is taken from the category 'vacant and lights on' this is the amount of energy saving potential reduced due to time delay. For hallways, there is a decrease of 'vacant and lights off,' of $3 \%$ which forms $3 \%$ of 'vacant and lights on due to time delay'.

The time delay data shows reduced energy saving potential, suggesting that the time delay setting may reduce energy saving potential from raw sensor results. The calculation used two space types, one of each to provide results, which may not be representative of all their corresponding space types, or actual reality. This calculation only considered time delay and did not include other sensitivity or space use aspects as that data was not available to the detail the sensor measurements. Though the calculation provides a possible understanding and cause for the difference between 'measured occupancy and light data' and an actual occupancy sensor, it is an area to be investigated more thoroughly, particularly for the lavatories and seminar rooms also.

\subsubsection{DAYLIGHT}

Occupancy sensors were used solely for this research as the space types in focus were predominantly internal, however, all the seminar rooms had external windows and daylight sensors could possibly provide further savings. Daylight sensors require more consideration and space assessment (see

Daylight Sensors Section) than occupancy sensors. Some suggest using occupancy sensors need to be "combined with daylight controls to achieve maximal energy savings" (Bellia and Fragliasso, 2017, Rossi et al., 2015). Daylight sensors reduce/turn off the lights accordingly based upon daylight availability. The sensor types are able to work together the occupancy sensor determines the light requirements, and the daylight sensors adjust based upon available daylight.

Each of the seminar rooms in the experiment were no deeper than $8 \mathrm{~m}$ from the windows, so daylight sensors may be a feasible option in these spaces. As established in the previous Time Delay section the sensors used in the experiment were not appropriate to measure long periods of use, much like the expected use of seminar rooms. To determine the percentage of time of occupied seminar rooms during daylight hours, the seminar room booking schedules were used to measure the percentage of time that the seminar rooms were expected to be occupied. To then determine the percentage of time they were occupied during daylight hours. 
The room bookings are not necessarily accurate as individuals or groups may use seminar rooms outside the scheduled times. For the purpose of comparing daylight hours, they provide a better perspective of occupant use than the experiment PIR sensor data.

Percentage of time seminar rooms were occupied during daylight hours based upon the booking room booking schedule occupancy are shown in Graph 32. Daylight hours are based upon sunrise and sunset, this analysis does not consider what the weather conditions were, sunny or otherwise. Room booking data found in appendix 9.4.3.

Graph 32 Percentage of time seminar rooms were occupied during daylight hours.

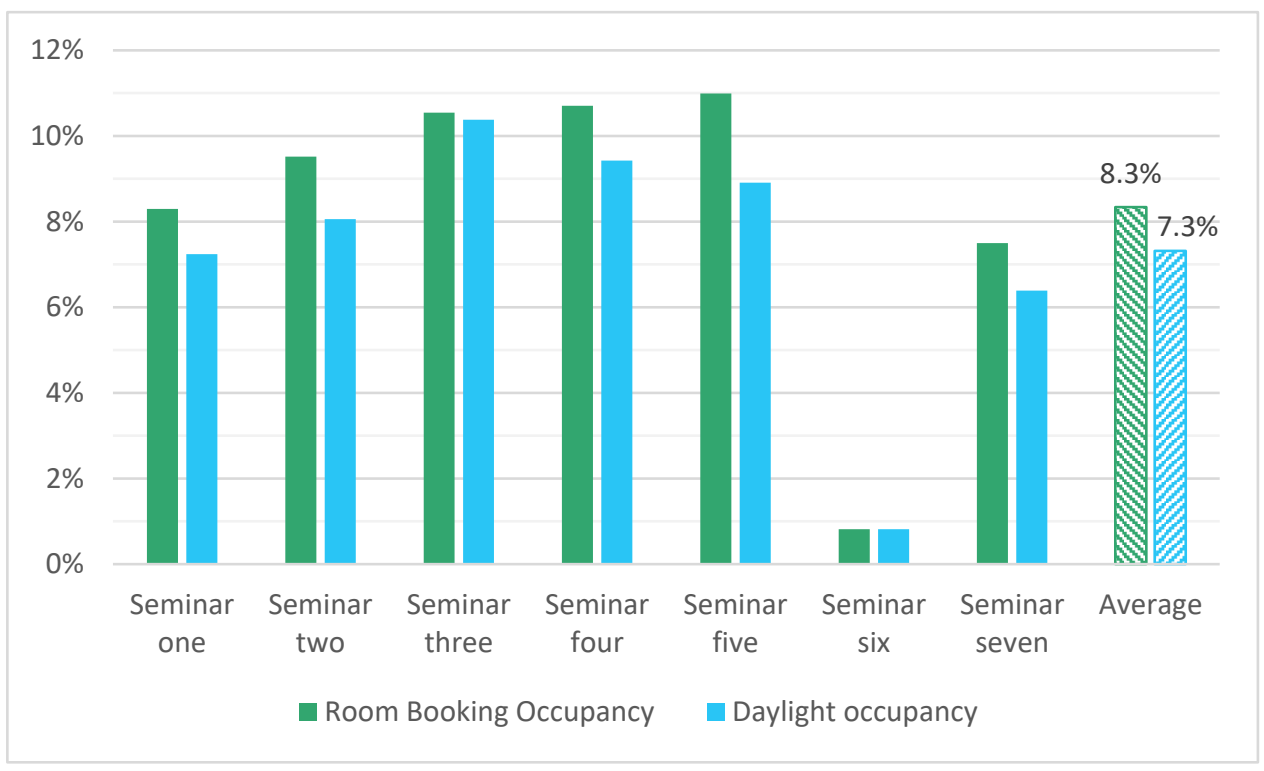

According to the room booking occupancy, seminar rooms are occupied about $8 \%$ of the time, about $7 \%$ of this is within daylight hours. The majority of time is within daylight hours and daylight sensors have the potential to provide additional energy savings on top of occupancy sensor potential energy savings. This calculation does not account for weather and assumes daylight all the time whereas in reality, the weather varies, reducing these figures further. Most of the seminar rooms would provide additional energy savings with a daylight sensor, particularly Seminar three as all but $0.2 \%$ of occupancy is within daylight hours. Seminar six has no difference between total occupancy and daylight occupancy, however, this seminar room has the lowest occupancy of less than $1 \%$. Seminar six is the only seminar room with north facing windows, and potential to receive direct sunlight for the majority of the day. The orientation of the windows in this seminar room may be a cause of the low occupancy, as direct sunlight can make a room glary and too hot. Seminar seven also has a few north facing windows and has the next lowest occupancy, possibly for the same reasons. 
North facing rooms can be prone to glare due to having too much direct light that may reflect into people's faces, computer screens, or projector screens, making it a difficult workspace when sunny. East or west facing rooms, like the other five seminar rooms can be more beneficial as they receive less direct sunlight and more indirect daylight which is more comfortable for working.

According to the results in Graph 32 using the room booking occupancy data, daylight sensors could be a beneficial opportunity to provide additional energy savings during occupancy and daylight hours. The average occupied daylight percentage of seminar rooms at $8.3 \%$ is lower than any of the 'vacant and lights on' percentages (Seminars lowest at $18 \%$ see section 6.2) and therefore, a daylight sensor would not be a primary recommendation. It is possible due to the limitations of the sensors that much of the 'vacant and lights on' time for seminar rooms may actually have been occupied and lights on. However, the high quantity of lights in seminar rooms compared to any other space type did provide the greatest annual energy savings $(\mathrm{kWh})$ despite the lowest energy saving potential (see Graph 21). Thus, daylight sensors could provide reasonable energy savings.

Some buildings and spaces can provide great energy savings from daylight sensors, but they require good access to natural daylight and minimal obstructions. When considering occupancy sensors and/or daylight sensors for energy saving purposes, consider the use of the space and the access to daylight. If the space is only intermittently used, it is likely that occupancy sensors will provide the most savings; where a daylight sensor may provide further additional savings, daylight dependent.

\subsection{SURVEY SIGNIFICANCE}

The significance of the survey is well phrased by Fontoynont (1999), "to acquire a good energy efficient performance in buildings, it is necessary to assure the comfort of users, without the comfort of users the solutions are not useful." Regardless of the outcome of the sensor experiment, user comfort is just as important as energy/cost savings. How would users feel upon exiting a seminar room to find a dark hallway. Awareness of occupancy sensors and how they control the lights would need to be spread to assure users. But, if a change in the lighting management would affect user comfort, it is worth considering how to best achieve energy savings and maintain user comfort. To consider the value of occupancy sensors in this context, the following iterative steps were used:

\begin{tabular}{l|l|l} 
Step 1 & Experiment results & $\begin{array}{l}\text { To determine whether hallways have good or bad } \\
\text { potential energy savings. }\end{array}$ \\
\hline Step 2 & Survey results & $\begin{array}{l}\text { To determine if dark or dimmed lighting affects the } \\
\text { users or not. }\end{array}$
\end{tabular}


Figure 17 Process of Combining results.

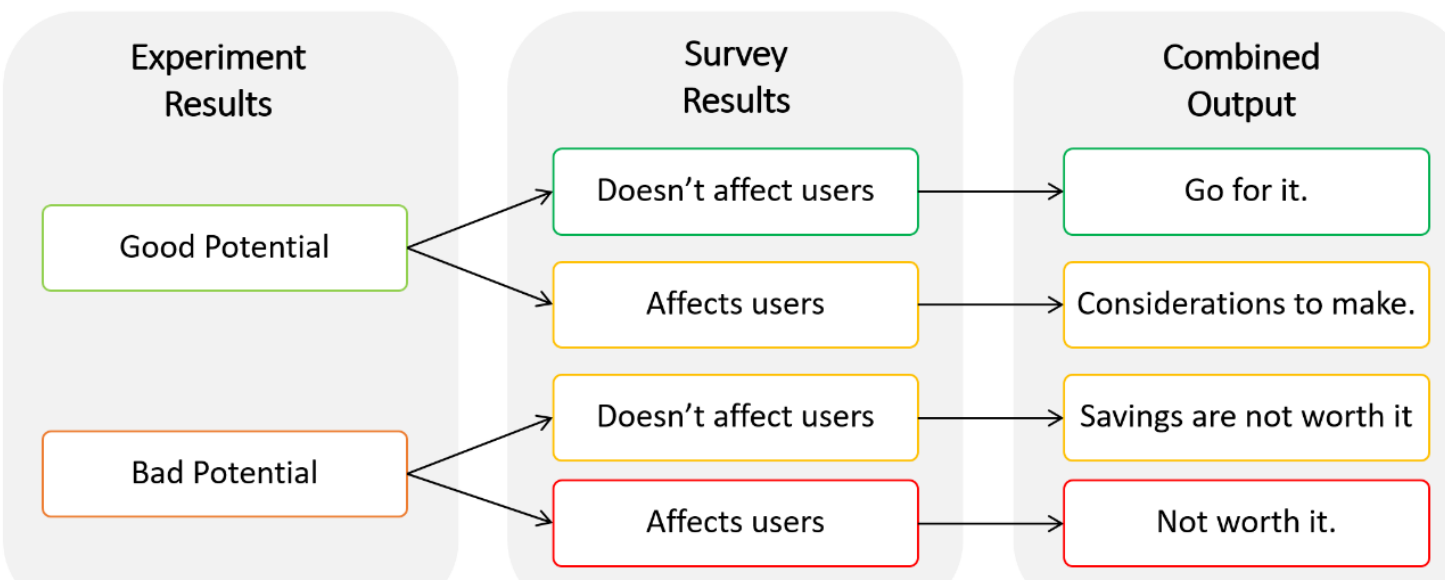

Considering these aspects together allows an assessment of the success or otherwise of occupancy sensors in hallways. The survey was designed as a preliminary measure and should be considered as a guidance for future work. The combined results are also preliminary. The potential outcomes had the survey worked, can be assessed on a simple traffic light scale as shown in Figure 17 Process of Combining results. Green, positive results, success for occupancy sensors in hallways. Orange, aspects to consider in more detail. Red, negative results for both survey and energy saving potential. This graphic shows the potential outputs and what this may have suggested for further work. To use the results of the experiment as an example, hallways on average had an energy saving potential of $40 \%$ and a payback of 8.6 years. Table 18 walks through the thought process of considering the combined results. 
Table 18 Combined result output example.

\begin{tabular}{|c|c|c|c|}
\hline $\begin{array}{l}\text { Experiment } \\
\text { Results }\end{array}$ & $\begin{array}{c}\text { Assumed } \\
\text { Survey Results }\end{array}$ & Determination & Output \\
\hline \multirow{2}{*}{$\begin{array}{l}40 \% \text { energy } \\
\text { savings: } \\
\text { Good } \\
\text { potential }\end{array}$} & $\begin{array}{c}\text { Doesn't affect } \\
\text { users }\end{array}$ & Go for it. & $\begin{array}{c}\text { There is good energy saving potential to } \\
\text { use occupancy sensors and survey results } \\
\text { show lighting can be changed in } \\
\text { transitional spaces without user } \\
\text { discomfort }\end{array}$ \\
\hline & Affects users & $\begin{array}{c}\text { Considerations } \\
\text { to make. }\end{array}$ & $\begin{array}{l}\text { The designers need to consider if the } \\
\text { energy savings are worth discomfort to } \\
\text { users and how this affects the client. }\end{array}$ \\
\hline \multirow{2}{*}{$\begin{array}{l}8.6 \text { years } \\
\text { payback: } \\
\text { Bad potential }\end{array}$} & $\begin{array}{c}\text { Doesn't affect } \\
\text { users }\end{array}$ & $\begin{array}{c}\text { Savings are not } \\
\text { worth it. }\end{array}$ & $\begin{array}{c}\text { Survey results suggest lighting can be } \\
\text { changed in transitional spaces without } \\
\text { negatively affecting user comfort, } \\
\text { however, the payback period is significant. }\end{array}$ \\
\hline & Affects users & Not worth it. & $\begin{array}{l}\text { User discomfort and significant payback } \\
\text { period suggests occupancy sensors are not } \\
\text { worth the cost or discomfort of users. }\end{array}$ \\
\hline
\end{tabular}

This research was not able to form any conclusions regarding the survey and thus it remains an area for future research alongside further experiments of occupancy sensors in intermittent-use spaces. Perhaps it is as simple as spreading awareness of occupancy sensors to reassure the users, perhaps more is required. These are the kinds of answers the survey would help to answer. 
Masters of Architectural Science

Georgia Alexander

Chapter 8 CONCLUSION 
Lighting is one of the largest energy consumption areas in the education sector at around one third of a buildings total energy use (EECA, 2010). This research has explored the widely discussed, but seldom executed, use of occupancy sensors in intermittent-use spaces as explained by Kinsley (1979). Occupancy sensors are not a new technology and have been used to reduce light use consumption for decades. However, their use has largely been allocated to open plan spaces, ignoring the potential use within intermittent-use spaces. These spaces are often fully illuminated while vacant for long periods. The idea and theory appear reasonable, yet there was no research to justify why the sensors are not more widely used in intermittent-use spaces.

Light use habits and energy saving behaviours were two themes discussed in the literature review section in an attempt to find a reason for occupant use of lighting controls in intermittent-use spaces. It was deduced that responsibility and habits were the probable causes. As explained by Bedwell et al. (2014) users are more likely to show energy saving behaviours at home where they are directly responsible. Users often have a lack of responsibility in intermittent-use spaces as they are public and hold no form of ownership or permanency for the users. Additionally, researchers found a close relationship between daily habits and light switching, rather than daylight accessibility. Yun et al. (2012) found three quarters of manual light switching to be within five minutes of arrival or departure in the office. This was common behaviour of users, but poor energy saving behaviour. Energy saving behaviour, much like occupancy sensors in intermittent-use spaces, is an accepted idea, with minimal research or implementation. The encouragement of energy saving behaviours has been successful in several researcher trials, each using different persuasive methods. There is no apparent consensus to which methods work best, but that BPS might be the best and most efficient solution to investigating which are most effective for the ability to simulate instances, rather than many real-world experiments. The problem with BPS is the imperfect nature of modelling occupancy which is often over simplified and doesn't account for the intricacies of human behaviour. This in turn leads us back to occupancy sensors, with technology which is known, trusted and based on realtime occupancy. Without trusting occupants to turn lights off, occupancy sensors are the next best option.

VUW buildings provided several intermittent-use spaces to test the effectiveness of occupancy sensors to turn lights off and reduce energy waste. Lighting is not for the benefit of the furniture, but for the users. Rather than implementing occupancy sensors, 20 PIR sensors and 20 light sensors were temporarily installed to monitor the occupancy and light use to determine the potential energy savings. A pair of sensors were distributed between 20 different intermittent-use spaces of four space types, hallways, stairwells, seminar rooms and lavatories. 
Results were used to calculate the percentage of time that lights were left on while spaces were vacant - this is the percentage of potential energy savings. Potential savings, energy savings, cost savings and payback periods were the four categories used to determine the worth of occupancy sensors in intermittent-use spaces. Lavatories measured the highest energy saving potential (54\%) and annual cost savings per fitting $(\$ 15.47)$, seminar rooms measured the highest annual energy savings ( $482 \mathrm{kWh}$ ) and hallways provided the quickest payback period (8.6 years).

Occupancy sensor settings such as time delay and sensitivity settings are designed to increase user comfort by minimising false offs. Consequently, there is a small period of time when users have left the space, but the lights remain turned on due to the time delay period. A simple calculation of the duration of use for each of the space types provided some perspective of potential time delay periods for the various space types. It was suggested that transitional spaces such as hallways and stairwells were able to account for $90 \%$ of occupant use periods with a time delay of 10 minutes. Lavatories required 20 minutes to achieve $90 \%$ of occupant use periods. Seminar rooms were excluded from this analysis as the sensors could not provide appropriate occupant data use for longuse spaces.

The measured potential energy savings from this experiment do not account for time delay and sensitivity settings which would reduce the energy saving potential by maintaining light longer than occupant use to minimise false offs. Due to the imperfections of occupancy sensors such as time delay settings designed to maintain user comfort; the potentials are not fully attainable with sensors. The calculation results in Table 17 suggest the expected actual performance of occupancy sensors in these spaces due to time delay, they would be less than the measured potential by about $6 \%$ and $12 \%$ for a stairwell and hallway.

The use of occupancy sensors was found to offer the potential for energy savings in all four intermittent-use space types. If energy savings are the primary intent, occupancy sensors will effectively achieve savings in these space types. If the intent is focused on cost savings and or short payback periods, the answer changes. Each of the four space types were ranked by the four measures of worth, Hallways and Lavatories were ranked first equal. The best space type of those two would be dependent on the intent. The results of this research experiment support the theoretical ideas and success of occupancy sensors in intermittent use spaces. This experiment focused on intermittent-use spaces within an educational building, but that is not to say that the results aren't reflective of intermittent-use spaces in other building types. The selected spaces were based upon a criteria (section 3.4.1), to an extent, these results could be representative of any intermittent-use spaces that match the criteria regardless of building type. 
To decide which space type has the most energy saving potential is subjective to current worst performance. Which in this case is the lavatories, however, lavatories alone are not the only answer. Due to user light switching behaviours of lavatories, they offered the highest potential. Hallways had the second highest potential, but additionally have on average more light fittings which provides high actual energy savings and high potential. Additionally, hallways had the lowest payback period. For these reasons, hallways are the best intermittent-use spaces to invest occupancy sensors.

A daylight analysis provided a perspective of the potential additional energy saving benefits from daylight sensors in seminar rooms. The analysis (section 7.3.2) found the majority of occupancy in seminars to occur within daylight hours, suggesting that there could be good potential for daylight sensors. They would be most beneficial in windowed spaces with high occupancy as they would help reduce light use when occupied if adequate daylight is present. The combination of occupancy sensors and daylight sensors have the potential to achieve more efficient light use than currently practiced by the users.

This experiment used a small sample of spaces at an educational institute to test the energy saving potential of occupancy sensors in intermittent-use spaces. The results suggest that there is potential for energy savings, supporting the use of them in intermittent-use spaces, especially hallways. The small sample of spaces and space types demonstrated energy saving results for occupancy sensors, but further work should be conducted to support the findings of this experiment.

\subsection{FUTURE WORK}

\section{REPEATED EXPERIMENTS TO MINIMISE ANOMALIES:}

The results produced in this experiment are considered reasonable and appropriate for educational institutes. Although all reasonable measures are taken to assure appropriate measurement and replicability of the experiment, it is understood that the results could be an anomaly due to the general culture of the institute or country. Many researchers suggested that intermittent use spaces could provide good energy savings, which supports the results of this experiment. However, additional experiments investigating the same question in different buildings, countries, or otherwise would provide supporting evidence to further support this work and the recommendations it provides. Seminar room data found discrepancies in the occupancy sensor measurements, which was deduced to be due to the long-term use of the seminar rooms. A repetition of this experiment in seminar rooms may require a different occupancy sensor. Additionally, a larger sample size of lavatories may provide opportunities to analyse the number of toilets, gender and staff or students. 


\section{TIME DELAY EXPERIMENTS FOR REFINEMENT AND SPECIFIC SPACE USE:}

The research found a number of technical questions lacking definitive answers which would have been beneficial to support the occupancy sensor technology discussed and used. Such as the difference between measured occupancy and measured light use versus the performance of an occupancy sensor it is. The time-delay setting of all occupancy sensors is a tuneable function which can be adjusted as necessary (though not often utilised). Many researchers suggest various periods for this setting, which firstly would be ideal to narrow down and secondly to quantify the impact of time delay and the amount of energy wasted. The results from Table 17 suggests the potential energy savings is reduced by $6 \%$ for a stairwell and $12 \%$ for a hallway. This calculation used a very small sample of spaces and only two space types. Future work could test all intermittent-use space types, and compare measured energy saving potential against actual energy saved potential with the installation of an occupancy sensor. Time delay could not be dismissed entirely as it is in place to maximise user comfort, however, it is often used too liberally where it could be better refined to occupant use and space type. These kinds of experiments could help to refine time delay and provide recommendations for different space types.

\section{USER PERCEPTION SURVEY:}

The user perception survey that could not continue would provide results that could influence the use of occupancy sensors in hallways. According to the results, occupancy sensors have good potential, but the effect on users is not known. A user survey investigating the perception of lights in hallways could either encourage or discourage occupancy sensor use. 



\section{BIBLIOGRAPHY}


2019. Wireless Sensor Tags [Online]. Irvine CA, USA: CAO Gadgets LLC. Available: https://wirelesstag.net/ [Accessed].

ADVANCE-ELECTRICAL. 25/10/2019 2019. RE: Advance Electrical Wholesalers Group Ltd.

AGHA-HOSSEIN, M. M., TETLOW, R. M., HADI, M., EL-JOUZI, S., ELMUALIM, A. A., ELLIS, J. \& WILLIAMS, M. 2015. Providing persuasive feedback through interactive posters to motivate energy-saving behaviours. Intelligent Buildings International, 7, 16-35.

AKRASAKIS, S. \& TSIKALAKIS, A. G. 2018. Corridor lighting retrofit based on occupancy and daylight sensors: implementation and energy savings compared to LED lighting. Advances in Building Energy Research, 12, 274-288.

BAIRD, G. 1995. Building Evaulation Techniques, United States, McGraw Hill.

BAIRD, G. \& THOMPSON, J. 2012. Lighting conditions in sustainable buildings: Results of a survey of users perceptions. Architectural Science Review, 55, 102-109.

BEDWELL, B., LEYGUE, C., GOULDEN, M., MCAULEY, D., COLLEY, J., FERGUSON, E., BANKS, N. \& SPENCE, A. 2014. Apportioning energy consumption in the workplace: a review of issues in using metering data to motivate staff to save energy. Technology Analysis \& Strategic Management, 26, 1196-1211.

BELLIA, L. \& FRAGLIASSO, F. 2017. New parameters to evaluate the capability of a daylight-linked control system in complementing daylight. Building and Environment, 123, 223-242.

BLEIL DE SOUZA, C. \& TUCKER, S. 2019. Guest Editorial: Special Issue on Building Performance Simulation and the User. Journal of Building Performance Simulation, 12, 243-245.

BORDASS, B., COHEN, R., STANDEVEN, M. \& LEAMAN, A. 2001. Assessing building performance in use 3: energy performance of the Probe buildings. Building Research \& Information, 29, 114128.

BREEAM 2019. BREEAM In-Use International Technical Manual. BRE Global Ltd.

CHUNG, T. M., BURNETT, J. 2001. On the prediction of lighting energy savings achieved by occupancy sensors. Energy Engineering: Journal of the Association of Energy Engineering, 98, 6-23.

DARBY, H., ELMUALIM, A., CLEMENTS-CROOME, D., YEARLEY, T. \& BOX, W. 2016. Influence of occupants' behaviour on energy and carbon emission reduction in a higher education building in the UK. Intelligent Buildings International, 8, 157-175.

DAVOODI, A., JOHANSSON, P. \& ARIES, M. 2020. The use of lighting simulation in the evidence-based design process: A case study approach using visual comfort analysis in offices. Building Simulation, 13, 141-153.

DE BAKKER, C., VAN DE VOORT, T. \& ROSEMANN, A. 2018. The energy saving potential of occupancybased lighting control strategies in open-plan offices: The influence of occupancy patterns. Energies, 11.

DELGOSHAEI, P., HEIDARINEJAD, M., XU, K., WENTZ, J. R., DELGOSHAEI, P. \& SREBRIC, J. 2017. Impacts of building operational schedules and occupants on the lighting energy consumption patterns of an office space. Building Simulation, 10, 447-458.

DILOUIE, C. 2017. Occupancy and Vacancy Sensors [Online]. Lighting Controls Association. Available: https://lightingcontrolsassociation.org/2017/08/21/all-about-occupancy-and-vacancysensors/ [Accessed].

DUBOIS, M. C. 2011. Energy saving potential and strategies for electric lighting in future North European, low energy office buildings: a Literature Review. Energy and Buildings, 43.

DUNLOP, T. 2019. Mind the gap: A social sciences review of energy efficiency. Energy Research and Social Science, 56.

EECA 2010. Saving energy in schools: lighting. In: EECA \& BUSINESS (eds.).

EECA. 2019. EECA Purpose [Online]. Available: https://www.eeca.govt.nz/ [Accessed 2019]. 
EECA, G. L. 2020. 3 Ways to avoid wasting light [Online]. Genless - EECA. Available: https://genless.govt.nz/businesses/efficient-energy-use/efficient-workplaces/lighting/ [Accessed 27/09/2020 2020].

EN-15193 2007. Energy Performance of buildings. Energy requirements for lighting. Technical Committee CEN/TC Light and Lighting DIN.

ENDREJAT, P. C., BAUMGARTEN, F. \& KAUFFELD, S. 2017. When Theory Meets Practice: Combining Lewin's Ideas about Change with Motivational Interviewing to Increase Energy-Saving Behaviours Within Organizations. Journal of Change Management, 17, 101-120.

ESTIDAMA 2010. The Pearl Rating System for Estidama Building Rating System Design and Construction. High Frequency Lighting. Abu Dhabi: Abu Dhabi Planning Council.

FERNANDES, L. L., LEE, E. S., DIBARTOLOMEO, D. L. \& MCNEIL, A. 2014. Monitored lighting energy savings from dimmable lighting controls in The New York Times Headquarters Building. Energy and Buildings, 68, 498-514.

FONTOYNONT, M. 1999. Daylight Performance of Buildings, London James \& James Science Publishers.

GALASIU, A. D., NEWSHAM, G. R., SUVAGAU, C. \& SANDER, D. M. 2007. Energy saving lighting control systems for open-plan offices: A field study. LEUKOS - Journal of Illuminating Engineering Society of North America, 4, 7-29.

GARDNER, G. \& STERN, P. 2002. Environmental Problems and Human Behavior, Second Edition.

GENESIS. 2020. Genesis Energy [Online]. Available:

https://www.genesisenergy.co.nz/business/electricity [Accessed].

GRAEBER, N. \& PAPAMICHAEL, K. 2011. Smart corridors light the way to energy efficiency: Managing the lighting in secondary spaces such as stairwells, lobbies and service rooms based on occupancy can carve a big chunk out of overall energy use. Lighting Design and Application: $L D$ and $A, 41,52-54$.

GREENSTAR 2017. GreenStar Technical Manual v3.2. New Zealand Green Building Council.

GUO, X., TILLER, D., HENZE, G. \& WATERS, C. 2010. The performance of occupancy-based lighting control systems: A review. Lighting Research \& Technology, 42, 415-431.

GUO, X. P., TILLER, D. K. D., HENZE, G. P. P. P. E. \& WATERS, C. E. P. P. E. 2009. Analytical Methods for Application to Sensor Networks for Lighting Control. Leukos, 5, 297-311.

HEBERT, P. R. \& CHANEY, S. 2012. Using end-user surveys to enhance facilities design and management. Facilities, 30, 458-471.

HEBERT, P. R., KANG, M. \& THOMPSEN, R. J. 2014. Energy saving via lighting study at US National Laboratories. Facilities, 32, 396-410.

JI, S. Y., KIM, M. K. \& JUN, H. J. Campus space management using a mobile bim-based augmented reality system. In: SCHNABEL, M. A., RAONIC, A., JANSSEN, P. \& LOH, P., eds. 22nd International Conference on Computer-Aided Architectural Design Research in Asia: Protocols, Flows and Glitches, CAADRIA 2017, 2017. The Association for Computer-Aided Architectural Design Research in Asia (CAADRIA), 105-114.

KINSLEY, J. R. 1979. Designing an energy-saving office tower. Electrical Construction \& Maintenance, 78.

KOLLMUSS, A. \& AGYEMAN, J. 2002. Mind the Gap: Why Do People Act Environmentally and What Are the Barriers to Pro-Environmental Behavior? Environmental Education Research, 8, 239260.

LEGRAND 2014. Lighting Management Sensors Design and Application Guide. Legrand Global Specialist in Electrical and Digital Building Infrastructures.

LI, J., YU, Z. J., HAGHIGHAT, F. \& ZHANG, G. 2019. Development and improvement of occupant behavior models towards realistic building performance simulation: A review. Sustainable Cities and Society, 50.

LINDELÖF, D. \& MOREL, N. 2006. A field investigation of the intermediate light switching by users. Energy and Buildings, 38, 790-801. 
MANZOOR, F., LINTON, D. \& LOUGHLIN, M. Occupancy Monitoring Using Passive RFID Technology for Efficient Building Lighting Control. 2012 Fourth International EURASIP Workshop on RFID Technology, 27-28 Sept. 2012 2012. 83-88.

MASOSO, O. T. \& GROBLER, L. 2010. The dark side of occupants' behaviour on building energy use. Energy and Buildings, 42, 173-177.

MATTERSON, M., L, G; FERRÀ, J, O; SALOM, J; PORTILLA, J, H. Dynamic Daylight Simulation And Visual Comfort Survey in Mediterranean Climate. Case Study in Office Building. COnference of international Building Performance Simulation Association, August 26-28 2013 Chambery, France.

MBIE 2019. NZBC B2 Durability. Ministry of business, Innovation and Employment.

MOORE, T., CARTER, D. J. \& SLATER, A. I. 2003. Long-term patterns of use of occupant controlled office lighting. Lighting Research \& Technology, 35, 43-57.

NIEHUS, T. 2004. Energy 101: Ten ways to reduce facility energy costs or what to look at first. Strategic Planning for Energy and the Environment, 24, 38-48.

NZS1680 2006. AS/NZS 1680.1 Interior and workplace lighting - General principles and recommendations. Standards New Zealand.

NZS4243.2 2007. Energy Efficiency - Large Buildings. Standards New Zealand.

O'SULLIVAN, P. E. \& VAUGHAN, N. D. LOW ENERGY HOUSES: PEOPLE AND PERFORMANCE. Colloquium on Electricity's Role in Low Energy Living., 1987 London, Engl. IEE, 5. 1-5. 4.

PAPAMICHAEL, K. Adaptive lighting for energy-efficient comfort and wellbeing. SID Symposium, Seminar, and Exhibition 2017, Display Week 2017, 2017. Blackwell Publishing Ltd, 306-309.

PATHAK, P. M., DONGRE, A. R. \& SHIWALKAR, J. P. 2015. Lighting design as a function of user comfort and performance in Indian work spaces. Journal of Architectural and Planning Research, 32, 168-180.

PEMSEL, S., WIDÉN, K. AND HANSSON, B. 2010. Managing the needs of end-users in the design and delivery of constuction projects. . Facilities, 28.

REINHART, C. F. \& VOSS, K. 2003. Monitoring manual control of electric lighting and blinds. Lighting Research \& Technology, 35, 243-258.

RICHMAN, E., DITTMER, A. \& KELLER, J. 2013. Field Analysis of Occupancy Sensor Operation: Parameters Affecting Lighting Energy Savings. Journal of the Illuminating Engineering Society, 25.

RICHMAN, E. E., DITTMER, A. L. \& KELLER, J. M. 1996. Field Analysis of Occupancy Sensor Operation: Parameters Affecting Lighting Energy Savings. Journal of the Illuminating Engineering Society, 25, 83-92.

ROISIN, B., BODART, M., DENEYER, A. \& D'HERDT, P. 2008. Lighting energy savings in offices using different control systems and their real consumption. Energy and Buildings, 40, 514-523.

ROSSI, M., PANDHARIPANDE, A., CAICEDO, D., SCHENATO, L. \& CENEDESE, A. 2015. Personal lighting control with occupancy and daylight adaptation. Energy and Buildings, 105, 263-272.

RUBINSTEIN, F. \& ENSCOE, A. 2010. Saving energy with highly-controlled lighting in an open-plan office. LEUKOS - Journal of Illuminating Engineering Society of North America, 7, 21-36.

SCHNEIDERELECTRIC. 2016. ULIS and Schneider Electric unveil new Advanced Occupancy Sensors [Online]. Available: https://www.se.com/ww/en/ [Accessed].

STADDON, S. C., CYCIL, C., GOULDEN, M., LEYGUE, C. \& SPENCE, A. 2016. Intervening to change behaviour and save energy in the workplace: A systematic review of available evidence. Energy Research and Social Science, 17, 30-51.

STANDARDSNZ 2008. AS/NZS1680.2.1:2008 Interior and workplace lighting Specific appliccations Circulation spaces and other general areas.

SU, K. 2016. The Lorax.

TAYLOR, J., LIU, Y., LIN, B., BURMAN, E., HONG, S.-M., YU, J., WANG, Z., MUMOVIC, D., SHRUBSOLE, C., VERMEER, D. \& DAVIES, M. 2018. Towards a framework to evaluate the 'total' 
performance of buildings. Building Services Engineering Research and Technology, 39, 609631.

TETLOW, R. M., BEAMAN, C. P., ELMUALIM, A. A. \& COULING, K. 2014. Simple prompts reduce inadvertent energy consumption from lighting in office buildings. Building and Environment, 81, 234-242.

TIME\&DATE. 2019. Available: https://www.timeanddate.com/sun/newzealand/wellington?month $=9$ \&year $=2019$ [Accessed 2019].

TOLAT, D. W. A. D. 2016. Sustainable Laboratory Design. 08-19-2016 ed.: Whole Building Design Guide.

ULUÇAY, N. Ö. 2019. An interior design exhibition: An assessment of color scheme preferences and the emotional states of students. Color Research and Application, 44, 132-138.

VALIBEIGI, M., GHORBANI, F. \& JAHANMEHMANI, R. 2018. Perceived Environmental Response Mechanism in Tehran Public Spaces. Social Indicators Research.

VONNEIDA B., M. D., TWEED A. 2000. An analysis of the energy and cost savings potential of occupancy sensors for commercial lighting systems. IES, 43.

WANG, X., TJALKENS, T. \& LINNARTZ, J. P. Smart office lighting control using occupancy sensors. In: GUERRIERI, A., FORTINO, G., VASILAKOS, A. V., ZHOU, M., LUKSZO, Z., PALAU, C., LIOTTA, A., VINCI, A., BASILE, F. \& FANTI, M. P., eds. 14th IEEE International Conference on Networking, Sensing and Control, ICNSC 2017, 2017. Institute of Electrical and Electronics Engineers Inc., 453-458.

WANG, Z., HONG, T. \& JIA, R. 2019. Buildings.Occupants: a Modelica package for modelling occupant behaviour in buildings. Journal of Building Performance Simulation, 12, 433-444.

WELL 2019. WELL Certification Guidebook. International WELL Building Institute. California.

WILKES, A. 2019. In: ALEXANDER, G. (ed.).

WILLIAMS, A., ATKINSON, B., GARBESI, K., PAGE, E. \& RUBINSTEIN, F. 2012. Lighting controls in commercial buildings. LEUKOS - Journal of Illuminating Engineering Society of North America, 8, 161-180.

XU, Y., STOJANOVIC, N., STOJANOVIC, L., ANICIC, D. \& STUDER, R. 2011. An approach for more efficient energy consumption based on real-time situational awareness. 8th Extended Semantic Web Conference, ESWC 2011. Heraklion, Crete.

YAN, D., HONG, T., DONG, B., MAHDAVI, A., D'OCA, S., GAETANI, I. \& FENG, X. 2017. IEA EBC Annex 66: Definition and simulation of occupant behavior in buildings. Energy and Buildings, 156, 258-270.

YUN, G. Y., KIM, H. \& KIM, J. T. 2012. Effects of occupancy and lighting use patterns on lighting energy consumption. Energy and Buildings, 46, 152-158. 



\subsection{PILOt DetaILS AND PLANS}

Table 19 Pilot Space Details

\begin{tabular}{|c|c|c|c|c|c|}
\hline Space & Light Description & $\begin{array}{c}\# \\
\text { Fittings }\end{array}$ & Wattage & $\begin{array}{l}\text { Window } \\
\text { Orientation }\end{array}$ & Sensor Location \\
\hline \multirow{2}{*}{$\begin{array}{l}\text { Hallway } 1.1 \\
\quad(2.44)\end{array}$} & $\begin{array}{l}\text { Single } 1500 \\
\text { fluorescent }\end{array}$ & 6 & 18 & $N / a$ & \multirow{4}{*}{$\begin{array}{l}\text { PIR mid-height beside } \\
\text { doorway. Light sensor } \\
\text { high on the wall near } \\
\text { light } \\
\text { PIR mid-height between } \\
\text { wall art. Light sensor on } \\
\text { top of cable tray facing } \\
\text { lights. }\end{array}$} \\
\hline & $\begin{array}{l}\text { Single } 1500 \\
\text { fluorescent }\end{array}$ & 1 & 58 & $N / a$ & \\
\hline \multirow{2}{*}{$\begin{array}{l}\text { Hallway } 1.2 \\
\quad(2.44)\end{array}$} & $\begin{array}{l}\text { Phillips Compact } \\
\text { Fluorescent }\end{array}$ & 1 & 18 & $N / a$ & \\
\hline & Phillips halogen & 2 & 120 & $N / a$ & \\
\hline $\begin{array}{c}\text { Hallway } 2 \\
(2.45)\end{array}$ & $\begin{array}{l}\text { Single batten } 1500 \\
\text { fluorescent }\end{array}$ & 2 & 58 & $N / a$ & $\begin{array}{l}\text { PIR above doorway. Light } \\
\text { sensor on light fitting. }\end{array}$ \\
\hline $\begin{array}{l}\text { Hallway } 3.1 \\
\quad(5.55)\end{array}$ & Round LED Tridonic & 8 & 13.3 & $N / a$ & $\begin{array}{l}\text { PIR mid-height above } \\
\text { light switch on the wall. } \\
\text { Light sensor within the } \\
\text { light fitting. }\end{array}$ \\
\hline $\begin{array}{l}\text { Hallway } 3.2 \\
\quad(5.55)\end{array}$ & LED Rectangle & 1 & 18 & $N / a$ & $\begin{array}{l}\text { PIR mid-height above } \\
\text { light switch on the wall. } \\
\text { Light sensor directly on } \\
\text { the light. }\end{array}$ \\
\hline $\begin{array}{l}\text { Stairwell } 1 \\
(2.71)\end{array}$ & $\begin{array}{l}\text { Single batten } 1500 \\
\text { fluorescent }\end{array}$ & 1 & 58 & $N / a$ & $\begin{array}{l}\text { PIR at mid-height on the } \\
\text { wall. Light switch same } \\
\text { location but high on the } \\
\text { wall close to ceiling. }\end{array}$ \\
\hline $\begin{array}{c}\text { Stairwell } 2 \\
(3.72)\end{array}$ & $\begin{array}{l}\text { x2 Fluorescent } \\
\text { battens with case }\end{array}$ & 1 & 58 & $N / a$ & $\begin{array}{l}\text { PIR near entry to } \\
\text { stairwell, mid-height on } \\
\text { wall. Light sensor directly } \\
\text { on the light. }\end{array}$ \\
\hline $\begin{array}{l}\text { Stairwell } \\
\text { three } \\
(4.72)\end{array}$ & $\begin{array}{l}\text { x2 Fluorescent } \\
\text { battens with case }\end{array}$ & 1 & 58 & $N / a$ & $\begin{array}{l}\text { PIR facing the two } \\
\text { staircases, mid height on } \\
\text { wall. Light sensor on } \\
\text { underside of level above } \\
\text { close to the ceiling. }\end{array}$ \\
\hline $\begin{array}{l}\text { Seminar } \\
\text { one } \\
(2.05)\end{array}$ & $\begin{array}{l}\text { Single batten } 1500 \\
\text { fluorescent }\end{array}$ & 3 & 58 & North & $\begin{array}{l}\text { PIR mid-height above } \\
\text { kitchenette near } \\
\text { doorway. Light sensor on } \\
\text { top of water heater near } \\
\text { light fittings. }\end{array}$ \\
\hline $\begin{array}{l}\text { Seminar } \\
\text { two } \\
(2.36)\end{array}$ & $\begin{array}{l}\text { Fluorescent Phillips } \\
\text { TLD batten } 1500\end{array}$ & 15 & 58 & West & $\begin{array}{l}\text { PIR near light switches, } \\
\text { mid-height on wall near } \\
\text { entry. Light sensor on } \\
\text { top of cable tray near } \\
\text { light fittings. }\end{array}$ \\
\hline
\end{tabular}


Table 20 Pilot Study Plans and Sensor Locations.
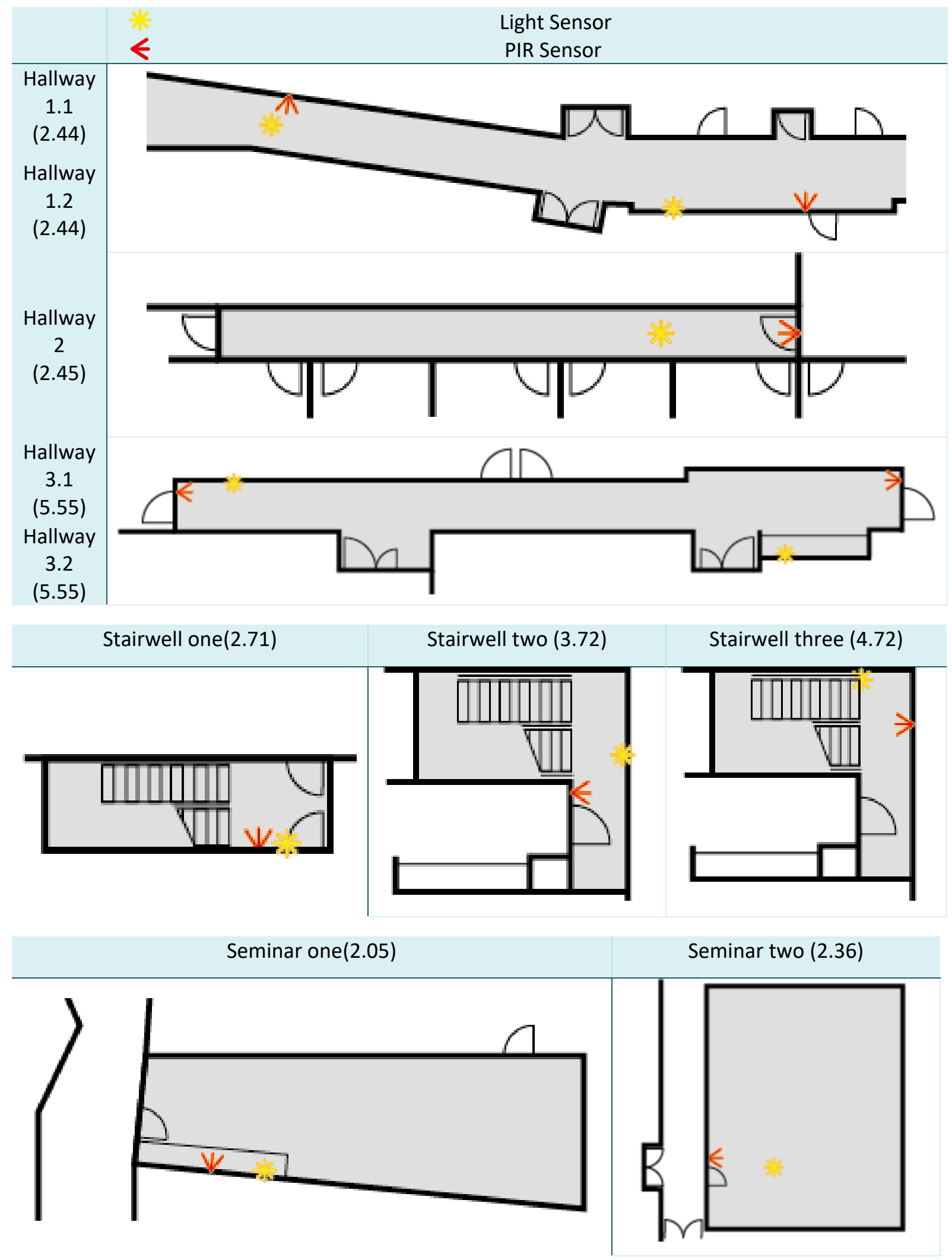


\subsection{Space Observational Survey Detalls}

\begin{tabular}{|c|c|c|c|c|c|c|}
\hline Space type & Tower & $\begin{array}{l}\text { Light } \\
\text { Count }\end{array}$ & Light type & $\begin{array}{c}\text { Window } \\
\text { Orientation }\end{array}$ & $\begin{array}{l}\text { Dead } \\
\text { End }\end{array}$ & Comments/Amenities/Behaviours \\
\hline Hallway 254 & North & 6 & LED Square troffers $600 \times 600$ & $\mathrm{~N} / \mathrm{a}$ & No & Another hallway crossing it mid-way. Offices, lavatories, stairwell. \\
\hline Hallway 357 & South & 3 & LED Square troffers $600 \times 600$ & $\mathrm{~N} / \mathrm{a}$ & Yes & Rubbish Bin. Seminar rooms and office. \\
\hline Hallway 457 & South & 4 & LED Square troffers $600 \times 600$ & $\mathrm{~N} / \mathrm{a}$ & No & Door to another building at one end. Seminar rooms. \\
\hline Hallway 554 & North & 4 & LED Square troffers $600 \times 600$ & $\mathrm{~N} / \mathrm{a}$ & No & To Offices. Seminar, offices, lifts, route to lavatories and stairwell. \\
\hline Hallway 555 & North & 6 & LED Square troffers $600 \times 600$ & $\mathrm{~N} / \mathrm{a}$ & No & L-shaped. Offices, kitchenette, lavatories, stairwell. \\
\hline Hallway 556 & South & 4 & LED Long single battens & $\mathrm{N} / \mathrm{a}$ & Yes & Couches, perhaps less of a hallway, more of a break-out space. Seminar rooms and offices. \\
\hline Hallway 659 & South & 7 & LED Long single battens & West & Yes & Not rectangular. Has bar window to kitchenette. Offices, seminar rooms, lavatories kitchen. \\
\hline Seminar 103 & North & 18 & LED Recessed panels in rows & $\mathrm{N} / \mathrm{a}$ & Yes & Occupancy: 20. \\
\hline Seminar 301 & South & 8 & LED Long single battens & East & Yes & Occupancy: 28. \\
\hline Seminar 303 & South & 4 & LED Long single battens & East & Yes & Occupancy: 16. Two doors into space. \\
\hline Seminar 401 & South & 4 & LED Long single battens & East & Yes & Occupancy: 18. \\
\hline Seminar 402 & South & 4 & LED Long single battens & East & Yes & Occupancy: 16. Two doors into space. \\
\hline Seminar 403 & South & 4 & LED Long single battens & West & Yes & Occupancy: 20 \\
\hline Seminar 404 & South & 4 & LED Long single battens & West & Yes & Occupancy: 18. \\
\hline Seminar 631 & South & 11 & LED Long single battens & North and East & No & Occupancy: 24 . Particularly high ceilings. \\
\hline Seminar $632 a$ & South & 16 & Recessed double battens + reflectors & East (and South) & No & Occupancy: 30 . Particularly high ceilings. \\
\hline Seminar $632 b$ & South & 16 & Recessed double battens + reflectors & East and South & No & Occupancy: 20 . Particularly high ceilings. \\
\hline Seminar 617 & North & 8 & LED Long single battens & North & No & Occupancy: 16. Two doors into space. \\
\hline Stairwell 183 & North & 1 & LED Long single battens & $\mathrm{N} / \mathrm{a}$ & No & Straight staircase. Cleaners, lavatory. \\
\hline Stairwell 272 & North & 1 & LED Long single battens & $\mathrm{N} / \mathrm{a}$ & No & Straight staircase. Cleaners, lavatory. \\
\hline Stairwell 273 & South & 2 & LED Twin panel & $\mathrm{N} / \mathrm{a}$ & No & Double staircase, U shape. Mostly closed room. \\
\hline Stairwell 372 & North & 1 & LED Long single battens & $\mathrm{N} / \mathrm{a}$ & No & Double staircase, U shape. Cleaners, lavatory. \\
\hline Stairwell 672 & North & 1 & LED Long single battens & $\mathrm{N} / \mathrm{a}$ & No & Straight staircase. Cleaners, lavatory. \\
\hline Lavatory 151 & North & 2 & LED Long single battens & $\mathrm{N} / \mathrm{a}$ & Yes & Baby change table and shower cubicle. Shower and Lavatory cubicles. \\
\hline Lavatory 251 & North & 2 & LED Long single battens & $\mathrm{N} / \mathrm{a}$ & Yes & four cubicles. \\
\hline Lavatory 252 & North & 2 & LED Long Single Battens & $\mathrm{N} / \mathrm{a}$ & Yes & two cubicles. \\
\hline Lavatory 351 & North & 2 & LED Square troffers $600 \times 600$ & $\mathrm{~N} / \mathrm{a}$ & Yes & one cubicle. \\
\hline Lavatory 352 & North & 2 & LED Square troffers $600 \times 600$ & $\mathrm{~N} / \mathrm{a}$ & Yes & two cubicles. \\
\hline
\end{tabular}


This page has been deliberately left blank. 


\subsection{EXPERIMENT PLANS AND IMAGES}

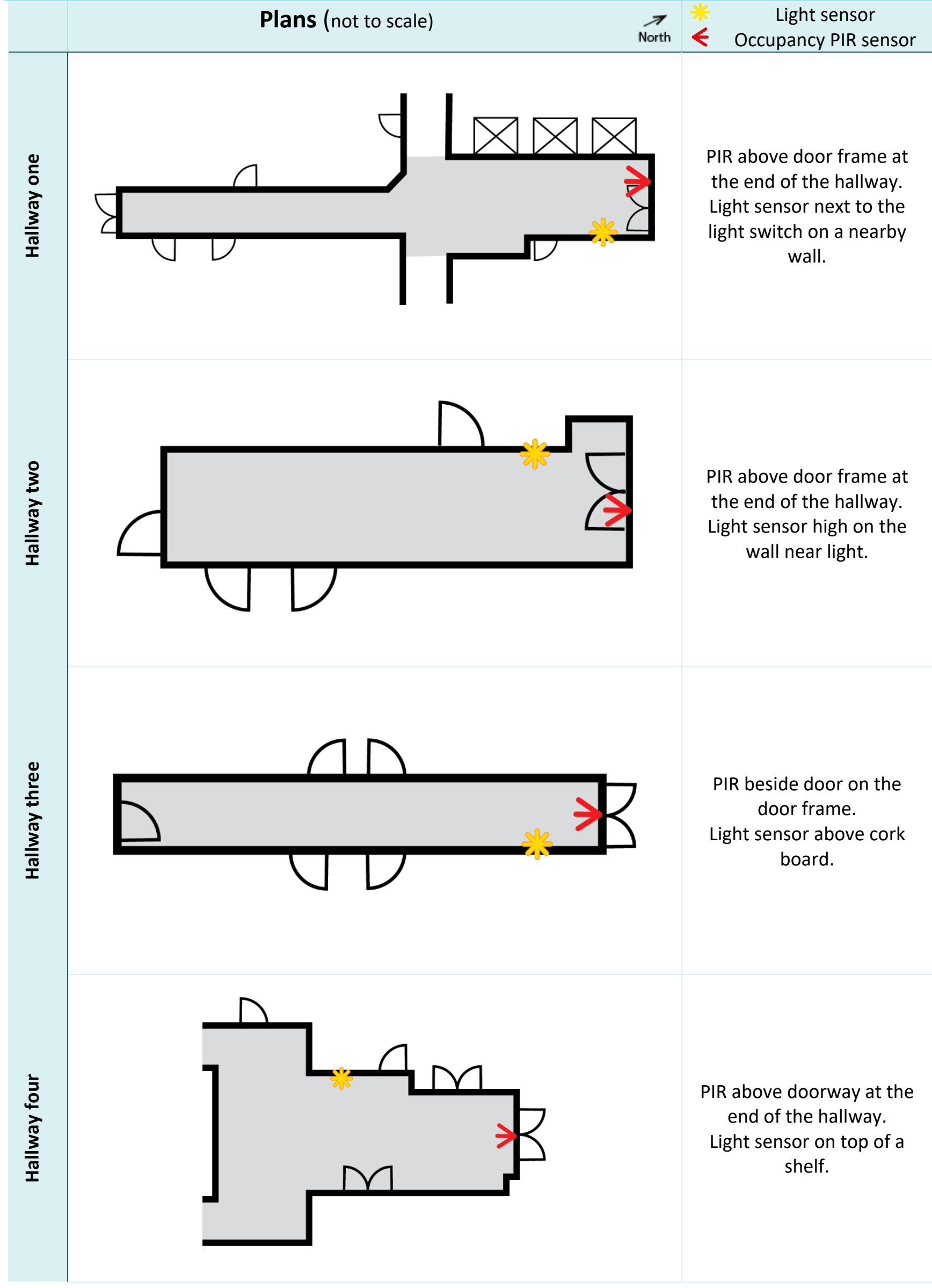




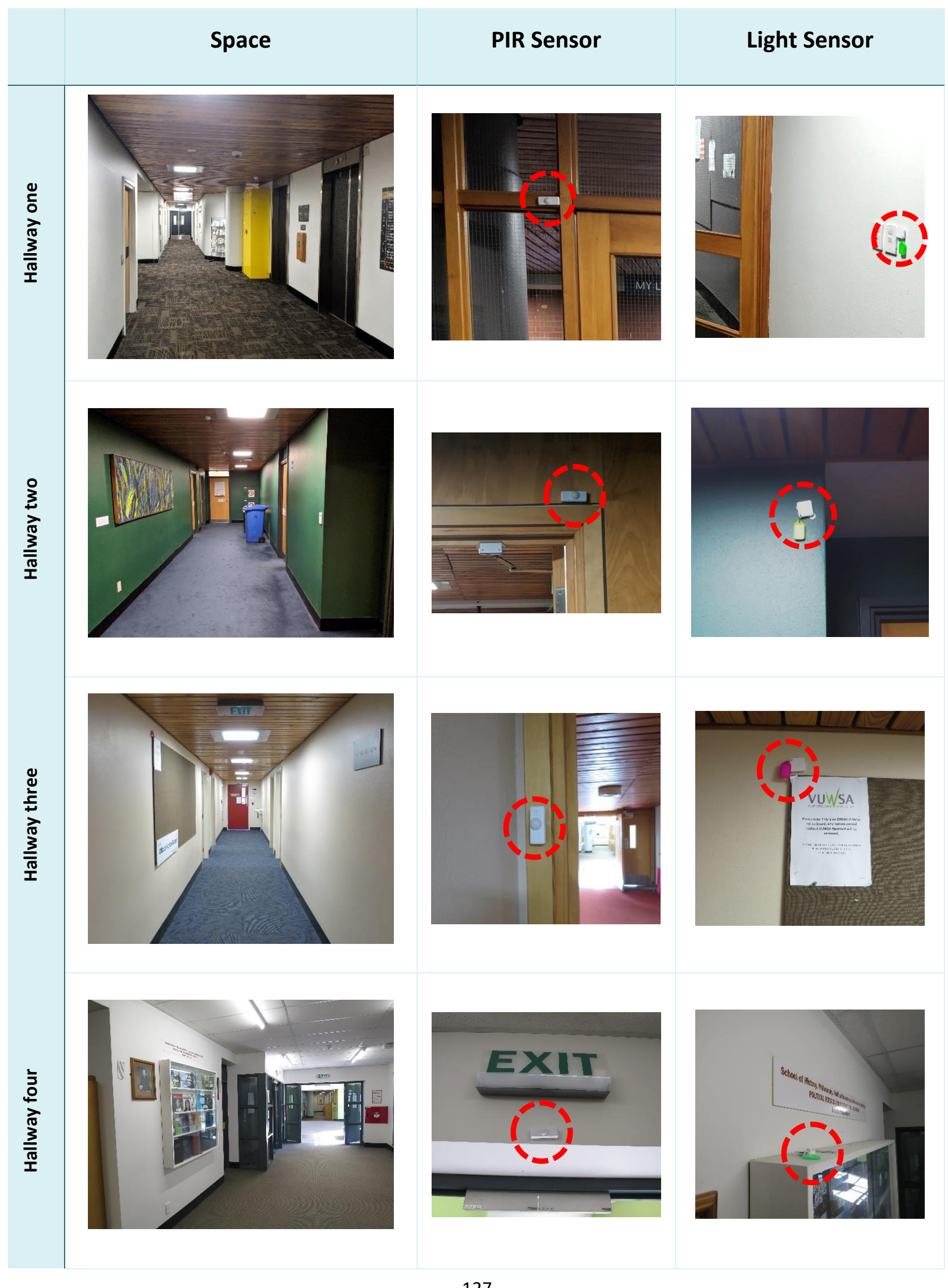




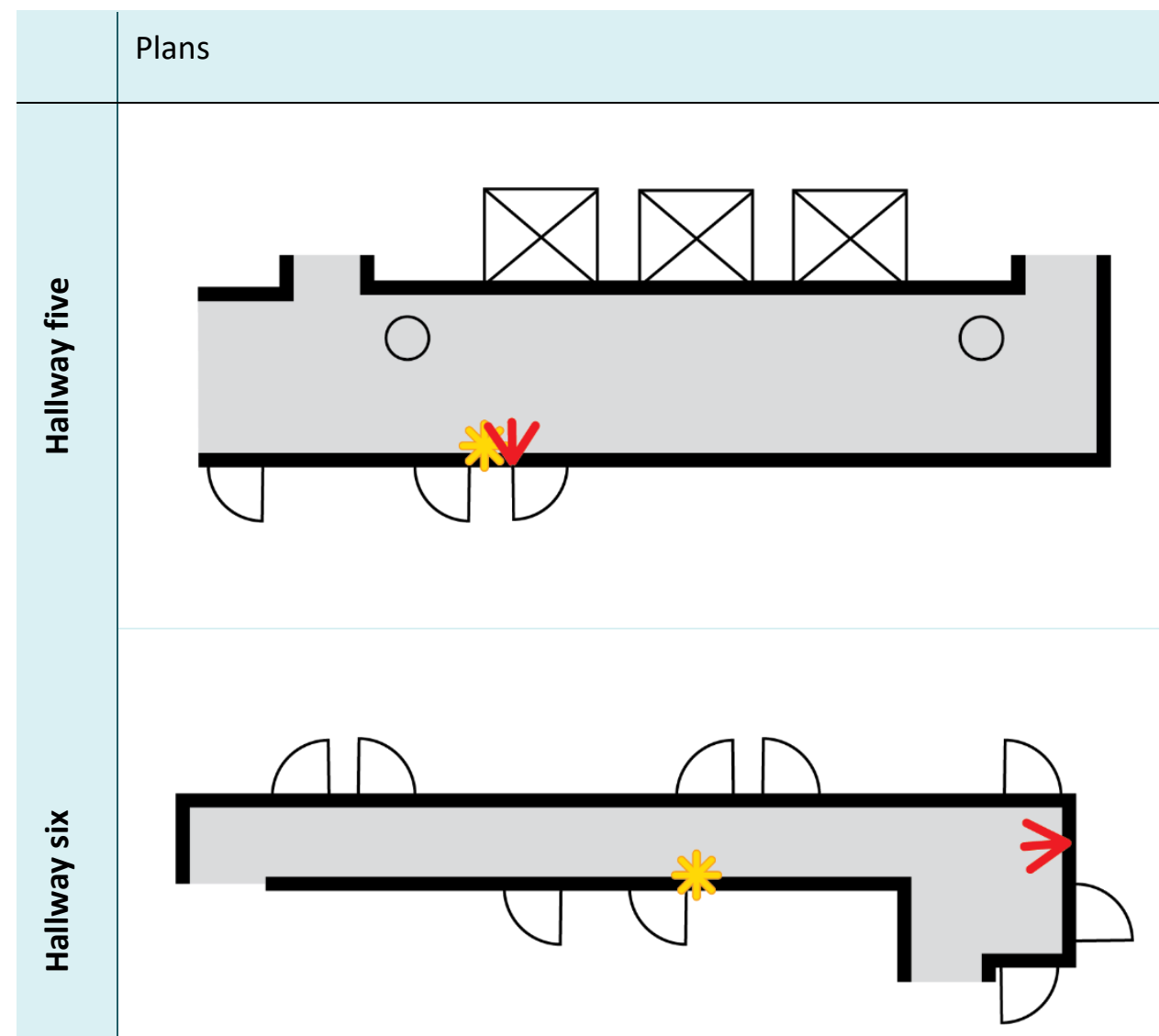

PIR above light switch halfway down the hallway.

Light sensor high on the wall near light.

PIR at the end of the hallway above some artwork.

Light sensor above doorway halfway down the hall.

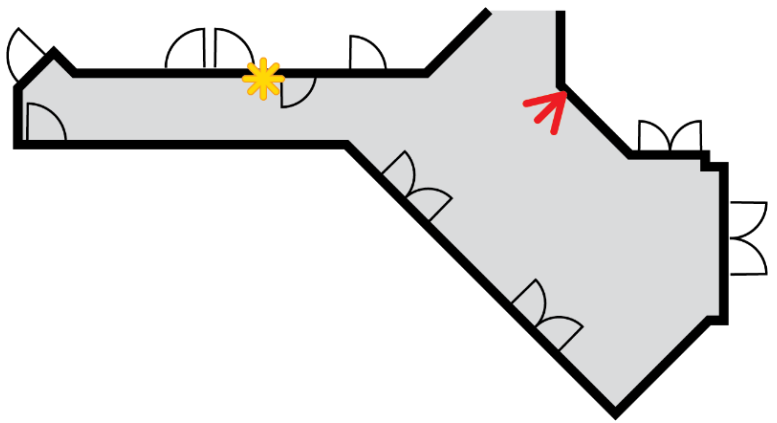

PIR at the turn of the hallway near the ceiling.

Light sensor above doorframe halfway down the hall.

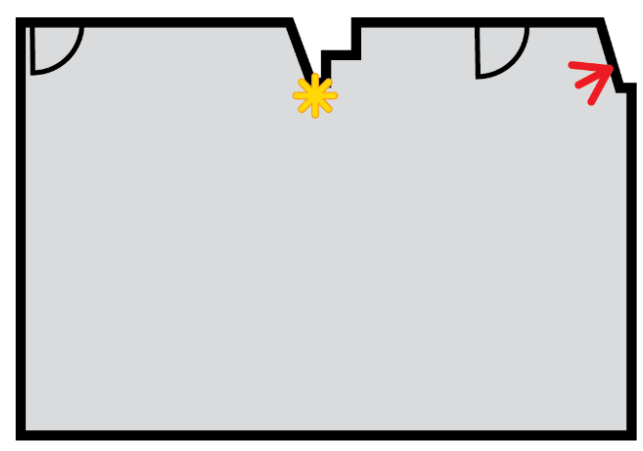

PIR above light switch in the angled corner. Light sensor at the top of a column. 


\section{Space}

PIR Sensor

Light Sensor
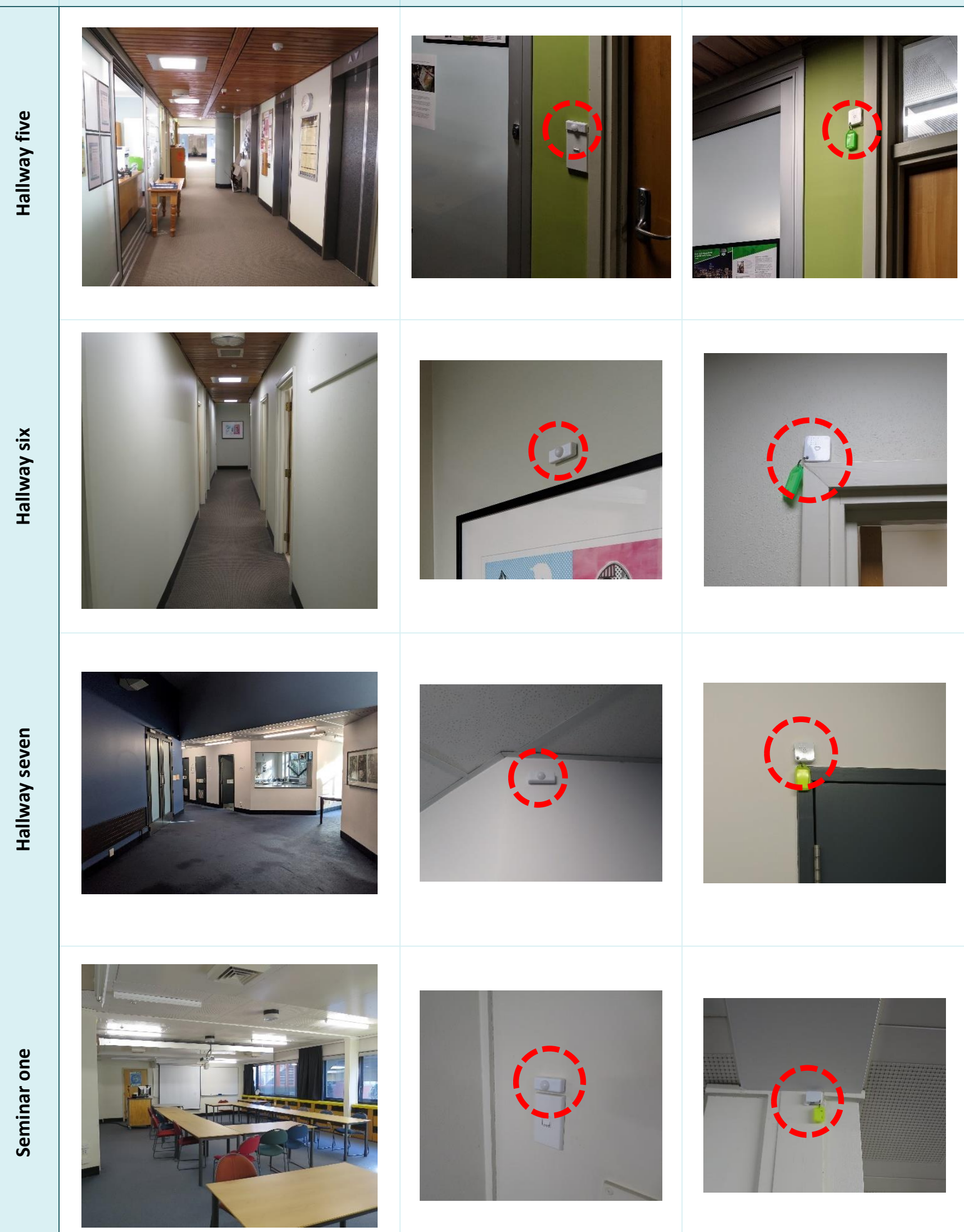
Plans
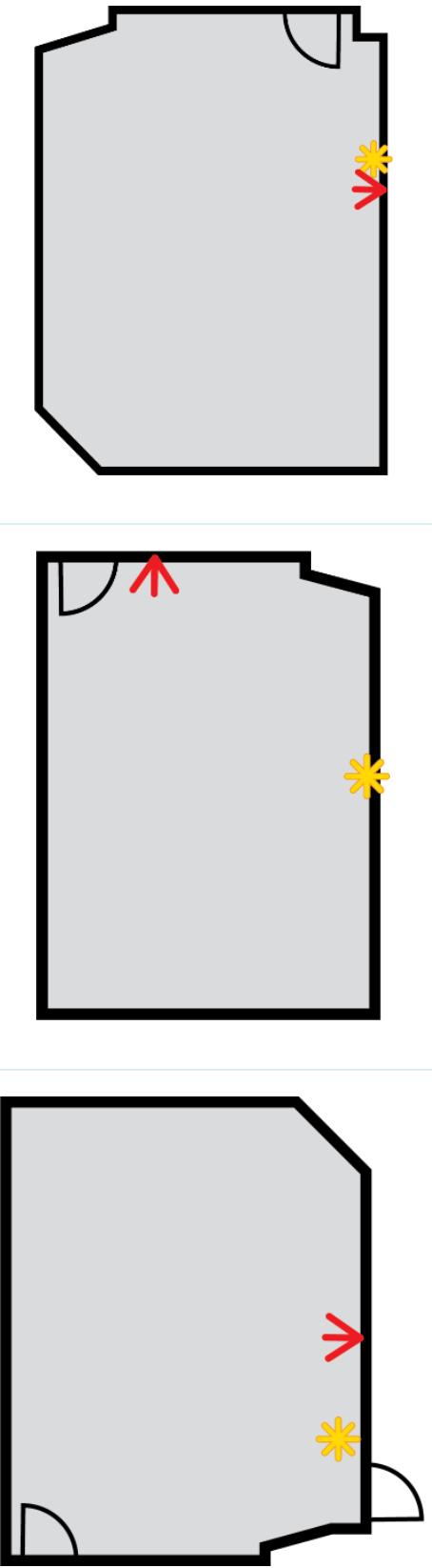

妾

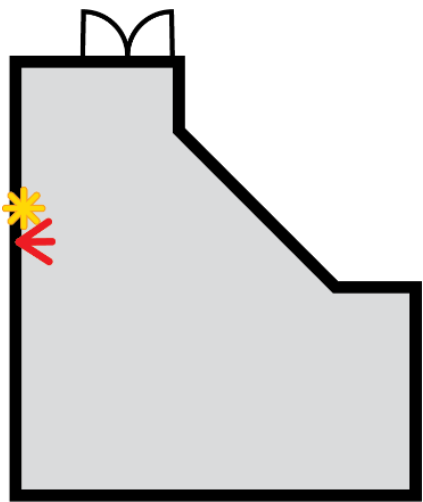

Sensor Description

PIR and Light sensor above central whiteboard.

PIR beside the light switch. Light sensor near the ceiling beside the projector screen.

PIR above the whiteboard. Light sensor at the top of a column.

\section{PIR and Light sensor above} central whiteboard. 


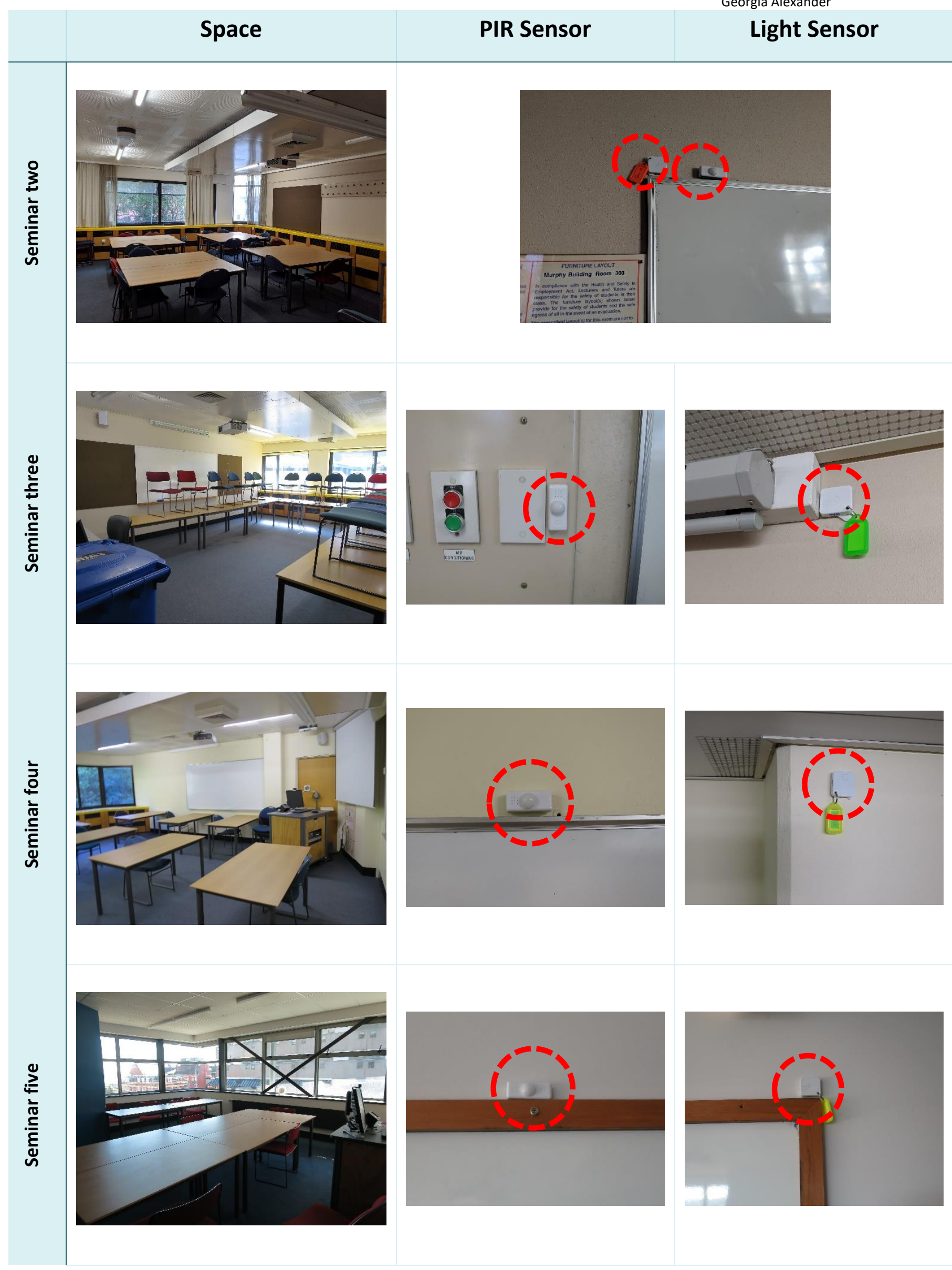




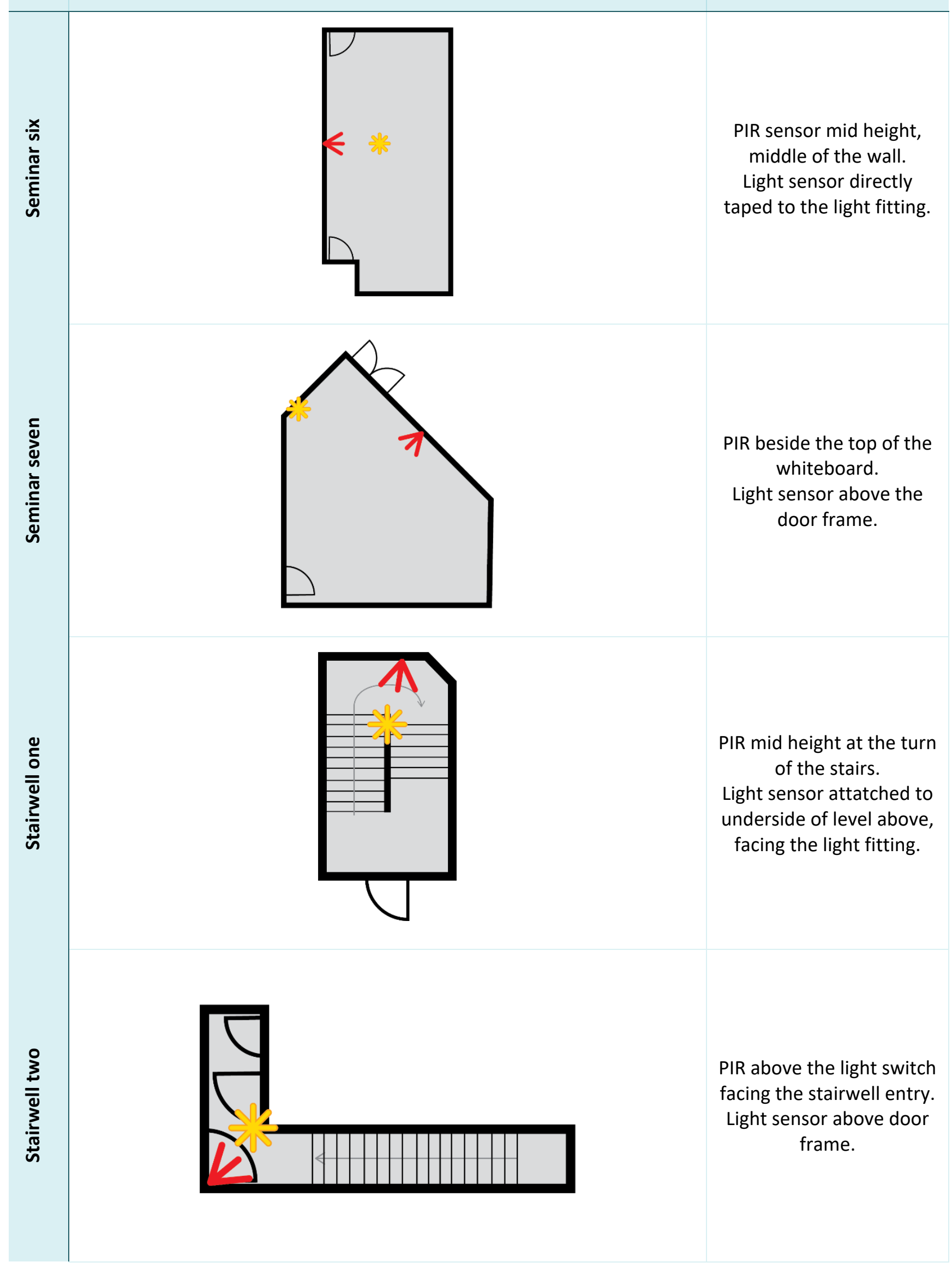


Georgia Alexander

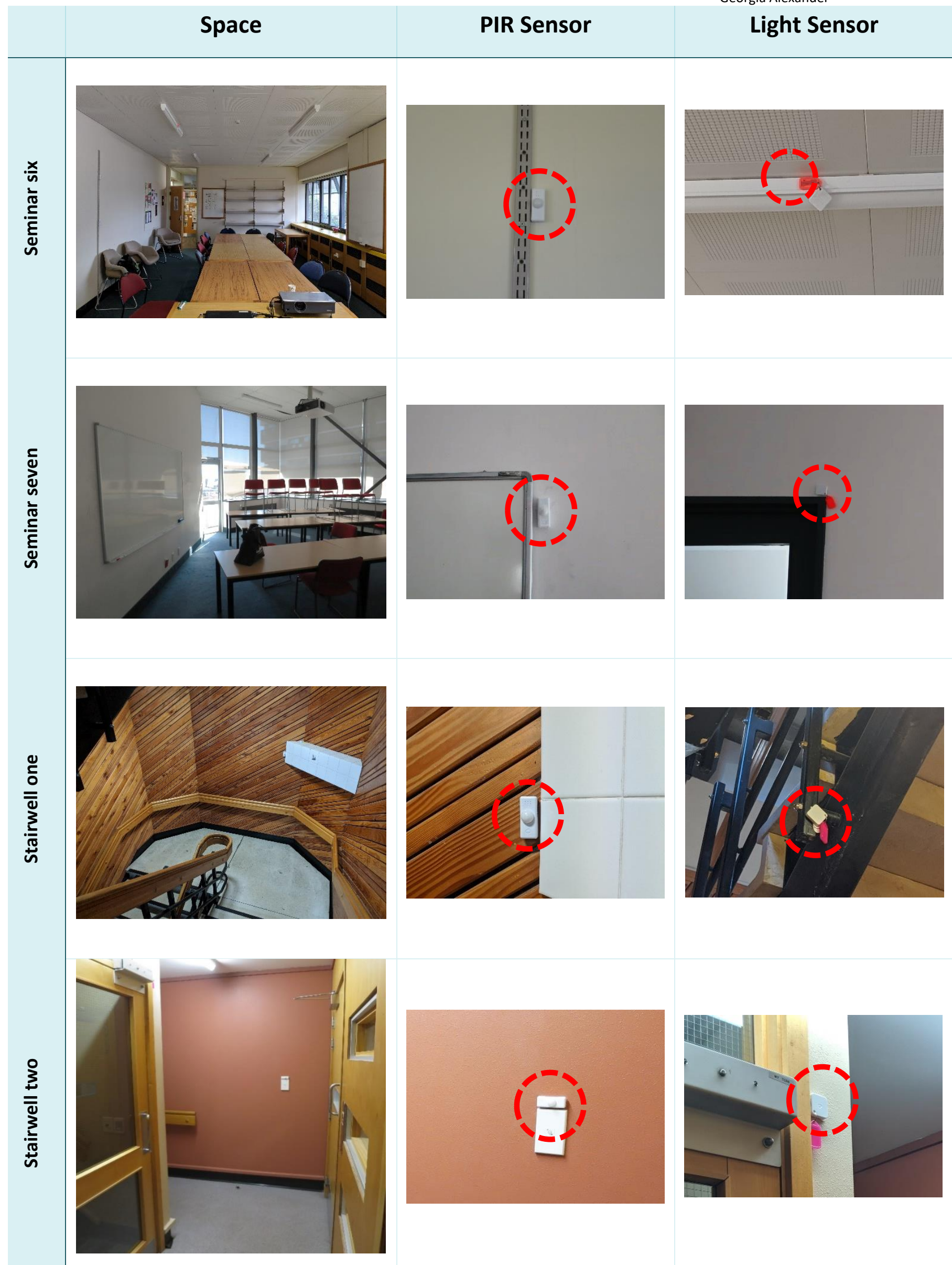


Plans
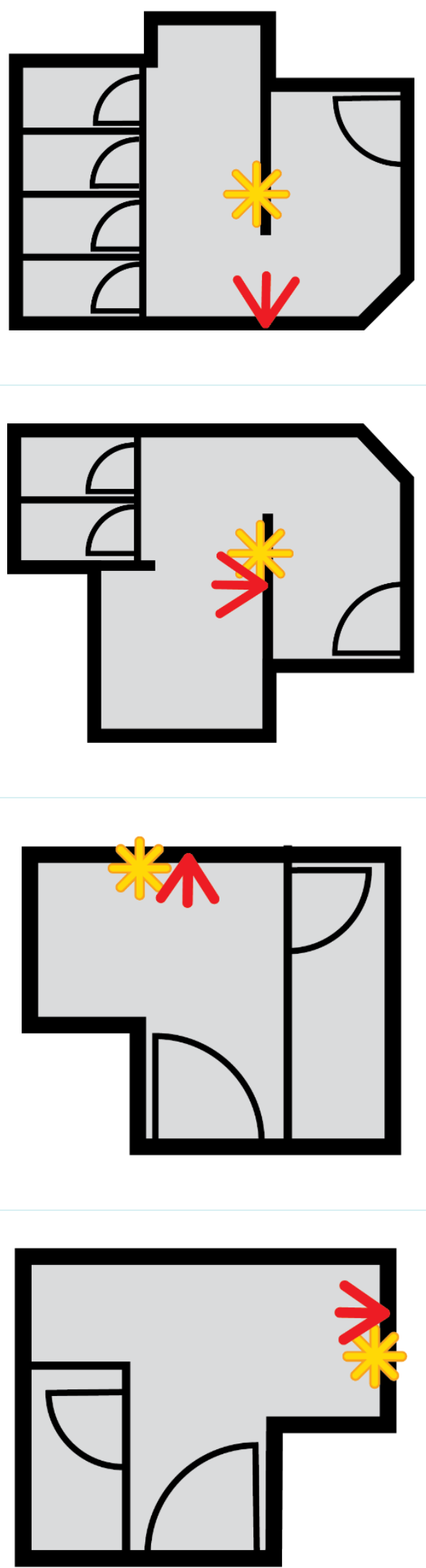

Sensor Description

PIR mid wall height at the turn of the U-shaped space.

Light sensor above the mirror.

PIR and Light sensor above the mirror.

PIR beside the door frame. Light sensor above the mirror.

\section{PIR and Light sensor above} the mirror. 


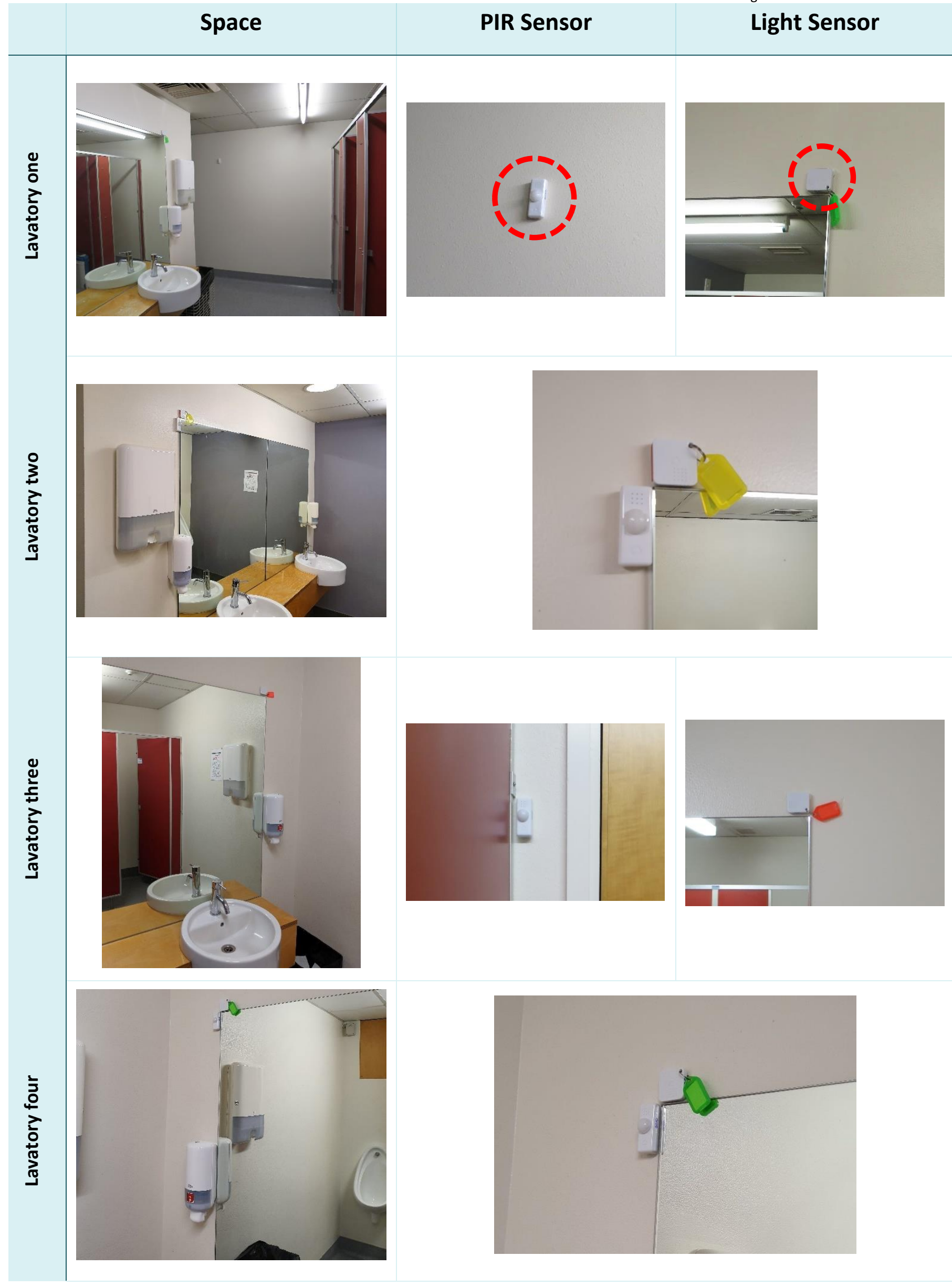




\subsubsection{AdDITIONAL LAVATORY DETAILS}

Table 21 Additional lavatory details

\begin{tabular}{|l|l|}
\hline Lavatory one & Female, four stalls, direct access off hallway, students and staff. \\
\hline Lavatory two & Male, two stalls and urinal, direct access of hallway, students and staff. \\
\hline Lavatory three & Female, one stall, off hallway, through stairwell, staff only. \\
\hline Lavatory four & Male, one stall and urinal, off hallway, through stairwell, staff only. \\
\hline
\end{tabular}

\subsubsection{AREA OF INTERMITTENT-USE SPACE TYPES}

Table 22 Measured building areas for scope building survey.

\begin{tabular}{|c|c|c|c|c|c|c|c|c|}
\hline \multirow[b]{3}{*}{ Vinl Duildin } & \multicolumn{4}{|c|}{ Intermittent-Use Spaces } & \multicolumn{2}{|c|}{ Other } & \multicolumn{2}{|c|}{ Total } \\
\hline & Hallway & Stairwell & Seminar & Lavatory & Offices & Other & $\begin{array}{l}\text { Intermittent- } \\
\text { Use Spaces }\end{array}$ & Other \\
\hline & $23 \%$ & $11 \%$ & $26 \%$ & $3 \%$ & $12 \%$ & $26 \%$ & $63 \%$ & $37 \%$ \\
\hline Murphy Building & $17 \%$ & $7 \%$ & $20 \%$ & $2 \%$ & $50 \%$ & $5 \%$ & $46 \%$ & $54 \%$ \\
\hline Von Zedlitz Building & $26 \%$ & $5 \%$ & $5 \%$ & $3 \%$ & $61 \%$ & $0 \%$ & $39 \%$ & $61 \%$ \\
\hline
\end{tabular}




\subsection{EXPERIMENT RESULT DETAILS \& DATA}

\subsubsection{INDIVIDUAL SENSOR DATA RESULTS}

Table 23 Experiment Individual Sensor Data Results

\begin{tabular}{|c|c|c|c|c|c|c|c|c|}
\hline & $\begin{array}{l}\text { Vacant } \\
\text { and } \\
\text { lights on }\end{array}$ & $\begin{array}{l}\text { Vacant } \\
\text { and } \\
\text { lights off }\end{array}$ & $\begin{array}{l}\text { Occupied } \\
\text { and } \\
\text { lights on }\end{array}$ & $\begin{array}{l}\text { Occupied } \\
\text { and } \\
\text { lights off }\end{array}$ & Vacant & Occupied & $\begin{array}{l}\text { Lights } \\
\text { on }\end{array}$ & $\begin{array}{l}\text { Lights } \\
\text { off }\end{array}$ \\
\hline $\begin{array}{l}\text { Hallway } \\
\text { one- } 254\end{array}$ & $38 \%$ & $38 \%$ & $21 \%$ & $3 \%$ & $76 \%$ & $24 \%$ & $59 \%$ & $41 \%$ \\
\hline $\begin{array}{c}\text { Hallway } \\
\text { two - } 357\end{array}$ & $42 \%$ & $53 \%$ & $5 \%$ & $0 \%$ & $95 \%$ & $5 \%$ & $47 \%$ & $53 \%$ \\
\hline $\begin{array}{c}\text { Hallway } \\
\text { three - } 457\end{array}$ & $37 \%$ & $58 \%$ & $5 \%$ & $0 \%$ & $95 \%$ & $5 \%$ & $42 \%$ & $58 \%$ \\
\hline $\begin{array}{l}\text { Hallway } \\
\text { four - } 556\end{array}$ & $39 \%$ & $46 \%$ & $14 \%$ & $1 \%$ & $85 \%$ & $15 \%$ & $53 \%$ & $47 \%$ \\
\hline $\begin{array}{c}\text { Hallway } \\
\text { five - } 554\end{array}$ & $51 \%$ & $34 \%$ & $14 \%$ & $1 \%$ & $85 \%$ & $15 \%$ & $65 \%$ & $35 \%$ \\
\hline $\begin{array}{l}\text { Hallway six } \\
-555\end{array}$ & $50 \%$ & $41 \%$ & $9 \%$ & $1 \%$ & $90 \%$ & $10 \%$ & $59 \%$ & $41 \%$ \\
\hline $\begin{array}{l}\text { Hallway } \\
\text { seven - } \\
659\end{array}$ & $20 \%$ & $65 \%$ & $4 \%$ & $11 \%$ & $85 \%$ & $15 \%$ & $25 \%$ & $75 \%$ \\
\hline $\begin{array}{l}\text { Stairwell } \\
\text { one- } 273\end{array}$ & $35 \%$ & $53 \%$ & $1 \%$ & $11 \%$ & $88 \%$ & $12 \%$ & $36 \%$ & $64 \%$ \\
\hline $\begin{array}{l}\text { Stairwell } \\
\text { two - } 272\end{array}$ & $35 \%$ & $55 \%$ & $10 \%$ & $1 \%$ & $90 \%$ & $10 \%$ & $44 \%$ & $56 \%$ \\
\hline $\begin{array}{l}\text { Seminar } \\
\text { one- } 301\end{array}$ & $15 \%$ & $82 \%$ & $3 \%$ & $1 \%$ & $96 \%$ & $4 \%$ & $18 \%$ & $82 \%$ \\
\hline $\begin{array}{l}\text { Seminar } \\
\text { two }-303\end{array}$ & $11 \%$ & $84 \%$ & $1 \%$ & $4 \%$ & $95 \%$ & $5 \%$ & $12 \%$ & $88 \%$ \\
\hline $\begin{array}{l}\text { Seminar } \\
\text { three - } 401\end{array}$ & $14 \%$ & $82 \%$ & $3 \%$ & $1 \%$ & $97 \%$ & $3 \%$ & $17 \%$ & $83 \%$ \\
\hline $\begin{array}{l}\text { Seminar } \\
\text { four - } 404\end{array}$ & $17 \%$ & $80 \%$ & $3 \%$ & $1 \%$ & $97 \%$ & $3 \%$ & $19 \%$ & $81 \%$ \\
\hline $\begin{array}{c}\text { Seminar } \\
\text { five - } 531\end{array}$ & $6 \%$ & $91 \%$ & $2 \%$ & $1 \%$ & $97 \%$ & $3 \%$ & $8 \%$ & $92 \%$ \\
\hline $\begin{array}{l}\text { Seminar } \\
\text { six }-617\end{array}$ & $36 \%$ & $62 \%$ & $2 \%$ & $0 \%$ & $98 \%$ & $2 \%$ & $38 \%$ & $62 \%$ \\
\hline $\begin{array}{c}\text { Seminar } \\
\text { seven - } \\
631\end{array}$ & $30 \%$ & $68 \%$ & $2 \%$ & $0 \%$ & $98 \%$ & $2 \%$ & $32 \%$ & $68 \%$ \\
\hline $\begin{array}{l}\text { Lavatory } \\
\text { one- } 251\end{array}$ & $54 \%$ & $38 \%$ & $8 \%$ & $0 \%$ & $92 \%$ & $8 \%$ & $62 \%$ & $38 \%$ \\
\hline $\begin{array}{l}\text { Lavatory } \\
\text { two - } 252\end{array}$ & $60 \%$ & $31 \%$ & $8 \%$ & $0 \%$ & $92 \%$ & $8 \%$ & $68 \%$ & $32 \%$ \\
\hline $\begin{array}{l}\text { Lavatory } \\
\text { three - } 351\end{array}$ & $22 \%$ & $76 \%$ & $1 \%$ & $1 \%$ & $99 \%$ & $1 \%$ & $23 \%$ & $77 \%$ \\
\hline $\begin{array}{l}\text { Lavatory } \\
\text { four - } 352\end{array}$ & $82 \%$ & $15 \%$ & $3 \%$ & $0 \%$ & $96 \%$ & $4 \%$ & $85 \%$ & $15 \%$ \\
\hline
\end{tabular}


9.4.2 Individual Space Annual Cost Savings and Payback

Table 24 Experiment individual space annual cost savings per fitting data

\begin{tabular}{|c|r|r|}
\hline Space & $\begin{array}{c}\text { Annual Cost } \\
\text { savings per fitting }\end{array}$ & Payback in years \\
\hline Hallway one - 254 & $\$ 7.23$ & 7.7 \\
Hallway two - 357 & $\$ 7.87$ & 14.1 \\
\hline Hallway three - 457 & $\$ 7.00$ & 11.9 \\
Hallway four - 556 & $\$ 14.52$ & 5.8 \\
\hline Hallway five - 554 & $\$ 9.70$ & 8.6 \\
\hline Hallway six - 555 & $\$ 9.42$ & 5.9 \\
\hline Hallway seven - 659 & $\$ 7.49$ & 6.4 \\
\hline Seminar one - 301 & $\$ 5.39$ & 7.8 \\
Seminar two - 303 & $\$ 3.99$ & 20.9 \\
\hline Seminar three - 401 & $\$ 5.34$ & 15.6 \\
\hline Seminar four - 404 & $\$ 6.15$ & 13.6 \\
Seminar five - 531 & $\$ 2.31$ & 24.1 \\
\hline Seminar six - 617 & $\$ 13.23$ & 3.2 \\
\hline Seminar seven - 631 & $\$ 11.16$ & 2.7 \\
\hline Lavatory one - 251 & $\$ 19.81$ & 8.4 \\
\hline Lavatory two - 252 & $\$ 22.35$ & 7.5 \\
\hline Lavatory three - 351 & $\$ 4.23$ & 39.4 \\
\hline Lavatory four - 352 & $\$ 15.50$ & 10.8 \\
\hline Stairwell one - 273 & $\$ 17.56$ & 9.5 \\
\hline Stairwell two - 272 & $\$ 12.88$ & 25.9 \\
\hline
\end{tabular}

\subsubsection{ANALYSIS SUNRISE AND SUNSET DETAILS}

Table 25 Experiment Sunrise and Sunset Details

\begin{tabular}{c|l|c} 
& Sunrise & Sunset \\
\hline $\begin{array}{c}\text { August } \\
\text { September }\end{array}$ & $06: 45: 00$ & $17: 15: 00$ \\
October & $06: 00: 00$ & $18: 00: 00$ \\
\hline
\end{tabular}

(Time\&Date, 2019) 


\subsubsection{Light FITTING DetaIls for CALCULATIONS.}

Table 26 Light Fitting Database for experiment analysis

\begin{tabular}{|c|c|c|c|c|c|c|}
\hline & $\begin{array}{c}\text { Quantity } \\
\text { of } \\
\text { Fittings }\end{array}$ & Model / Type & Light Description & Wattage & $\begin{array}{c}\text { Space } \\
\text { Load } \\
\text { (Power } \\
\text { W) }\end{array}$ & $\begin{array}{l}\text { Load } \\
\text { (kW) }\end{array}$ \\
\hline $\begin{array}{l}\text { Hallway } \\
\text { one - } 254\end{array}$ & 6 & $\begin{array}{l}\text { PXF PX2065150 } \\
21 W \text { 4000K }\end{array}$ & $\begin{array}{l}\text { Square troffers } \\
600 \times 600\end{array}$ & 21 & 126 & 0.13 \\
\hline $\begin{array}{l}\text { Hallway } \\
\text { two - } 357\end{array}$ & 3 & $\begin{array}{l}\text { PXF PX2065150 } \\
21 W 4000 K\end{array}$ & $\begin{array}{l}\text { Square troffers } \\
600 \times 600\end{array}$ & 21 & 63 & 0.06 \\
\hline $\begin{array}{l}\text { Hallway } \\
\text { three - } 457\end{array}$ & 4 & $\begin{array}{l}\text { PXF PX2065150 } \\
21 W 4000 K\end{array}$ & $\begin{array}{l}\text { Square troffers } \\
600 \times 600\end{array}$ & 21 & 84 & 0.08 \\
\hline $\begin{array}{l}\text { Hallway } \\
\text { four - } 556\end{array}$ & 4 & $\begin{array}{l}\text { Thorn LED Batten } \\
41 \mathrm{w} 4000 \mathrm{~K}\end{array}$ & Long single battens & 41 & 164 & 0.16 \\
\hline $\begin{array}{l}\text { Hallway } \\
\text { five - } 554\end{array}$ & 4 & $\begin{array}{l}\text { PXF PX2065150 } \\
21 W 4000 K\end{array}$ & $\begin{array}{l}\text { Square troffers } \\
600 \times 600\end{array}$ & 21 & 84 & 0.08 \\
\hline $\begin{array}{l}\text { Hallway six } \\
\quad-555\end{array}$ & 6 & $\begin{array}{l}\text { PXF PX2065150 } \\
21 W 4000 K\end{array}$ & $\begin{array}{l}\text { Square troffers } \\
600 \times 600\end{array}$ & 21 & 126 & 0.13 \\
\hline $\begin{array}{c}\text { Hallway } \\
\text { seven - } 659\end{array}$ & 7 & $\begin{array}{l}\text { Thorn LED Batten } \\
41 \mathrm{w} 4000 \mathrm{~K}\end{array}$ & $\begin{array}{l}\text { Long single battens } \\
\text { and others }\end{array}$ & 41 & 287 & 0.29 \\
\hline $\begin{array}{l}\text { Seminar } \\
\text { one - } 301\end{array}$ & 8 & $\begin{array}{c}\text { Thorn LED Batten } \\
41 \mathrm{w} 4000 \mathrm{~K}\end{array}$ & Long single battens & 41 & 328 & 0.33 \\
\hline $\begin{array}{l}\text { Seminar } \\
\text { two - } 303\end{array}$ & 4 & $\begin{array}{c}\text { Thorn LED Batten } \\
41 \mathrm{w} 4000 \mathrm{~K}\end{array}$ & Long single battens & 41 & 164 & 0.16 \\
\hline $\begin{array}{l}\text { Seminar } \\
\text { three - } 401\end{array}$ & 4 & $\begin{array}{c}\text { Thorn LED Batten } \\
41 \mathrm{w} 4000 \mathrm{~K}\end{array}$ & Long single battens & 41 & 164 & 0.16 \\
\hline $\begin{array}{l}\text { Seminar } \\
\text { four }-404\end{array}$ & 4 & $\begin{array}{c}\text { Thorn LED Batten } \\
41 \mathrm{w} 4000 \mathrm{~K}\end{array}$ & Long single battens & 41 & 164 & 0.16 \\
\hline $\begin{array}{l}\text { Seminar } \\
\text { five - } 531\end{array}$ & 6 & $\begin{array}{c}\text { Thorn LED Batten } \\
41 \mathrm{w} 4000 \mathrm{~K}\end{array}$ & Long single battens & 41 & 246 & 0.25 \\
\hline $\begin{array}{l}\text { Seminar six } \\
\quad-617\end{array}$ & 8 & $\begin{array}{c}\text { Thorn LED Batten } \\
41 \mathrm{w} 4000 \mathrm{~K}\end{array}$ & Long single battens & 41 & 328 & 0.33 \\
\hline $\begin{array}{l}\text { Seminar } \\
\text { seven - } 631\end{array}$ & 11 & $\begin{array}{l}\text { Thorn LED Batten } \\
41 \mathrm{w} 4000 \mathrm{~K}\end{array}$ & $\begin{array}{l}\text { Long single battens } \\
\text { and others }\end{array}$ & 41 & 451 & 0.45 \\
\hline $\begin{array}{l}\text { Lavatory } \\
\text { one - } 251\end{array}$ & 2 & $\begin{array}{l}\text { Thorn LED Batten } \\
41 \mathrm{w} 4000 \mathrm{~K}\end{array}$ & Long single battens & 41 & 82 & 0.08 \\
\hline $\begin{array}{l}\text { Lavatory } \\
\text { two - } 252\end{array}$ & 2 & $\begin{array}{l}\text { Thorn LED Batten } \\
41 \mathrm{w} 4000 \mathrm{~K}\end{array}$ & Long Single Battens & 41 & 82 & 0.08 \\
\hline $\begin{array}{l}\text { Lavatory } \\
\text { three - } 351\end{array}$ & 2 & $\begin{array}{l}\text { PXF PX2065150 } \\
\text { 21W 4000K }\end{array}$ & $\begin{array}{l}\text { Square troffers } \\
600 \times 600\end{array}$ & 21 & 42 & 0.04 \\
\hline $\begin{array}{l}\text { Lavatory } \\
\text { four - } 352\end{array}$ & 2 & $\begin{array}{l}\text { PXF PX2065150 } \\
21 W \text { 4000K }\end{array}$ & $\begin{array}{l}\text { Square troffers } \\
600 \times 600\end{array}$ & 21 & 42 & 0.04 \\
\hline $\begin{array}{l}\text { Stairwell } \\
\text { one - } 273\end{array}$ & 2 & Twin 28W panel & Small rectangle & 56 & 112 & 0.11 \\
\hline $\begin{array}{l}\text { Stairwell } \\
\text { two }-272\end{array}$ & 1 & $\begin{array}{l}\text { Thorn LED Batten } \\
41 \mathrm{w} 4000 \mathrm{~K}\end{array}$ & Long single battens & 41 & 41 & 0.04 \\
\hline
\end{tabular}




\subsection{DISCUSSION DATA}

9.5.1 LAMP TYPES

Table 27 Light type comparison data.

\begin{tabular}{|l|l|l|l|l|l|}
\hline & Watt & Load $(\mathrm{kw})$ & $\begin{array}{l}\text { Annual Potential } \\
\text { savings (kWh/year) }\end{array}$ & $\begin{array}{l}\text { Annual Cost } \\
\text { Savings }\end{array}$ & $\begin{array}{l}\text { Payback } \\
\text { Period (years) }\end{array}$ \\
\hline LED & 25 & 0.125 & 433 & $\$ 44.60$ & 7.5 \\
\hline Fluorescent & 44 & 0.222 & 770 & $\$ 79.40$ & 4.2 \\
\hline Halogen & 125 & 0.625 & 2167 & $\$ 223.20$ & 1.5 \\
\hline Incandescent & 160 & 0.800 & 2774 & $\$ 285.70$ & 1.2 \\
\hline
\end{tabular}

(Average 40\% potential) 
9.5.2 TIME DELAY CALCULATIONS

Table 28 Percentage of Occupancy Instances up to 30 minutes.

\begin{tabular}{|c|c|c|c|c|}
\hline Duration (minutes) & Hallway & Stairwell & Seminar Room & Lavatory \\
\hline 1 & $45.4 \%$ & $53.4 \%$ & $68.3 \%$ & $29.2 \%$ \\
\hline 2 & $17.2 \%$ & $15.3 \%$ & $11.2 \%$ & $12.8 \%$ \\
\hline 3 & $6.8 \%$ & $6.2 \%$ & $4.5 \%$ & $5.9 \%$ \\
\hline 4 & $8.1 \%$ & $5.6 \%$ & $3.4 \%$ & $10.5 \%$ \\
\hline 5 & $3.8 \%$ & $2.9 \%$ & $1.9 \%$ & $8.0 \%$ \\
\hline 6 & $2.8 \%$ & $2.2 \%$ & $1.2 \%$ & $5.2 \%$ \\
\hline 7 & $2.2 \%$ & $1.7 \%$ & $1.0 \%$ & $3.5 \%$ \\
\hline 8 & $1.7 \%$ & $1.3 \%$ & $0.7 \%$ & $2.8 \%$ \\
\hline 9 & $1.4 \%$ & $1.3 \%$ & $0.6 \%$ & $2.1 \%$ \\
\hline 10 & $1.0 \%$ & $1.0 \%$ & $0.5 \%$ & $1.6 \%$ \\
\hline 11 & $0.9 \%$ & $0.9 \%$ & $0.4 \%$ & $1.5 \%$ \\
\hline 12 & $0.8 \%$ & $0.7 \%$ & $0.3 \%$ & $1.3 \%$ \\
\hline 13 & $0.7 \%$ & $0.7 \%$ & $0.2 \%$ & $1.0 \%$ \\
\hline 14 & $0.5 \%$ & $0.4 \%$ & $0.2 \%$ & $0.9 \%$ \\
\hline 15 & $0.5 \%$ & $0.4 \%$ & $0.2 \%$ & $0.8 \%$ \\
\hline 16 & $0.4 \%$ & $0.3 \%$ & $0.2 \%$ & $0.7 \%$ \\
\hline 17 & $0.3 \%$ & $0.3 \%$ & $0.1 \%$ & $0.5 \%$ \\
\hline 18 & $0.3 \%$ & $0.4 \%$ & $0.1 \%$ & $0.6 \%$ \\
\hline 19 & $0.3 \%$ & $0.3 \%$ & $0.1 \%$ & $0.4 \%$ \\
\hline 20 & $0.3 \%$ & $0.2 \%$ & $0.1 \%$ & $0.4 \%$ \\
\hline 21 & $0.3 \%$ & $0.2 \%$ & $0.1 \%$ & $0.5 \%$ \\
\hline 22 & $0.2 \%$ & $0.2 \%$ & $0.1 \%$ & $0.4 \%$ \\
\hline 23 & $0.2 \%$ & $0.2 \%$ & $0.1 \%$ & $0.4 \%$ \\
\hline 24 & $0.2 \%$ & $0.1 \%$ & $0.1 \%$ & $0.4 \%$ \\
\hline 25 & $0.2 \%$ & $0.2 \%$ & $0.1 \%$ & $0.4 \%$ \\
\hline 26 & $0.2 \%$ & $0.2 \%$ & $0.1 \%$ & $0.4 \%$ \\
\hline 27 & $0.1 \%$ & $0.1 \%$ & $0.1 \%$ & $0.4 \%$ \\
\hline 28 & $0.2 \%$ & $0.1 \%$ & $0.0 \%$ & $0.3 \%$ \\
\hline 29 & $0.1 \%$ & $0.1 \%$ & $0.1 \%$ & $0.3 \%$ \\
\hline 30 & $0.2 \%$ & $0.1 \%$ & $0.1 \%$ & $0.2 \%$ \\
\hline
\end{tabular}


9.5.3 OCCUPANCY DAYLIGHT DATA

Table 29 Room booking daylight occupancy data.

\begin{tabular}{|c|r|r|r|}
\hline & $\begin{array}{c}\text { Room Booking } \\
\text { Occupancy }\end{array}$ & Seminar seven & $\begin{array}{c}\text { Experiment } \\
\text { Occupancy }\end{array}$ \\
\hline Seminar one & $8 \%$ & $7 \%$ & $4 \%$ \\
Seminar two & $10 \%$ & $8 \%$ & $5 \%$ \\
Seminar three & $11 \%$ & $10 \%$ & $3 \%$ \\
\hline Seminar four & $11 \%$ & $9 \%$ & $3 \%$ \\
Seminar five & $11 \%$ & $9 \%$ & $3 \%$ \\
\hline Seminar six & $1 \%$ & $1 \%$ & $2 \%$ \\
Seminar seven & $8 \%$ & $6 \%$ & $2 \%$ \\
Average & $8 \%$ & $7 \%$ & $3 \%$ \\
\hline
\end{tabular}





\section{UNLESS}

someone like you cares a whole awful lot, nothing

is going to get better. It's not."

- Dr. Seuss, The Lorax 


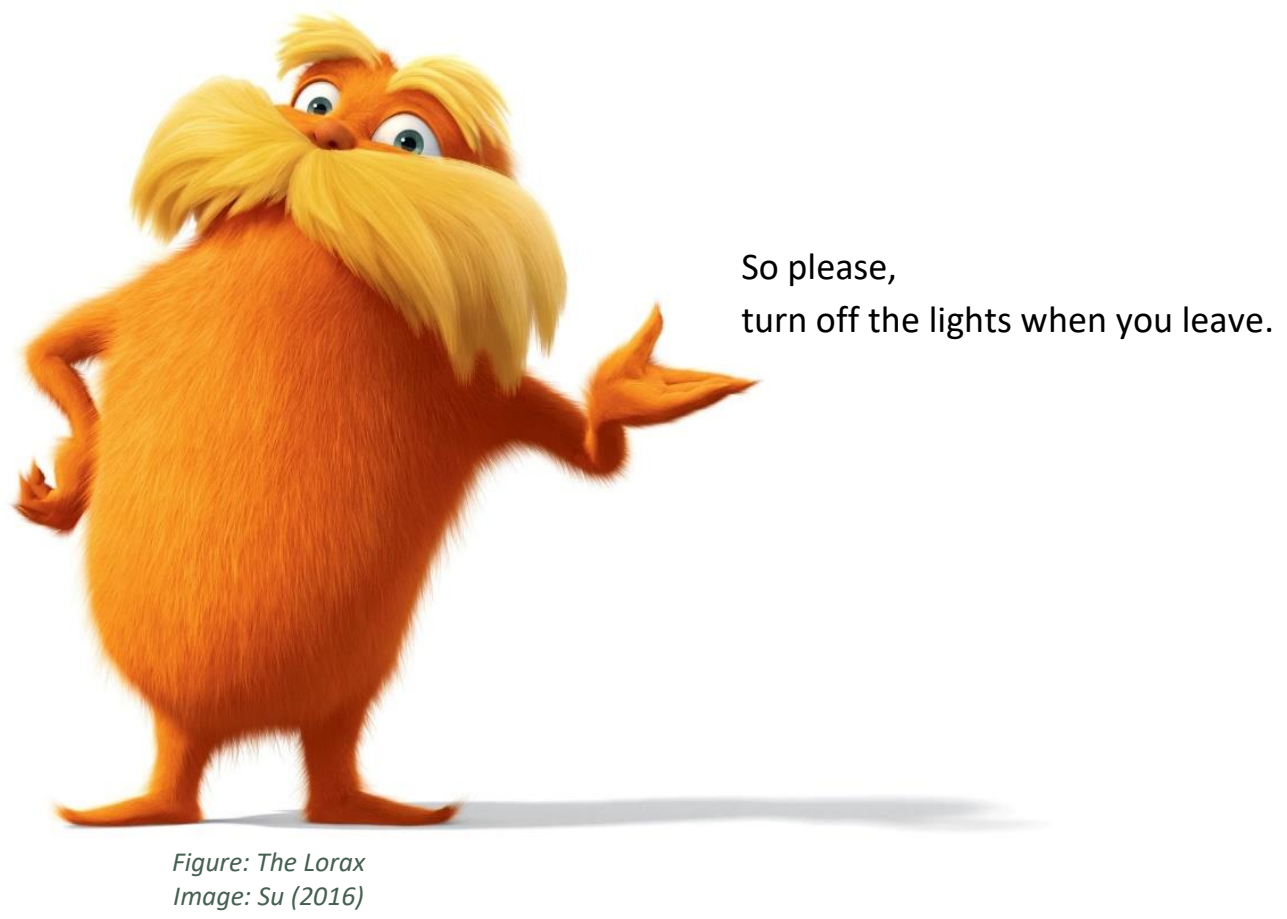

